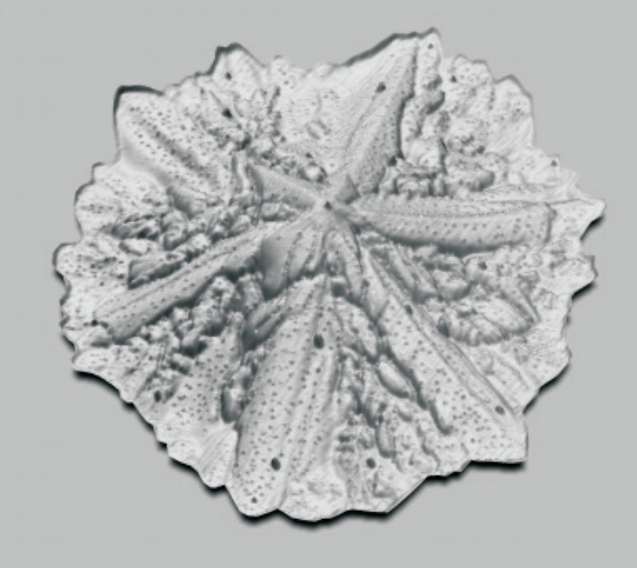

It is my pleasure to invite you to the public defence of my doctoral dissertation

on September $29^{\text {th }}$, Wednesday at 15:00 hr, in Room 4 of Waaier building of the University of Twente, Enschede.

The ceremony will be followed by a reception.

In the evening, you are cordially invited to a party at 20:30 hr in Blauwe Kater, De Kater Brasserie, Oude 


\section{Reflow Bonding of Borosilicate Glass Tubes to Silicon Substrates as Fluidic Interconnects}


The research described in this thesis was carried out at the Transducer Science and Technology group of the MESA+ Institute of Nanotechnology and the Institute of Mechanics, Processes and Control - Twente (IMPACT) at the University of Twente, Enschede, the Netherlands and at the Inorganic Microstructures group of the Material Science and Metallurgy department at the University of Cambridge, Cambridge, United Kingdom. This project was funded by the Dutch National MicroNed Programme within the MISAT cluster.

Graduation committee:

Prof. Dr. A. J. Mouthaan University of Twente Chairman

Prof. Dr. M. C. Elwenspoek University of Twente Promoter

Dr. H. V. Jansen University of Twente Assistant Promoter

Prof. Dr. H. J. M. ter Brake University of Twente

Dr. K. M. Knowles University of Cambridge

Prof. Dr. P. Woias University of Freiburg

Prof. Dr. J. G. E. Gardeniers University of Twente

Dr. J. C. T. Eijkel University of Twente

Ph. D. Thesis, University of Twente, Enschede, the Netherlands

Title: Reflow bonding of borosilicate glass tubes to silicon substrates as fluidic interconnects

Author: Berker Moğulkoç

ISBN: $\quad 978-90-365-3083-5$

DOI: $\quad 10.3990 / 1.9789036530835$

Cover design by Esen Moğulkoç.

Copyright (C) 2010 by Berker Moğulkoç, Enschede, the Netherlands.

All rights reserved. 


\title{
REFLOW BONDING OF BOROSILICATE GLASS TUBES TO SILICON SUBSTRATES AS FLUIDIC INTERCONNECTS
}

\section{DISSERTATION}

\author{
to obtain \\ the degree of doctor at the University of Twente, \\ on the authority of the rector magnificus, \\ prof.dr. H. Brinksma, \\ on account of the decision of the graduation committee, \\ to be publicly defended \\ on Wednesday, the 29th of September 2010 at 15:00 \\ by \\ Berker Moğulkoç \\ born on the 13th of May 1982 \\ in Eskişehir, Turkey.
}


This dissertation is approved by the promoter and the assistant promoter:

Prof. Dr. M. C. Elwenspoek

Dr. H. V. Jansen 


\section{Contents}

\section{Introduction}

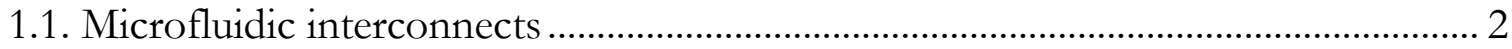

1.2. MEMS-on-tube assembly............................................................................. 4

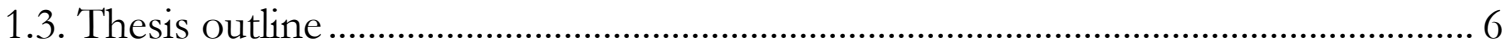

\section{Reflow bonding}

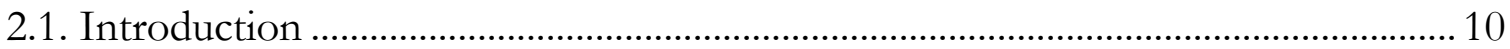

2.2. Selection and preparation of silicon wafers ............................................................. 10

2.3. Selection and preparation of glass tubes ............................................................... 10

2.4. Bonding procedure.......................................................................................... 14

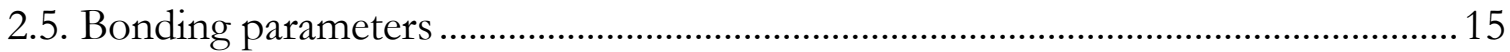

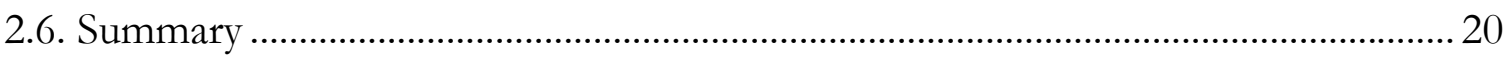

\section{Devitrification of borosilicate glass}

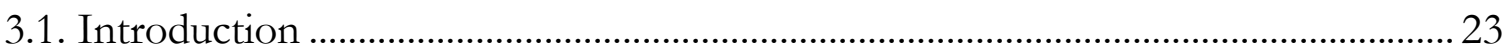

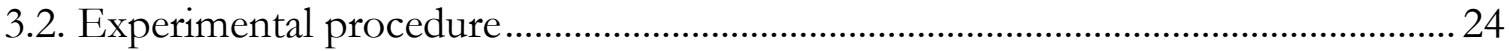


3.3. Results and discussion

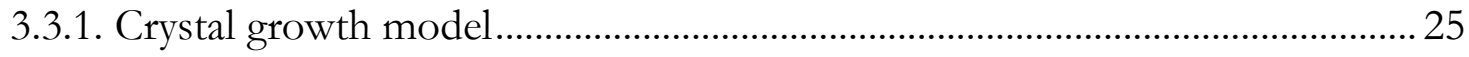

3.3.2. Kinetics of surface devitrification.................................................................... 31

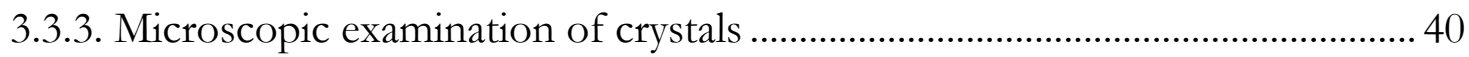

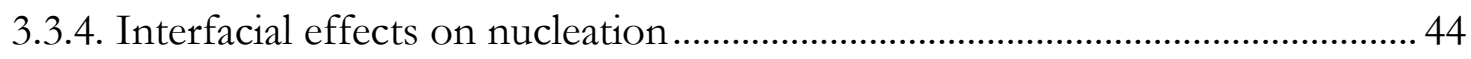

3.4. Effect of crystallisation on the reflow bonding......................................................... 46

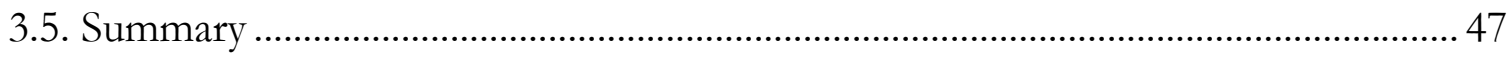

\section{Characterisation of tube-silicon assembly}

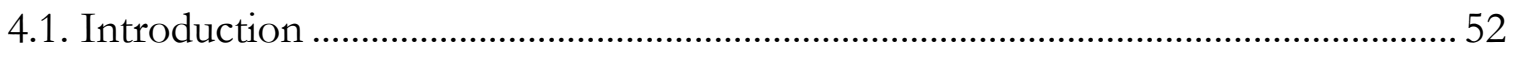

4.2. Devitrification of glass tubes ................................................................................. 52

4.3. Thermal stresses between the borosilicate matrix and silica crystals...................... 54

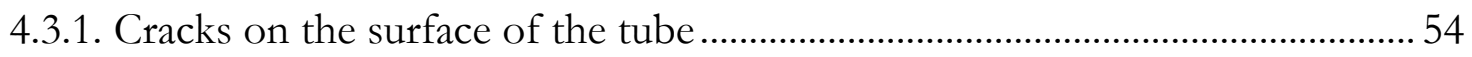

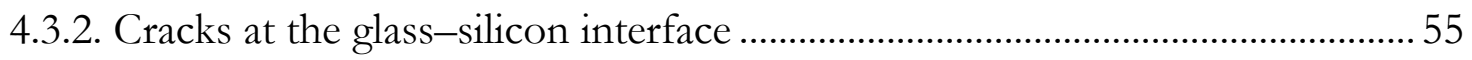

4.4. Thermal stresses between the borosilicate glass and silicon substrate ................... 57

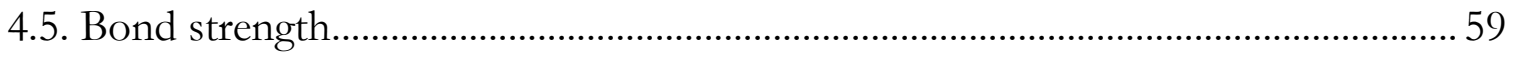

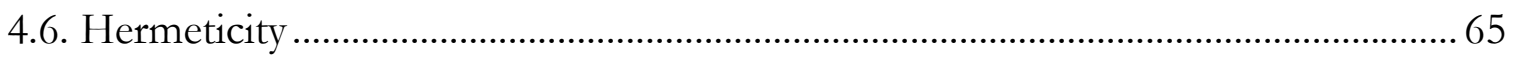

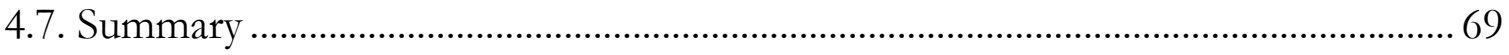




\section{Characterization of glass-silicon interface}

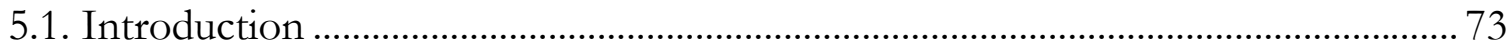

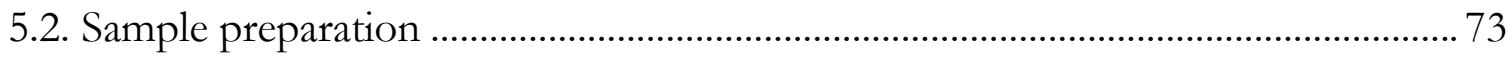

5.3. Microscopic examination of the bond interface …………………………………...... 77

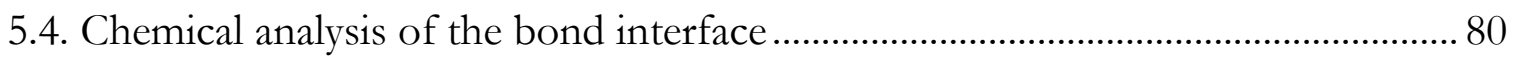

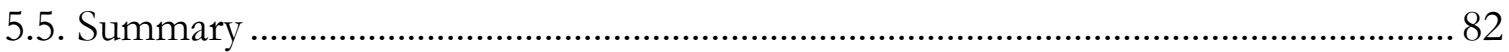

\section{Incorporation of in-plane electrical interconnects}

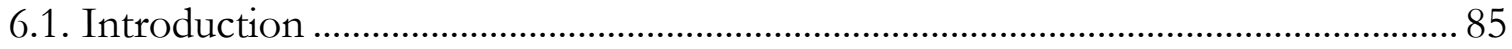

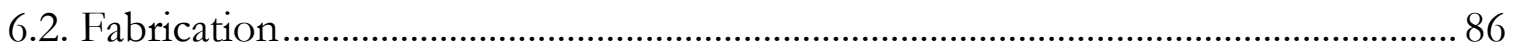

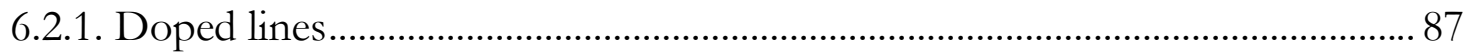

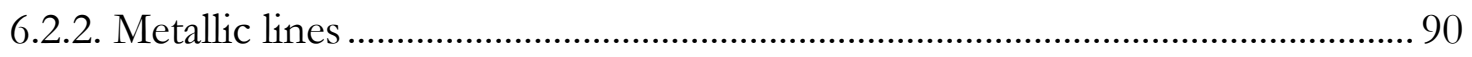

6.3. Results and discussion ........................................................................................ 90

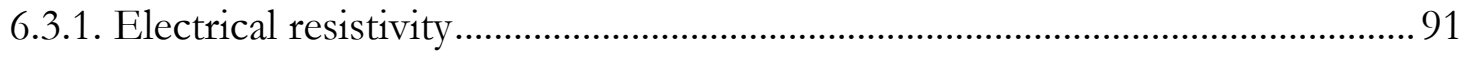

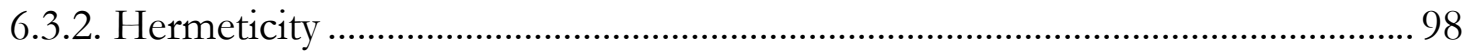

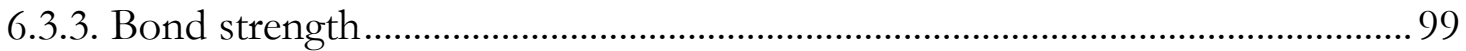

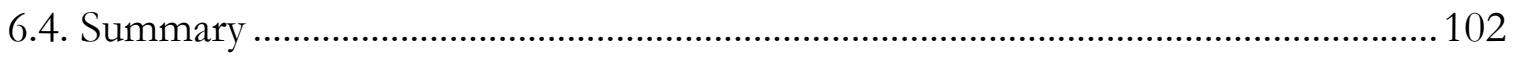




\section{Example applications of MEMS-on-tube assembly}

7.1. Introduction . 106

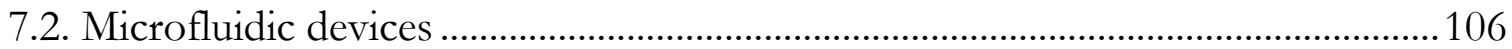

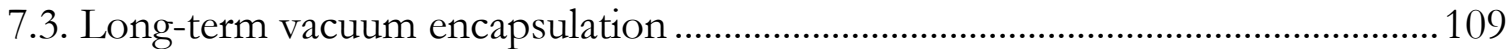

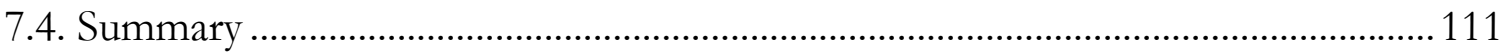

\section{Conclusions and outlook}

8.1. Conclusions

8.2. Outlook 116

Summary

Samenvatting

Acknowledgements

About the author 


\section{1}

\section{Introduction}

An introduction to the subject of the thesis is given in this chapter. The relevant literature on microfluidic interconnects is briefly presented and the use of borosilicate glass $\left(\right.$ Duran $\left.^{\circledR}\right)$ tubes as an interface to microfluidic devices is explained. After defining the novelty of the approach, the thesis outline is discussed. 


\subsection{Microfluidic interconnects}

Over the past twenty years, there has been intensive research on a wide range of miniature fluidic devices such as valves, pumps, mixers, filters and flow sensors [1.1] because the fluids can behave differently at microscale [1.2] and the change in the dominant physical behaviour of the system brings new functionalities and scientific and technological challenges $[1.3,1.4]$. As with the packaging of integrated circuits, one of the major challenges is the packaging of microfluidic devices and their connections to other micro-devices and the external macro-world fluidic structures. This thesis focuses on the out-of-plane interconnection technologies to interface planar micro- and nano-devices and couple them to the macro-world equipment. Such fluidic packaging technologies usually require hermetic seals, chemical inertness, high temperature stability and high working pressures. To date, various types of connection technologies have been demonstrated using capillary tubing made out of polymeric, metallic or ceramic materials. Examples of connection techniques and capillary tube materials reported are:

- Fused silica capillaries connected to the devices either by marine epoxy or a press-fitted silicon/plastic coupler [1.5] as depicted in Figure 1.1(a). Tubes are inserted into the out-of-plane sleeves that are etched in silicon with a through hole in the middle. Fused silica capillaries are sealed by adhesive. Injectionmolded plastic tubes are press fitted without the use of glue as sealant.

- Silastic capillary tubes connected to the devices by a heat shrink tubing sleeve [1.6] as drawn in Figure 1.1(b). Flanges with a through hole in the middle are fabricated in silicon and heat shrink tubing is used to connect silastic tubes to silicon flanges. 
- Thermoplastic tubing connected to the devices either by softening and deformation of the tube ends through the application of heat and applied pressure [1.7], or by briefly melting the tube ends, followed by gluing using a high-temperature epoxy [1.8] as shown Figure 1.1(c).

- $\mathrm{Ni}-\mathrm{Co}-\mathrm{Fe} \mathrm{Kovar}^{\circledR}$ alloy connections to a Pyrex-silicon fluidic structure made by anodic bonding [1.9] as shown in Figure 1.1(d). A ring-shaped groove had to be etched in Pyrex around the contact region with the Kovar tube to release the thermal stresses.

- Kovar capillary tubes connected to silicon devices using glass sealing [1.10] as pictured in Figure 1.1(e). Donut shaped glass preforms are made molten to enable the Kovar tubing passing through their middles to be joined to the underlying silicon.

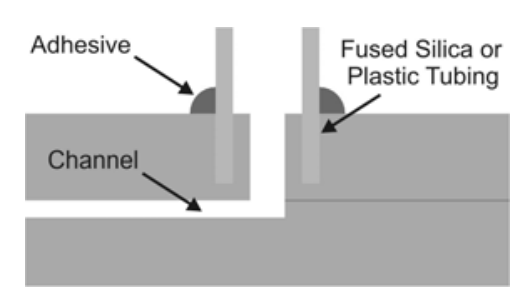

(a)

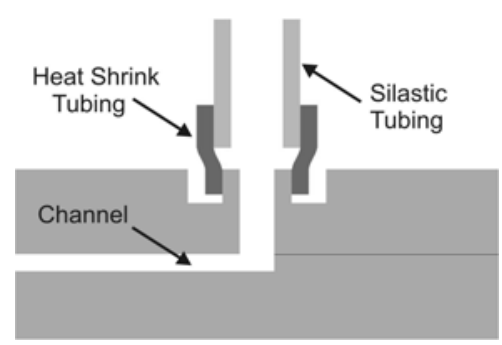

(b)

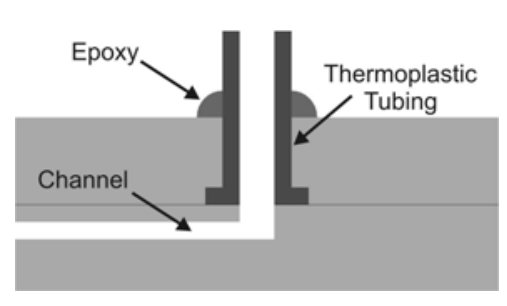

(c)

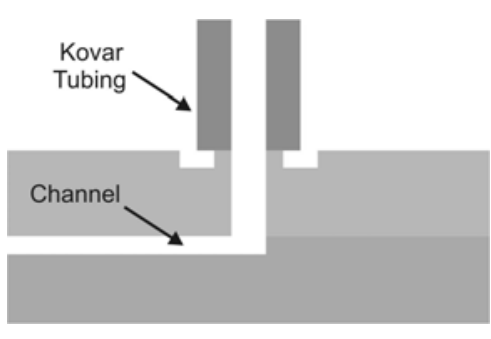

(d)

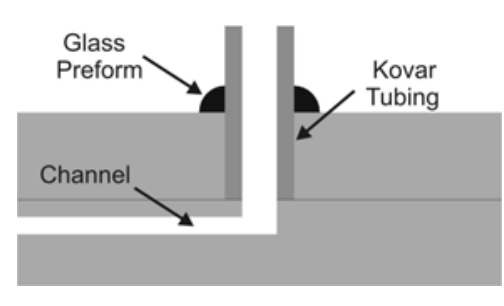

(e)

Figure 1.1 Schematic representations of different connection technologies from the literature using capillary tubing made out of various materials. 
Most of the aforementioned techniques are valid for multi-wafer encapsulated channels and devices. Press-fitted connections [1.5] and heat-shrink tubing sleeves [1.6] suffer from low working pressures of typically less than 0.5 MPa for sub-mm inner diameter tubes. Thermoplastic tubing connections [1.7] have similar limitations in working pressure [1.7], unless the tubing is supported by epoxy [1.8], which then enables working pressures of $2 \mathrm{MPa}$ to be achieved. Adhesive-held fused silica capillaries have been tested to a similar pressure level of 3.4 MPa [1.5]. However, if

the sealing is not done properly, gluing has the risk of permanently blocking the channel and mixing with the sample fluid. Attaching Kovar tubes to silicon devices using glass sealing can enable high working pressures of more than $10 \mathrm{MPa}$ to be achieved at room temperature [1.10], although it is noteworthy that such pressures are inferred indirectly from the tensile testing of joints, rather than from pressure tests. Hermeticity is usually determined by measuring the pressure drop in a closed line and observing bubble formation when the sample is immersed in liquid [1.5-1.8], which is rather inaccurate for determining small leakages. Finally, most interconnections using polymeric and plastic materials are restricted to lower operation temperatures of $300{ }^{\circ} \mathrm{C}$ or less.

\subsection{MEMS-on-tube assembly}

In the work reported in this thesis, the use of borosilicate glass tubes as fluidic interconnects has been characterised. A preliminary study to this work was undertaken by Fazal et al. and is reported elsewhere [1.11, 1.12]. The results demonstrate that $3 \mathrm{~mm}$ inner diameter capillary connections can be safely operated at pressures of more than $7 \mathrm{MPa}$ and that they are inherently hermetically sealed. The technology is based on the reflow bonding of borosilicate Duran ${ }^{\circledR}$ tubes to single crystal silicon wafers. Duran tubes of the desired dimensions are placed on silicon 
wafers after suitable surface preparation of the ends of the tubes. The whole assembly is heated up above the glass transition temperature of the Duran tubes. The glass transition temperature refers to the temperature at which the transition between the molten liquid and the solid states of the glass happens and is conventionally determined by dilatometry [1.13]. Because of the decreased viscosity of the glass as a function of increased temperature, the glass at the interface with the silicon is able to flow slowly over time, thereby enabling voids at the interface between the local points of contact between the glass and the silicon to be filled, producing a permanent bond between the glass and the silicon substrate.

The process is mask-less and adhesive free. It is not only a very reliable interconnect for microdevices to couple them to the macro-world by means of Swagelok ${ }^{\circledR}$ connectors (Figure 1.2), but it is also a very robust package and is capable of mass production. The tubes can be used as a package for the so-called MEMS-on-a-tube assembly [1.14], for which a number of microfluidic device applications have been proposed and demonstrated $[1.15,1.16]$. Furthermore, the technique can allow encapsulation of MEMS structures \devices under vacuum conditions or selected gas environments. 


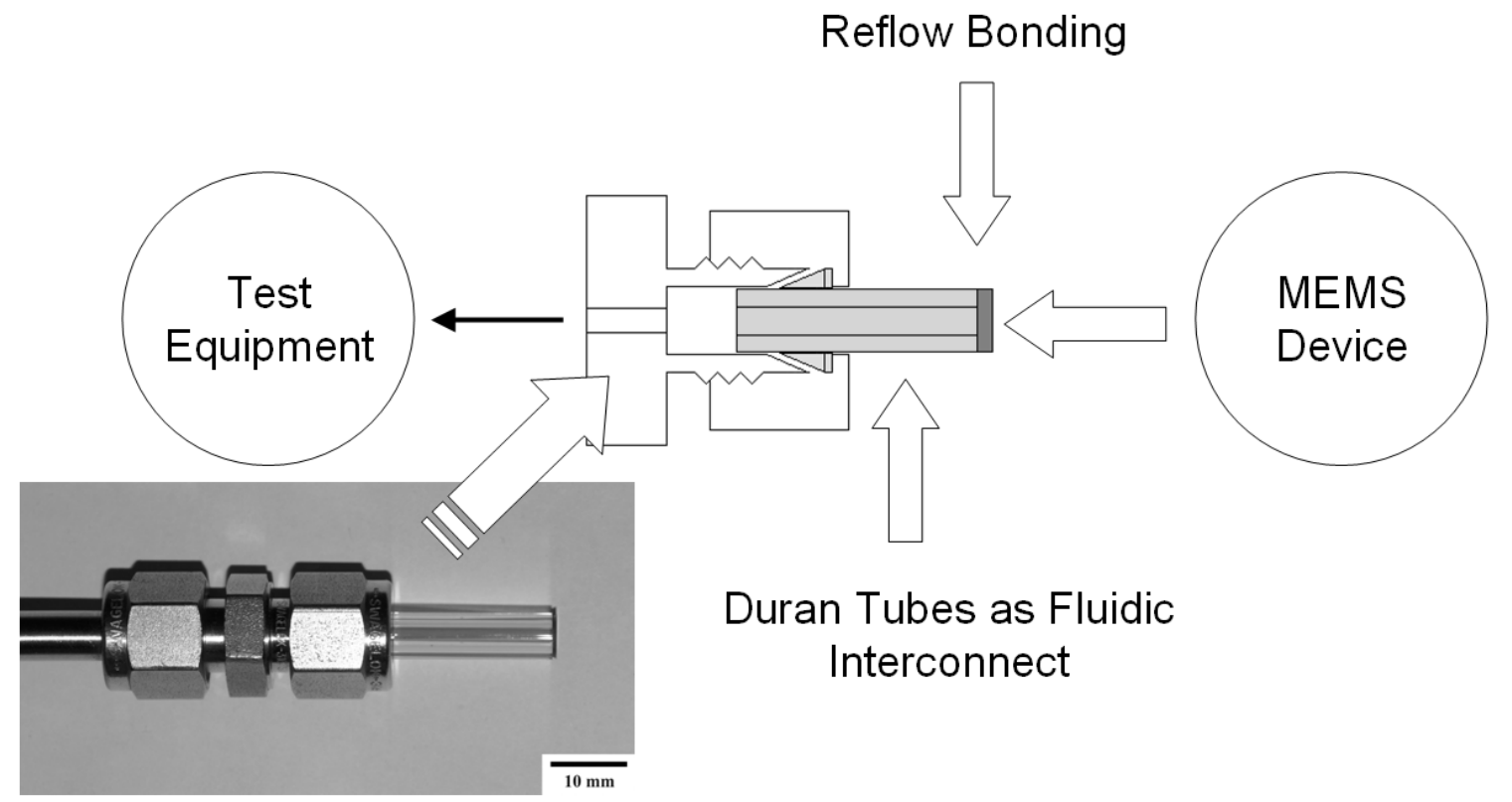

Figure 1.2 Schematic representation of concept.

\subsection{Thesis outline}

The choice of materials, the preparation procedures for the wafers and tubes prior to joining and the mechanism of joining are discussed in Chapter 2. An unintended aspect of the heat treatments used for the reflow bonding was surface crystallization of the glass arising from heterogeneous nucleation and growth of cristobalite crystals. The kinetics and morphology of this crystal growth and its reflection on the reflow bonding have been studied in Chapter 3 .

The nature of the stresses that arise due to the thermal expansion mismatch of the materials being joined are considered in Chapter 4. The second aspect considered is the burst pressure tests as a measure of bond strength, which is followed by a discussion on the reasons for material failure. The hermeticity of reflow bonding of glass tube to silicon is also demonstrated in Chapter 4.

The borosilicate glass-silicon interface formed by the reflow bonding has been characterised by electron microscopy and the results are reported in Chapter 5 . 
Integrated microfluidic devices incorporate a lot of functionality which usually require electrical connections for sensing and actuation. Therefore, the incorporation of inplane electrical interconnects to reflow bonding has been studied in Chapter 6, where methods of fabrication of electrical interconnects that would survive the bonding and not alter the quality of the bond interface were investigated.

Example applications of MEMS-on-tube assembly are presented in Chapter 7, where the glass tube can be perceived both as an interface and a package. Conclusions of the investigations on the joining of borosilicate glass tubes to silicon substrates are presented and the future prospects of joining technology are discussed in Chapter 8.

\section{References}

[1.1] P. Gravesen, J. Branebjerg, and O. S. Jensen, J. Micromech. Microeng. 3, 168 (1993).

[1.2] T. M. Squires, and S. R. Quake, Rev. Mod. Phys. 77, 977 (2005).

[1.3] D. Mijatovic, J. C. T. Eijkel, and A. van den Berg, Lab Chip 5, 492 (2005).

[1.4] G. M. Whitesides, Nature 442, 368 (2006).

[1.5] B. L. Gray, D. Jaeggi, N. J. Mourlas, B. P. van Drieenhuizen, K. R. Williams, N. I. Maluf, and G. T. A. Kovacs, Sens. Actuators A 77, 57 (1999).

[1.6] T. Pan, A. Baldi, and B. Ziaie, J. Microelectromech. Syst. 15, 267 (2006).

[1.7] A. Puntambekar, and C. H. Ahn, J. Micromech. Microeng. 12, 35 (2002).

[1.8] A. V. Pattekar, and M. V. Kothare, J. Micromech. Microeng. 13, 337 (2003). 
[1.9] M. T. Blom, E. Chmela, J. G. E. Gardeniers, J. W. Berenschot, M. Elwenspoek, R. Tijssen, and A. van den Berg, J. Micromech. Microeng. 11, 382 (2001).

[1.10] Y. Peles, V. T. Srikar, T. S. Harrison, C. Protz, A. Mracek, and S. M. Spearing, J. Microelectromech. Syst. 13, 31 (2004).

[1.11] I. Fazal, E. Berenschot, R. de Boer, H. Jansen, and M. Elwenspoek, Proceedings of International Conference on Solid-State Sensors, Actuators and Microsystems (Transducers ‘05), pp 936-9 (2005).

[1.12] I. Fazal, and M. C. Elwenspoek, J. Micromech. Microeng. 18, 055011 (2008).

[1.13] W. Vogel, Glass Chemistry (Springer-Verlag, Berlin, 1994), p 25.

[1.14] S. Unnikrishnan, H. V. Jansen, J. W. Berenschot, I. Fazal, M. C. Louwerse, B. Moğulkoç, R. Sanders, M. J. de Boer, and M. C. Elwenspoek, A method for making a glass supported system, such glass supported system, and the use of a glass support therefor, European Patent 08007746.4-2111 (2008).

[1.15] S. Unnikrishnan, H. V. Jansen, J. W. Berenschot, B. Moğulkoç, and M. C. Elwenspoek, Proceedings of IEEE International Conference on Micro Electro Mechanical Systems (MEMS '09), pp 324-7 (2009).

[1.16] S. Unnikrishnan, H. V. Jansen, J. W. Berenschot, B. Moğulkoç, and M. C. Elwenspoek, Lab Chip 9, 1966 (2009). 


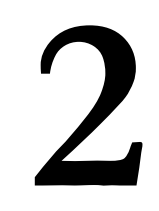

\section{Reflow bonding}

Practical aspects of the joining of borosilicate glass $\left(\right.$ Duran $\left.^{\circledR}\right)$ tubes to silicon substrates for MEMS-on-tube assembly are considered in this chapter. Initially, selection and preparation of the silicon substrates and the glass tubes are detailed. Then, the positioning of the samples in an oven and the formation of bond at high temperature due to capillarity are explained. Lastly, the selection of bonding parameters is discussed. 


\subsection{Introduction}

The reflow bonding process consists of the selection and cleaning of the silicon substrates, the selection and surface preparation of glass tubes, positioning of the samples in an oven and the formation of the bond at high temperature. Details of each of these process steps are given in this chapter.

\subsection{Selection and preparation of silicon wafers}

Non-processed silicon wafers supplied by Okmetic (Vantaa, Finland) were used. $<100>$ oriented single side polished (SSP) and double side polished (DSP) wafers 525 micron thick, $<111>$ oriented SSP wafers 525 micron thick, $<100>$ oriented SSP wafers 380 micron thick and $<110>$ oriented DSP wafers 380 micron thick were selected for the tests. These were first cleaned in $100 \% \mathrm{HNO}_{3}$ at room temperature for 10 minutes. After rinsing in deionised (DI) water, cleaning was continued in boiling $69 \% \mathrm{HNO}_{3}$ for 10 minutes. The wafers were then rinsed once again in DI water and spin-dried.

\subsection{Selection and preparation of glass tubes}

Duran tubes are made from borosilicate glass and their composition is displayed in Table 2.1. These were supplied by Schott AG (Mainz, Germany). Tubes of $3 \mathrm{~mm}$ inner diameter (ID), $6 \mathrm{~mm}$ outer diameter (OD) and $30 \mathrm{~mm}$ in length were selected for the bonding procedure. These tubes are provided in lengths of metres and therefore had to be cut down to size. For this, the tubes were bundled and embedded in glue on a flat plate to minimize any vibrations. After suitable aligning, an automated machine diced the tubes to the desired length using a rotating diamond blade. As a result of the dicing procedure, the ends of the tubes were roughened. Scanning electron micrographs (SEM) of the as-cut tube ends are displayed in Figure 2.1(a) and Figure 2.1(b) to example the initiated cracks on the surface. Their atomic 
force micrographs (AFM) are shown in Figure 2.1(c) and Figure 2.1(d) to quantify the topography. All micrographs are taken at random places after the tubes are cut down to size. The root mean square roughness of the tube ends was between 0.1 and $0.5 \mu \mathrm{m}$. Initial bonding experiments with as-cut tubes showed poor reproducibility. Therefore, a separate post-cutting polishing step of the ends of the tubes was included prior to bonding.

Table 2.1 The composition of Duran glass [2.1].

\begin{tabular}{|c|c|}
\hline \multicolumn{2}{|c|}{ Weight Percentage (\%) } \\
\hline $\mathrm{SiO}_{2}$ & 81 \\
\hline $\mathrm{B}_{2} \mathrm{O}_{3}$ & 13 \\
\hline $\mathrm{Al}_{2} \mathrm{O}_{3}$ & 2 \\
\hline $\mathrm{Na}_{2} \mathrm{O}+\mathrm{K}_{2} \mathrm{O}$ & 4 \\
\hline
\end{tabular}




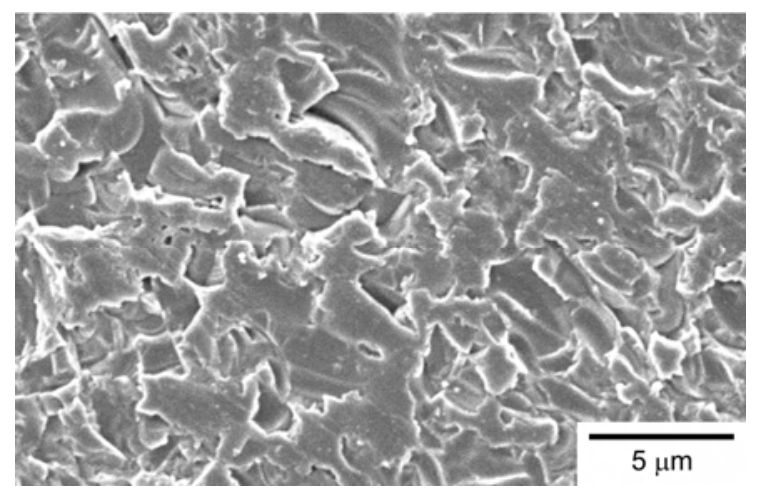

(a)

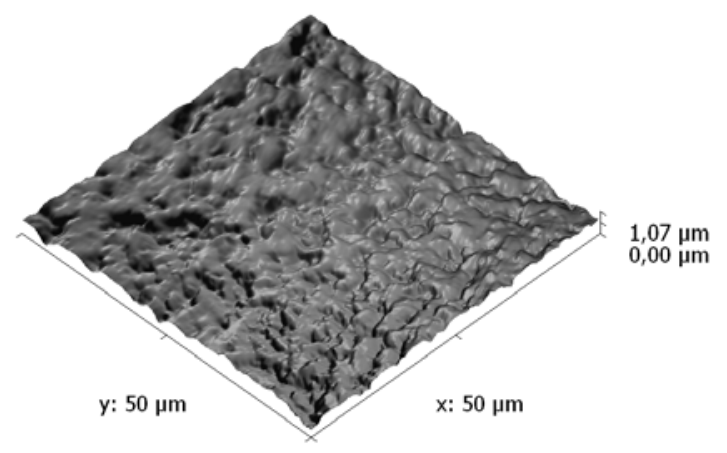

(c)

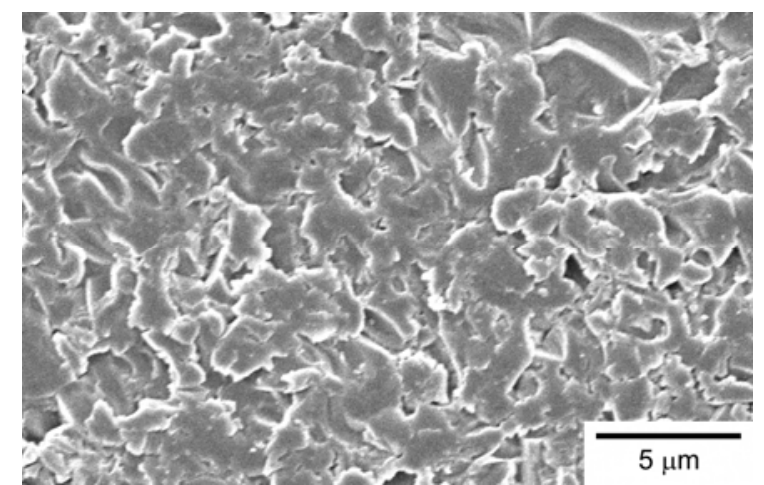

(b)

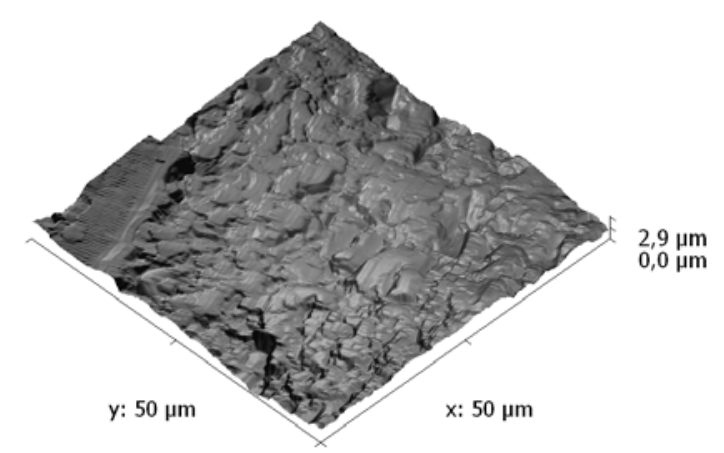

(d)

Figure 2.1 Scanning electron micrographs ((a) and (b)) and atomic force micrographs ((c) and (d)) of the as-cut tube ends at random places.

For polishing, the tubes were packed hexagonally in a wax matrix and polished to optical grade using a $\mathrm{CeO}_{2}$ and pitch suspension. The surface polishing was achieved with the $\mathrm{CeO}_{2}$ particles, while the pitch suspension helped to retain sharp corners after polishing. The bulk of the wax was then removed by boiling the polished tubes in chloroform, after which the tubes were put in $100 \% \mathrm{HNO}_{3}$ at room temperature for $10 \mathrm{~min}$ to remove any remaining wax. The tubes were then rinsed in DI water and flushed with ethanol for ease of drying. Final cleaning was accomplished by immersing the tubes in an ultrasonic bath with chloroform, acetone and isopropanol successively for 10 minutes each. 
After the cleaning, the tube ends were inspected by SEM. The pictures of the chipped glass pieces are displayed in Figure 2.2(a) and the accumulation of polishing powder in Figure 2.2(b). The root mean square of the topography on the particle free regions was lower than $0.5 \mathrm{~nm}$ indicating the possibility of direct bonding [2.2]. However, the polishing was not uniform and the scratched and defected parts of the tube ends are presented in Figure 2.2(c) and Figure 2.2(d). Although the quality of the surface finish after this post-cutting polishing procedure did not exhibit the required uniformity and cleanliness to enable direct wafer bonding at room temperature [2.2], it did enable reproducible results to be obtained from the reflow bonding procedure.

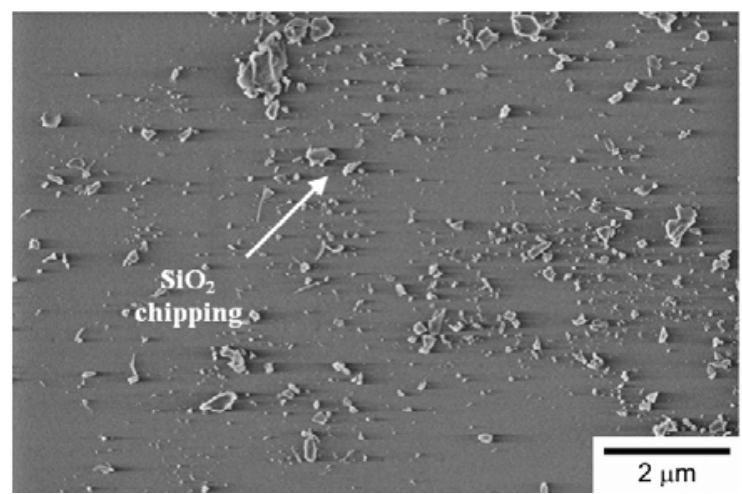

(a)

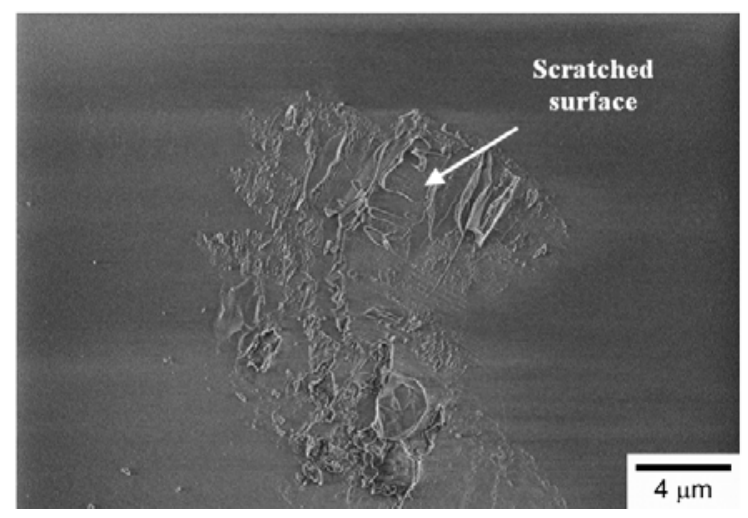

(c)

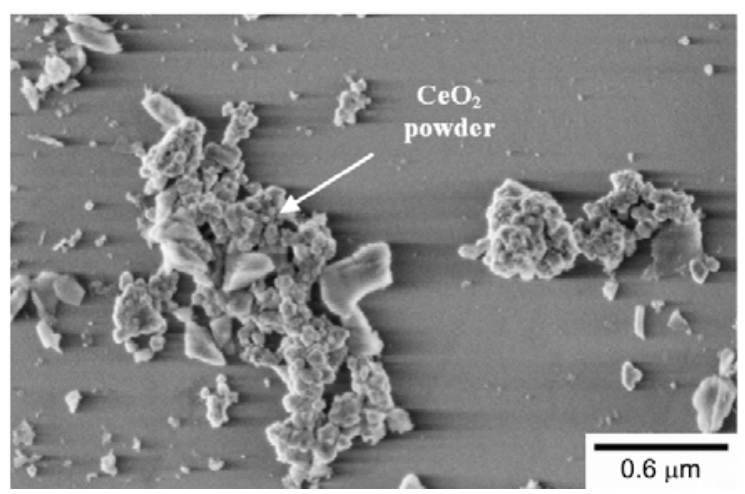

(b)

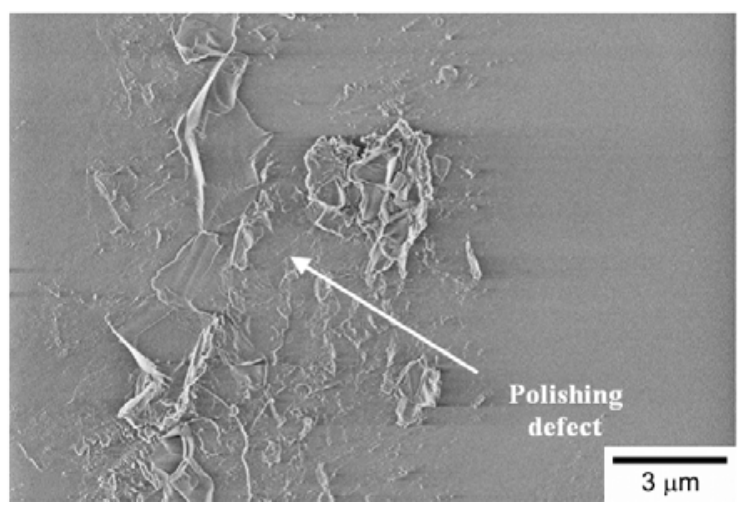

(d)

Figure 2.2 Defects on the polished surface of the glass tube after cleaning procedure. 


\subsection{Bonding procedure}

Tubes were first placed on top of silicon wafers as shown in Figure 2.3(a). The subsequent step was simply to heat treat the specimen at a suitable high temperature to form a bond between the tubes and the silicon wafers. This type of joining is called reflow bonding (or capillary bonding) since at elevated temperatures, the viscosity of the glass is lowered and initial contact is formed with the silicon wafer at various spots through wetting (Figure 2.3(b)). These contact regions grow in size by surface tension and capillary pressure between the glass and silicon, so that eventually the true area of contact between the wafer and the tube is equal to the apparent area of contact. Meanwhile, the other ends of the tube exhibit free surface relaxation (Figure 2.3(b)). Imperfections remaining after the polishing procedure will be removed by the softening of the glass during the bonding procedure. Since the glass is deformable and highly transparent to gases at the heat treatment temperature, any air trapped in pockets at the silicon-glass interface is able to diffuse out during bonding, as a result of which no voids remain at the silicon-glass interface in good bonds after bonding has taken place.

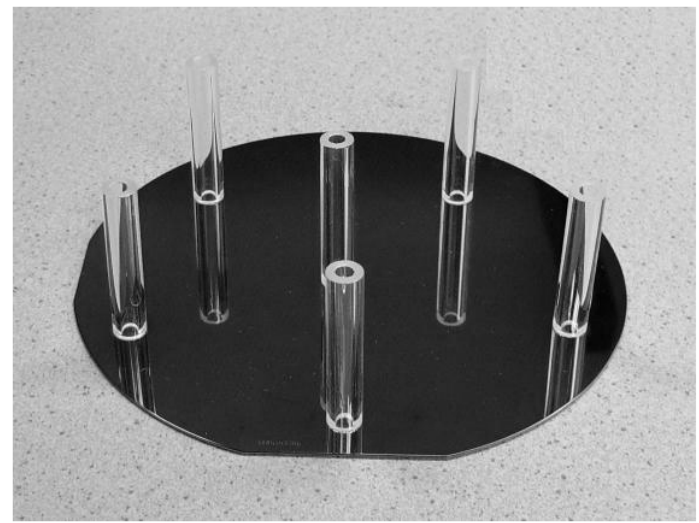

(a)

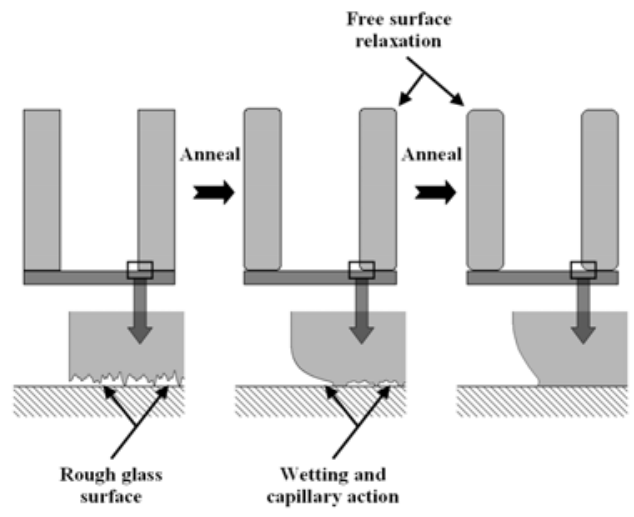

(b)

Figure 2.3 (a) Duran tubes place on top of a silicon wafer prior to bonding and (b) bonding procedure of a randomly rough glass tube to smooth silicon surface. 
Within the framework of fluid mechanics, the glass during the bonding process acts as a highly viscous, incompressible fluid which simultaneously goes through free surface relaxation and wets a perfectly smooth solid surface. For capillarity driven viscous flow, the calculation of Laplace and Bond numbers indicates that the inertial and gravitational forces are small in comparison to viscous and capillary forces and the material flow rates are inversely proportional to the viscosity [2.3]. In literature, the surface tension driven flows on free surfaces are modelled particularly for sintering applications [2.3] and morphological relaxation of viscous fluids [2.4, 2.5]. Qualitatively, these models discuss that the topographies with higher spatial frequency will flatten faster than the ones with lower spatial frequency because of the higher Laplace pressure inside the irregularities. Its practical implication on the reflow bonding is that the flatness of the tube end is more important than the short term irregularities induced by the tube preparation procedure. In an earlier text, Mullins developed a general solution of capillary induced relaxation of textured surfaces for the combined action of the transport processes of viscous flow, volume diffusion and surface diffusion [2.6], however Cassidy and Gjostein demonstrated that viscous flow dominates the smoothing process of glass surfaces for the roughness profiles having periodicity larger than $5 \mu \mathrm{m}$ [2.7]. The results of their experiments reflect that the dominant transport process during the reflow bonding is viscous flow of glass due to the length scale of the tubes being in the order of millimetres. Although above mentioned papers fail to explain the wet contact, they clearly establish the physical framework of the reflow bonding.

\subsection{Bonding parameters}

As explained in the previous section, sufficient material flow has to arise at the glasssilicon interface to ensure a strong bond. However, the bonding parameters, i.e. the 
heat treatment temperature and time, should be determined experimentally. In an earlier study of this technology, the bonding was performed by annealing the samples at $800^{\circ} \mathrm{C}$ for 30 minutes [2.8] but the process needs to be defined in a wider perspective. If the bonding is to be performed at a different temperature, the annealing time should be adjusted to account for the slower or faster flow of the glass because the glass flow rate is inversely proportional to the viscosity. Therefore, the ratio of the glass' viscosity to the heat treatment time at a certain temperature is kept constant for comparable material flow. Hence, the viscosity of the glass is studied to estimate the scaling of the annealing time. The temperature dependence of the viscosity of glass is expressed by the Vogel-Fulcher-Tammann [2.9] equation, which accounts for the variability of the activation energy for viscous flow and is often written in the form:

$$
\log \eta=-A+\frac{B}{T-T_{0}}
$$

where $\eta$ is the viscosity in $\mathrm{Pas}, T$ is the annealing temperature in ${ }^{\circ} \mathrm{C}$ and $A, B$ and $T_{0}$ are mathematical constants. The strain point of Duran glass is $518^{\circ} \mathrm{C}[2.10]$ and is defined as the temperature at which stresses relax within several hours and the viscosity of the glass is equal to $10^{13.5} \mathrm{~Pa} \mathrm{~s}$ [2.11]. The annealing point of Duran glass is $560{ }^{\circ} \mathrm{C}[2.10]$ and is defined as the temperature at which stresses relax over a period of several minutes and the viscosity of the glass is equal to $10^{12} \mathrm{Pas}$ [2.11]. Substituting the viscosity values for the strain point, the annealing point and the softening point $\left(10^{6.6} \mathrm{Pas}\right.$ at $\left.820{ }^{\circ} \mathrm{C}\right)$ of the glass [2.10] in eq. (2.1); $A, B$ and $T_{0}$ were calculated to be $2.99,6920.28$ and 371.31 respectively. 
With the temperature dependence of the viscosity from eq. (2.1), the dashed black line in Figure 2.4 was drawn to show the scaling of the annealing time of 30 minutes at $800{ }^{\circ} \mathrm{C}$ if the bonding temperature is lowered. After some preliminary experiments, the dotted black line in Figure 2.4 was determined to be the starting point of bond formation. Above the solid black line in Figure 2.4; a strong bond will form between the borosilicate glass tubes and the silicon substrates.

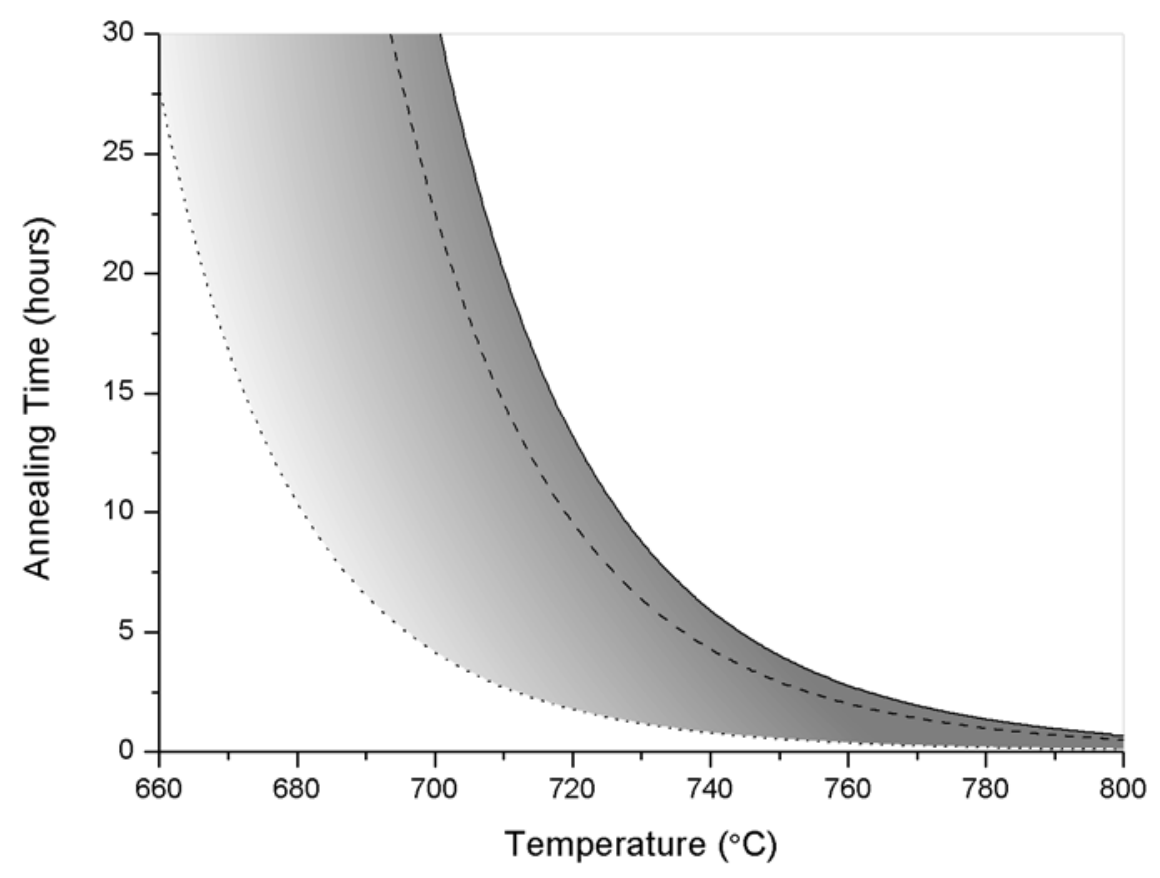

Figure 2.4 The required annealing times to achieve the reflow bonding at different temperatures. The regions above the solid black line will bond while the regions below the dotted black line will not bond.

During the bonding process, the tubes also deform on a macroscale. They tend to bend along their length because of gravitational effects introduced by the non-levelled dicing and thermal gradients in the oven. Therefore, the bonding temperature needs 
to be low as possible, while ensuring enough flow of glass near the silicon interface through prolonged, but still practical, heat treatment times. Not only does this reduce the effects of temperature non-uniformity inside the oven, but it also helps to make the tube bonding procedure feasible for incorporation of other materials. Thus, the temperature / time heat treatments were chosen to be (i) $680^{\circ} \mathrm{C}$ for 10 hours and (ii) - (iv) $700{ }^{\circ} \mathrm{C}$ for 10,20 and 30 hours to achieve bonding. By comparison, the glass transition temperature of Duran borosilicate glass is quoted by the manufacturers to be $525{ }^{\circ} \mathrm{C}$ [2.1]. All of the heat treatments are carried out in a Nabertherm LH 15/12 oven. The temperature profile of the oven during bonding is shown in Figure 2.5. Once the target temperature was set, the oven was heated up at $10{ }^{\circ} \mathrm{C}$ per minute to $15^{\circ} \mathrm{C}$ below the target temperature, after which heating continued at $1{ }^{\circ} \mathrm{C}$ per minute to prevent any overshoot. During the stable operating period, the temperature of the oven was typically $2{ }^{\circ} \mathrm{C}$ below the target temperature. After each heat treatment the furnace was switched off and the samples were furnace cooled to room temperature. The tubes also become thicker at the bottom due to the gravity driven flow of the glass. Using the analytical model of Stokes [2.12], this increase in the wall thickness of $30 \mathrm{~mm}$ long glass tube is roughly estimated to be $5 \%$ after the bonding at $700{ }^{\circ} \mathrm{C}$ for 30 hours. 


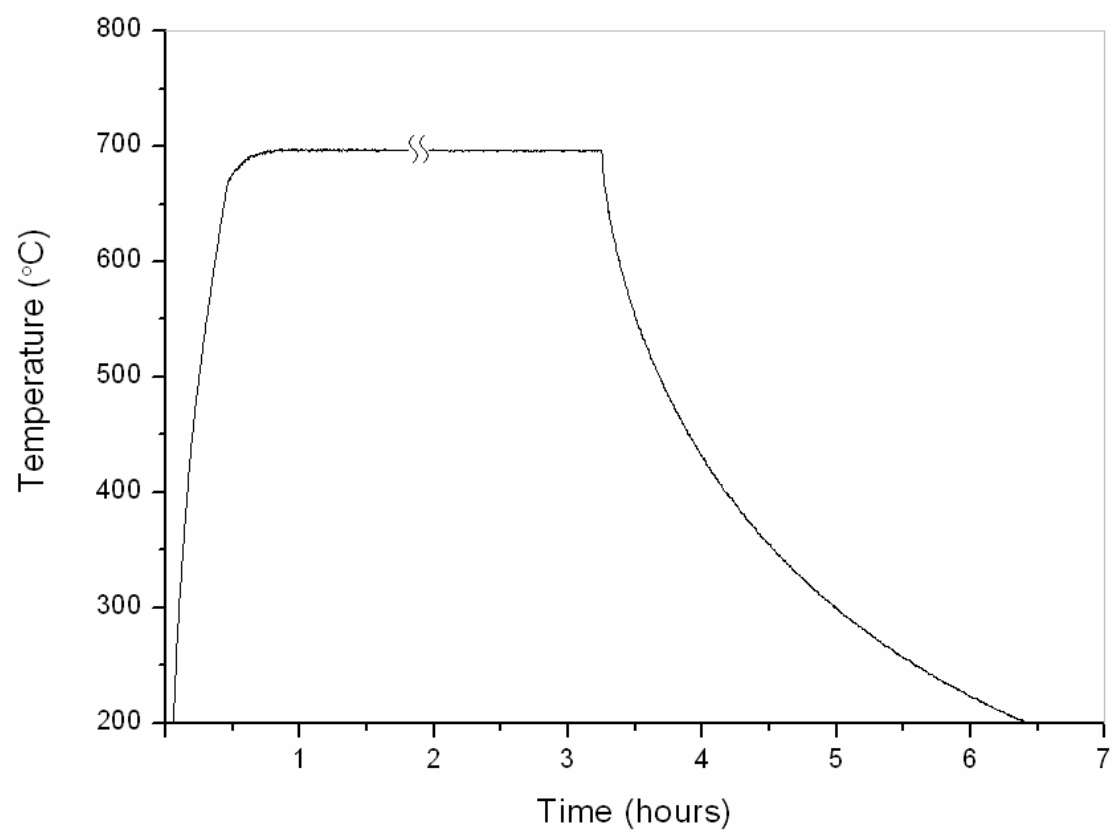

Figure 2.5 Temperature profile of the oven during bonding.

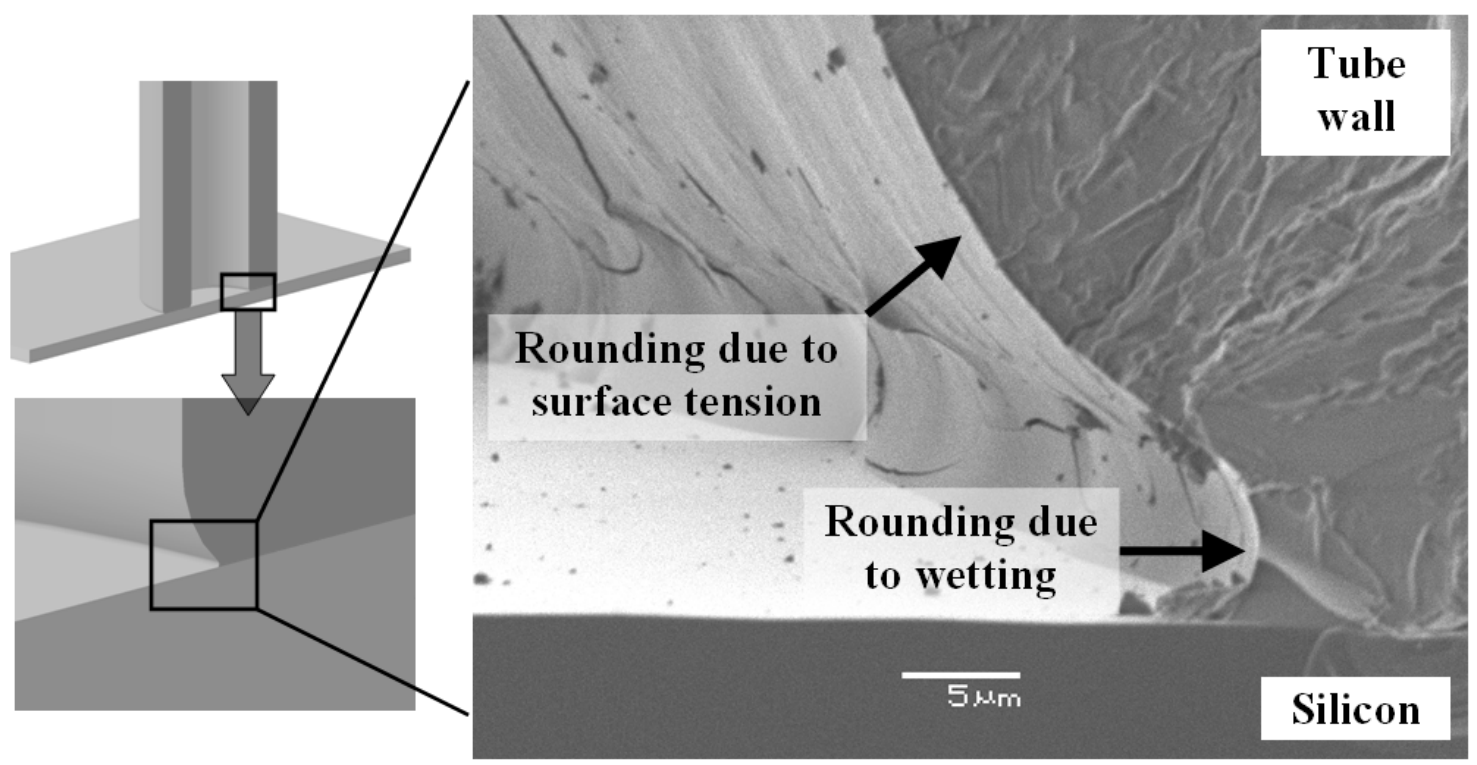

Figure 2.6 Cross-section of a bonded tube to silicon with a close-up of its inner rim to highlight the spreading feet and the contact line. 
A scanning electron micrograph of the edges of a glass tube on silicon heat treated at $700{ }^{\circ} \mathrm{C}$ for 30 hours is shown in Figure 2.6, together with schematics of the region at lower magnifications. The corners of the glass tube are made round during the heat treatment through surface relaxation. Initially they are not in contact with silicon because of defects on the end of the glass tube. As the heat treatment continues the contact line of glass to silicon continues to develop and a small wetting angle is clearly seen.

\subsection{Summary}

The choice of materials, the preparation procedures for the silicon wafers and the glass tubes prior to joining are discussed. Positioning of the samples and the mechanism behind the joining of glass tubes to silicon substrates by reflow bonding for MEMS-on-tube assembly have been described. The details of heat treatment procedure are given and the bonding parameters have been specified.

\section{References}

[2.1] http://www.duran-group.com/en/about-duran.html, accessed 1 July 2010.

[2.2] C. Gui, M. Elwenspoek, N. Tas, and J. G. E. Gardeniers, J. Appl. Phys. 85, 7448 (1999).

[2.3] R. W. Hopper, J. Fluid Mech. 213, 349 (1990).

[2.4] H. K. Kuiken, J. Fluid Mech. 214, 503 (1990).

[2.5] G. de With, and A. J. Corbijn, J. Mater. Sci. 30, 3155 (1995). 
[2.6] W. M. Mullins, J. Appl. Phys. 30, 77 (1959).

[2.7] D. C. Cassidy, and N. A. Gjostein, J. Am. Ceram. Soc. 53, 161 (1970).

[2.8] I. Fazal, and M. C. Elwenspoek, J. Micromech. Microeng. 18, 055011 (2008).

[2.9] J. E. Shelby, Introduction to glass science and technology (The Royal Society of Chemistry, Cambridge, 2005), pp 120-1.

[2.10] http://www.schott.com/borofloat/english/, accessed 1 July 2010.

[2.11] W. Vogel, Glass Chemistry (Springer-Verlag, Berlin, 1994), p 30.

[2.12] Y. M. Stokes, Proc. R. Soc. A - Math. Phys. Eng. Sci. 455, 2751 (1999). 


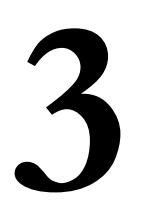

\section{Devitrification of}

\section{borosilicate glass}

In this chapter, the heterogeneous nucleation and growth of crystals in borosilicate 8330 glass during its prolonged heat treatment above its glass transition temperature of $525{ }^{\circ} \mathrm{C}$ are investigated. Initially, the kinetics and morphology of this crystal growth have been studied for heat treatment temperatures at and above $660{ }^{\circ} \mathrm{C}$. The activation energy for crystal growth is estimated to be $185 \pm 10 \mathrm{~kJ} \mathrm{~mol}^{-1}$. This is attributed to the diffusion of boron, rather than sodium, being the rate-limiting step within the borosilicate framework. In addition, contact with the atmosphere is shown to initiate the nucleation of cristobalite crystals, while deposition of a thin silicon nitride surface coating on the glass helps to prevent this nucleation. Lastly, the implications of the devitrification of glass on the reflow bonding are discussed. 


\subsection{Introduction}

Duran ${ }^{\circledR}$ tubes and Borofloat ${ }^{\circledR}$ glass wafers are made from the same glass composition (borosilicate 8330) and have been used extensively in various configurations in microelectromechanical systems as substrates or packaging materials $[3.1,3.2]$. They have also been used in basic research over the years in powdered form as matrix materials in the production of silicon carbide fibre-reinforced inorganic glasses [3.3]. Sintering and sealing applications, as well as the reflow bonding, take place in the viscous flow temperature regime of borosilicate glasses, i.e. above their glass transition temperatures. However, unless suitable precautions are taken, significant surface devitrification can arise in this temperature regime through heterogeneous nucleation and the subsequent growth of cristobalite crystals within the borosilicate glasses [3.4, 3.5]. Surface crystallisation is favoured over crystallisation in the bulk of the glass because the surface acts as a heterogeneous nucleation site. Therefore, the rates of crystallisation in commercially available glass and the study of the microstructure which develops as a result of crystallisation have been of interest.

In this chapter, the rates of crystal growth have been studied as a function of temperature in Borofloat (borosilicate 8330) glass [3.6]. Spherulitic growth of cristobalite is observed in this glass. Although previous studies have addressed devitrification for a similar type of borosilicate glass $\left(\operatorname{Pyrex}^{\circledR}\right.$ - Corning 7740) [3.7, 3.8], the temperatures chosen for these previous studies were $700{ }^{\circ} \mathrm{C}$ and above. In this prior work, the rate-limiting step determining the activation energy for crystal growth in Pyrex was inferred to be the diffusion of sodium out of the silica framework $[3.7,3.8]$. By heat treating for extended periods of time at temperatures at and above $660{ }^{\circ} \mathrm{C}$, the rates of devitrification in Borofloat glass over an extended temperature range were determined. 


\subsection{Experimental procedure}

In agreement with the work of Ainslie et al. in their study of the devitrification of fused silica [3.9], the nucleation of crystals in borosilicate glasses is observed to be catalysed by impurities, dust particles and other contaminants on the surface. Therefore, all growth experiments were undertaken with pieces of glass which had all been subjected to the same preparation procedure. $100 \mathrm{~mm}$ diameter Borofloat wafers $500 \mu \mathrm{m}$ thick were selected for the experiments. These were cleaned initially in 100\% nitric acid $\left(\mathrm{HNO}_{3}\right)$ solution for 20 minutes, after which they were etched in $50 \%$ hydrofluoric acid (HF) solution for 5 minutes. This etching process thinned the substrates down to a final thickness of about $410 \mu \mathrm{m}$.

All of the heat treatments were carried out in a Nabertherm LH 15/12 oven in air. As detailed in Chapter 2, the oven was slowly heated up to the target temperature to prevent any overshoot. After each heat treatment, the samples were furnace cooled to room temperature with an initial cooling rate about $-20{ }^{\circ} \mathrm{C}$ per minute, eventually reaching below $100{ }^{\circ} \mathrm{C}$ after $8-10$ hours. When the firing temperature was at and above $800{ }^{\circ} \mathrm{C}$, the glass wafers were supported by (001) single crystalline silicon substrates. Having support at and above $800{ }^{\circ} \mathrm{C}$ prevented the Borofloat wafers from forming a droplet because the glass wetted the silicon, helping to preserve the planar shape of the wafers.

X-ray diffractometry (XRD) at room temperature confirmed that the spherulites of crystals produced as a consequence of the devitrification process were $\alpha$-cristobalite, a polymorph of silica, as expected from previous work [3.3, 3.4, 3.7, 3.8]. Energy dispersive X-ray (EDX) analysis confirmed that the crystals were of the correct chemical composition expected for silica. For inspection of the cross-sections of the crystals, samples were first cleaved after annealing on $\{110\}$ planes of the underlying silicon. They were then etched for 15 minute in buffered hydrofluoric acid (BHF) to 
increase the contrast during scanning electron microscopy (SEM). For the analysis of the growth kinetics, the radii of the largest crystals were measured by optical microscopy after every heat treatment. When the crystal sizes were plotted with respect to the annealing time for constant annealing temperature, a straight line could be fitted to the data to obtain the linear crystal growth rates. The position where the line crosses the time axis was taken as the incubation time for nucleation. At each measurement temperature, 4 or 5 different time steps were chosen to find the linear crystal growth rate and the incubation time for nucleation. The samples were etched for 5 minutes in BHF to improve the contrast during the optical microscopy when the diameters of the largest spherulites present were less than $20-30 \mu \mathrm{m}$.

To examine the effect of protecting the surface during heat treatment, samples were made in which the glass had been bonded to silicon wafers by reflow bonding [3.2]. The silicon was removed by immersing the bonds in tetramethylammonium hydroxide (TMAH) solution at $85{ }^{\circ} \mathrm{C}$. In addition, a glass wafer was coated with a $0.5 \mu \mathrm{m}$ thick silicon nitride film by plasma enhanced chemical vapour deposition (PECVD) at $300{ }^{\circ} \mathrm{C}$ with a base pressure of $133 \mathrm{~Pa}$ in an Oxford Instruments Plasmalab $80+$ system prior to heat treatment.

\subsection{Results and discussion}

\subsubsection{Crystal growth model}

The process of crystallisation is nicely described by Doremus [3.10]. As the molten glass is cooled below its liquidus temperature, the rate of crystal growth first rises to a maximum, and then decreases. As the temperature difference from the liquidus temperature becomes higher, the thermodynamic driving force is increased, thereby

increasing the rate. However, further reducing the temperature drastically reduces the mobility of the chemical constituents within the glass, thereby reducing the rate at 
which they can be incorporated into the crystals being produced [3.10]. Prior to the modern theories of crystal growth, Cox and Kirby [3.7] developed an empirical growth model to describe the crystallisation process. Their analysis showed that the activation energy for the growth of cristobalite in Pyrex is closer in magnitude to that relevant for the diffusion of sodium ions, rather than to an activation energy suitable for describing the variation with temperature of the viscosity of Pyrex in the crystal growth temperature range, in contrast to the conventional understanding at that time.

In the modern theory of crystal growth from the liquid described by Turnbull and Cohen [3.11], amongst others, the linear crystal growth rate, $u$, at a temperature $T$ can be written in the form

$$
u=a_{0} v \exp \left(-\frac{Q}{R T}\right)\left[1-\exp \left(-\frac{\Delta g}{R T}\right)\right]
$$

in which $a_{0}$ is the molecular diameter (or jump distance), $v$ is the vibration frequency (or attempted jump frequency), $Q$ is the activation energy for diffusion governing the transport of material across the crystal-liquid interface, $R$ is the gas constant, and $\Delta g$ is the free energy decrease per mole between the crystal and the liquid. This model is based on the assumptions that (i) the enthalpy release during crystal growth does not locally alter the isothermal growth condition at the crystal-melt interface and (ii) the reaction at the crystal-melt interface is fast, so that the crystal growth is limited by the transport processes. Qualitatively, the crystal grows by the advancing of the crystal-melt interface; the process is limited by rate of removal of foreign atoms that can not be incorporated into the growing crystal. 
Making the assumption that the enthalpy difference, $\Delta h$, and the entropy of formation, $\Delta s$, for cristobalite from the supercooled liquid (or glass) are both independent of temperature within the devitrification temperature regime and are equal to their values at the liquidus temperature, $\Delta g$ is expressed in the form [3.11]

$$
\Delta g=\Delta h_{f} \frac{\left(T_{\text {liq }}-T\right)}{T_{\text {liq }}}=\Delta s_{f}\left(T_{\text {liq }}-T\right)
$$

where $T_{\text {liq }}$ is the liquidus temperature, $\Delta h_{f}$ is the enthalpy of formation at the liquidus temperature and $\Delta s_{f}=\Delta h_{f} / T_{\text {liq }}$ is the entropy of formation at the liquidus temperature. Hence, eq. (3.1) can be rearranged in a form suitable for determining $Q$ :

$$
\ln \left(\frac{u}{\left[1-\exp \left(-\Delta s_{\mathrm{r}}\left(\frac{1}{T_{\mathrm{r}}}-1\right)\right)\right]}\right)=\ln A-\frac{Q}{R T}
$$

in which $A=a_{0} v$ is a constant independent of temperature, $T_{\mathrm{r}}=T / T_{\text {liq }}$ is the reduced temperature and $\Delta s_{\mathrm{r}}=\Delta s_{f} / R$ is the reduced melting entropy. For $\Delta s_{r} \rightarrow 0$, $\Delta g<<R T$ and eq. (3.3) can be written as eq. (3.4), while for $\Delta s_{r} \rightarrow \infty, \Delta g>>R T$ and eq. (3.3) can be written as eq. (3.5). 


$$
\begin{gathered}
\ln \left(\frac{u}{\left[\Delta s_{\mathrm{r}}\left(\frac{1}{T_{\mathrm{r}}}-1\right)\right]}\right)=\ln A-\frac{Q_{1}}{R T} \text { for } \lim _{x \rightarrow 0}[1-\exp (-x)]=x \\
\ln (u)=\ln A-\frac{Q_{2}}{R T} \text { for } \lim _{x \rightarrow \infty}[1-\exp (-x)]=1
\end{gathered}
$$

In this context, $Q$ is the activation energy to be calculated for finite $\Delta s_{\mathrm{r}}$ values. However, $Q_{1}$ and $Q_{2}$ will be limiting values for $\Delta s_{\mathrm{r}}$ approaching zero and infinity respectively. If eq. (3.3), (3.4) and (3.5) are presumed to be valid between temperatures $T_{2}$ and $T_{1}$ (so that $T_{\text {liq }}>T_{1}>T_{2}$ ) with corresponding growth rates $u_{2}$ and $u_{1} ; Q, Q_{1}$ and $Q_{2}$ can be expressed as in eq. (3.6), (3.7) and (3.8) for different ranges of $\Delta s_{\mathrm{r}}$ values:

$$
Q=\frac{R \ln \left(\frac{u_{1}}{u_{2}}\left[1-\exp \left(-\Delta s_{\mathrm{r}}\left(\frac{T_{\text {liq }}}{T_{2}}-1\right)\right)\right]\right]}{\left(\frac{1}{T_{2}}-\frac{1}{T_{1}}\right)}
$$




$$
\begin{aligned}
& Q_{1}=\frac{R \ln \left(\frac{\left.u_{1} \frac{T_{\text {liq }}}{T_{2}}-1\right]}{u_{2}\left[\frac{T_{\text {liq }}}{T_{1}}-1\right]}\right)}{\left(\frac{1}{T_{2}}-\frac{1}{T_{1}}\right)}=\frac{R \ln \left(\frac{u_{1}}{u_{2}}\right)}{\left(\frac{1}{T_{2}}-\frac{1}{T_{1}}\right)}+\frac{R \ln \left(\frac{\left[\frac{T_{\text {liq }}}{T_{2}}-1\right]}{\left[\frac{T_{l i q}}{T_{1}}-1\right]}\right)}{\left(\frac{1}{T_{2}}-\frac{1}{T_{1}}\right)} \\
& Q_{2}=\frac{R \ln \left(\frac{u_{1}}{u_{2}}\right)}{\left(\frac{1}{T_{2}}-\frac{1}{T_{1}}\right)}
\end{aligned}
$$

Eq. (3.6) will approximate to eq. (3.7) for $\Delta s_{r} \rightarrow 0$, i.e. $\Delta g<<R T$, and to eq. (3.8) for $\Delta s_{r} \rightarrow \infty$, i.e. $\Delta g>>R T$. Therefore for finite values of $\Delta s_{\mathrm{r}}, Q$ will satisfy the inequality $Q_{1}>Q>Q_{2}$ : higher values of $\Delta s_{\mathrm{r}}$ will result in the calculation of lower activation energies. Thus, as in the work of Jean and Fang [3.8], undertaking an analysis of the crystal growth rates by simply plotting $\ln u$ vs $T^{-1}$ will produce a lower bound estimate of the activation energy, $Q$, with the inherent assumption that $\Delta g>>R T$.

The temperature at which the crystal growth is maximum, $T_{\max }$, can be calculated analytically by equating the first derivative of eq. (3.1) with respect to temperature to zero, as displayed in eq. (3.9): 


$$
T_{\text {max }}=\frac{Q T_{\text {liq }}}{Q+\frac{Q}{\Delta s_{r}} \ln \left(1+\frac{R T_{\text {liq }}}{Q} \Delta s_{r}\right)}=\frac{Q T_{\text {liq }}}{Q+R T_{\text {liq }} \frac{\ln \left(1+\frac{R T_{\text {liq }}}{Q} \Delta s_{r}\right)}{\frac{R T_{\text {liq }}}{Q} \Delta s_{r}}}
$$

Eq. (3.9) will approximate to eq. (3.10) for $\Delta s_{r} \rightarrow 0$, i.e. $\Delta g<<R T$ and to eq. (3.11) for $\Delta s_{r} \rightarrow \infty$, i.e. $\Delta g>>R T$.

$$
\begin{gathered}
T_{\mathrm{m} 1}=\frac{Q T_{\text {liq }}}{Q+R T_{\text {liq }}} \text { for } \lim _{y \rightarrow 0} \frac{\ln (1+y)}{y}=1 \\
T_{\mathrm{m} 2}=T_{\text {liq }} \text { for } \lim _{y \rightarrow \infty} \frac{\ln (1+y)}{y}=0
\end{gathered}
$$

Therefore for finite values of $\Delta s_{\mathrm{r}}, T_{\max }$ will satisfy the inequality $T_{\mathrm{m} 2}=T_{\text {liq }}>T_{\max }>T_{\mathrm{m} 1}$. Qualitatively, higher values of $\Delta s_{\mathrm{r}}$ will result in the calculation of higher $T_{\max }$ values. Analysis of the crystal growth rates by simply plotting $\ln u$ vs $T^{-1}$ would force $T_{\max }=T_{\text {liq }}$, i.e. $u$ will increase continuously up to $T_{\text {liq }}$, and vanish rapidly at $T=T_{\text {liq }}$. Physically, if $\Delta g>>R T$, the enthalpy release during growth would be expected to make the assumption of isothermal growth conditions invalid. 


\subsubsection{Kinetics of surface devitrification}

As shown in the previous section, the activation energy for crystal growth, $Q$, can be determined from eq. (3.3) if the liquidus temperature, $T_{\text {liq }}$, and the reduced melting entropy, $\Delta s_{\mathrm{r}}$, of the glass are known. If the slight alumina and potassium oxide contents of Borofloat glass are disregarded (Table 2.1 of Chapter 2 - Borofloat and Duran are in essence the same material as described by the manufacturer), an inspection of the liquidus surface of the high-silica portion of the $\mathrm{Na}_{2} \mathrm{O}-\mathrm{B}_{2} \mathrm{O}_{3}-\mathrm{SiO}_{2}$ system [3.12] suggests that the liquidus surface of Borofloat glass can be expected to lie in the range $1000-1100{ }^{\circ} \mathrm{C}$. If the glass composition is assumed to be on the silica-sodium tetraborate pseudobinary join [3.13], the liquidus temperature would be expected to be around $1065^{\circ} \mathrm{C}$. This value is close to the reported liquidus temperature of Pyrex of $1064{ }^{\circ} \mathrm{C}$ [3.7]. For this reason, the value of $1064{ }^{\circ} \mathrm{C}$ has been assumed to be the liquidus temperature for Borofloat glass in the analysis presented here. The reduced melting entropy is reported to be 0.79 for silica [3.14] and to have an average of $5 \pm 3$ in fourteen silicate glasses [3.15]. Therefore, the full form of the growth model, i.e. eq. (3.3), was used to examine the crystal growth data using a range of values for $\Delta s_{\mathrm{r}}$, paying particular attention to values of $\Delta s_{\mathrm{r}}$ less than 5 . 


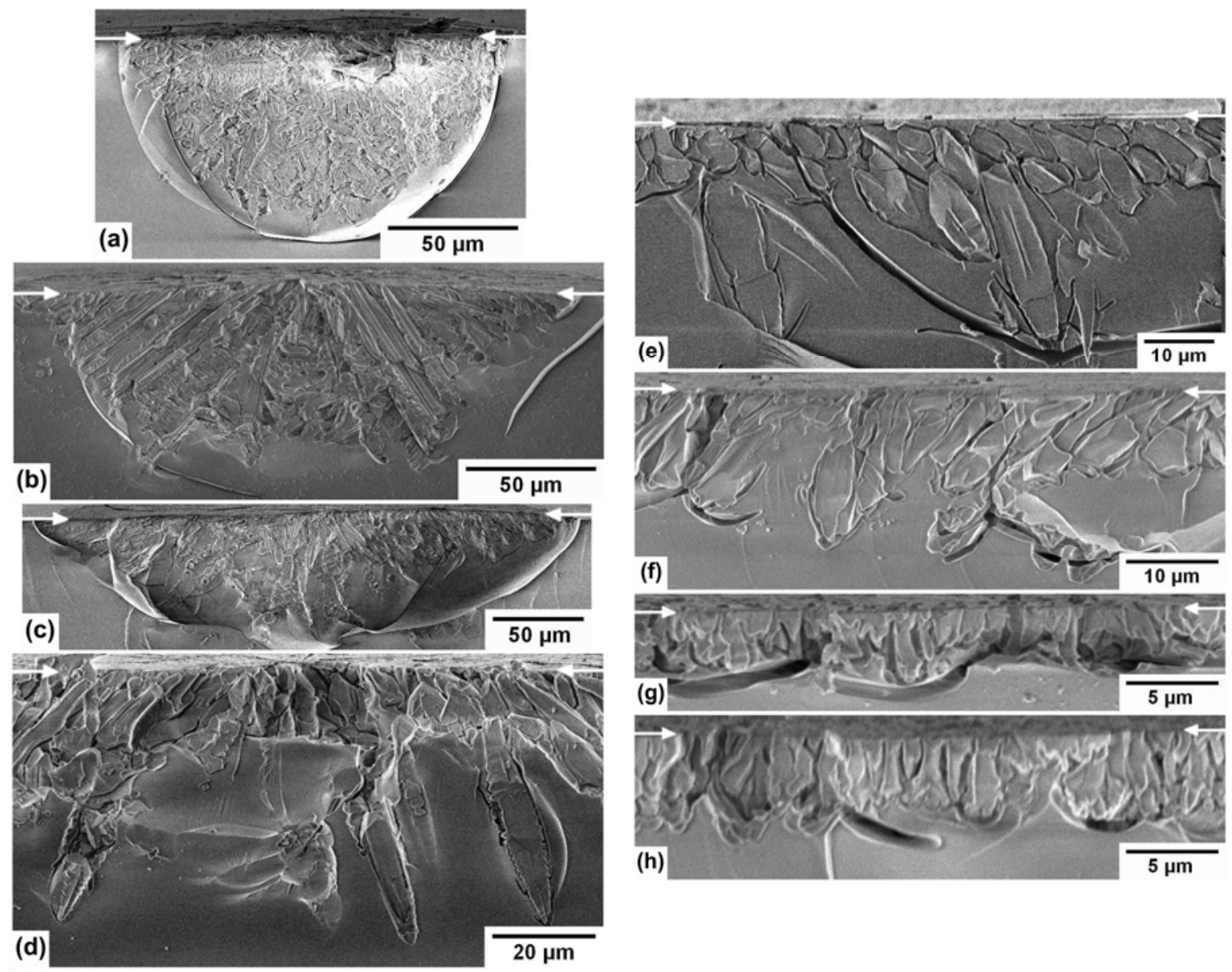

Figure 3.1 Cross-sectional views of approximately the mid-planes of cristobalite crystals after annealing 10 hours at (a) $900{ }^{\circ} \mathrm{C}$, (b) $950{ }^{\circ} \mathrm{C}$, (c) $970{ }^{\circ} \mathrm{C}$, (d) $1000^{\circ} \mathrm{C}$, (e) $1020^{\circ} \mathrm{C}$, (f) $1050{ }^{\circ} \mathrm{C}$, (g) $1150{ }^{\circ} \mathrm{C}$, and (h) $1200{ }^{\circ} \mathrm{C}$. Samples were cleaved and etched in BHF for 15 minutes before microscopy. Arrows indicate the line formed by the silicon wafer surface and the Borofloat glass cross-section.

Inspection of the crystallisation process showed that for temperatures below $900{ }^{\circ} \mathrm{C}$, the surface growth rate was very similar to the growth rate into the bulk of the material, i.e. the crystalline regions approximated to a hemisphere and showed classical spherulitic growth. However, above $900{ }^{\circ} \mathrm{C}$, there was a clear difference between crystal growth rates parallel and perpendicular to the surface. Scanning electron micrographs of the cross-sections of some cristobalite crystals are shown in Figure 3.1; arrows indicate the edge formed by the surface and the cross-section. The 
samples were annealed for 10 hours at various temperatures and cleaved easily on $\{110\}$ planes of the underlying silicon support. The cleavage planes hit the midplanes of some crystals, which were randomly spread on the glass surface. Samples were then etched for 15 minutes in BHF to obtain better contrast during scanning electron microscopy, through the etch selectivity of crystals relative to the surrounding glass matrix.

At suitably high temperatures, evaporation of volatile constituents such as boron [3.16] will alter the surface composition of the glass, causing the crystalline region to deviate from the hemispherical shape as displayed in Figure 3.1(a) - Figure 3.1(f). At temperatures well above the presumed liquidus temperature of the glass, $1064{ }^{\circ} \mathrm{C}$, the crystalline regions never penetrated more than $5 \mu \mathrm{m}$ into the glass after 10 hours (Figure 3.1(g) and Figure 3.1(h)), even though at $1200{ }^{\circ} \mathrm{C}$ they were able to grow at more than $100 \mu \mathrm{m} \mathrm{h}^{-1}$ parallel to the surface. Similar observations have been reported by Oldfield and Wright [3.17], who studied volatilization of constituents from a similar type of borosilicate glass at elevated temperatures and reported that the rate of loss became negligible after 40 hours of annealing at $1200{ }^{\circ} \mathrm{C}$ because the surface cristobalite layer stopped further evaporation.

XRD measurements of the glass samples annealed at $950{ }^{\circ} \mathrm{C}, 1150{ }^{\circ} \mathrm{C}$ and $1200{ }^{\circ} \mathrm{C}$ for 10 hours were taken at room temperature with $\mathrm{Cu} \mathrm{K} \alpha$ radiation and the results are plotted in Figure 3.2 as a function of 20 . As expected from $\alpha$-cristobalite $[3.3,3.8]$, the strongest reflection was from $\{101\}$ planes but reflection peaks from $\{111\},\{102\}$ and $\{200\}$ planes were also apparent. If the evaporation of volatile constituents alters the surface composition of Borofloat, the surface of the glass enriches in silica and the local concentration falls in the stable tridymite + liquid region of the phase diagram of Rockett and Foster [3.13], while the bulk remains liquid. Therefore, XRD patterns of samples heat treated at $1150{ }^{\circ} \mathrm{C}$ and $1200{ }^{\circ} \mathrm{C}$ for 
10 hours, i.e. above the presumed liquidus temperature and where maximum evaporation was expected, were required to confirm the crystals at any temperature were cristobalite.

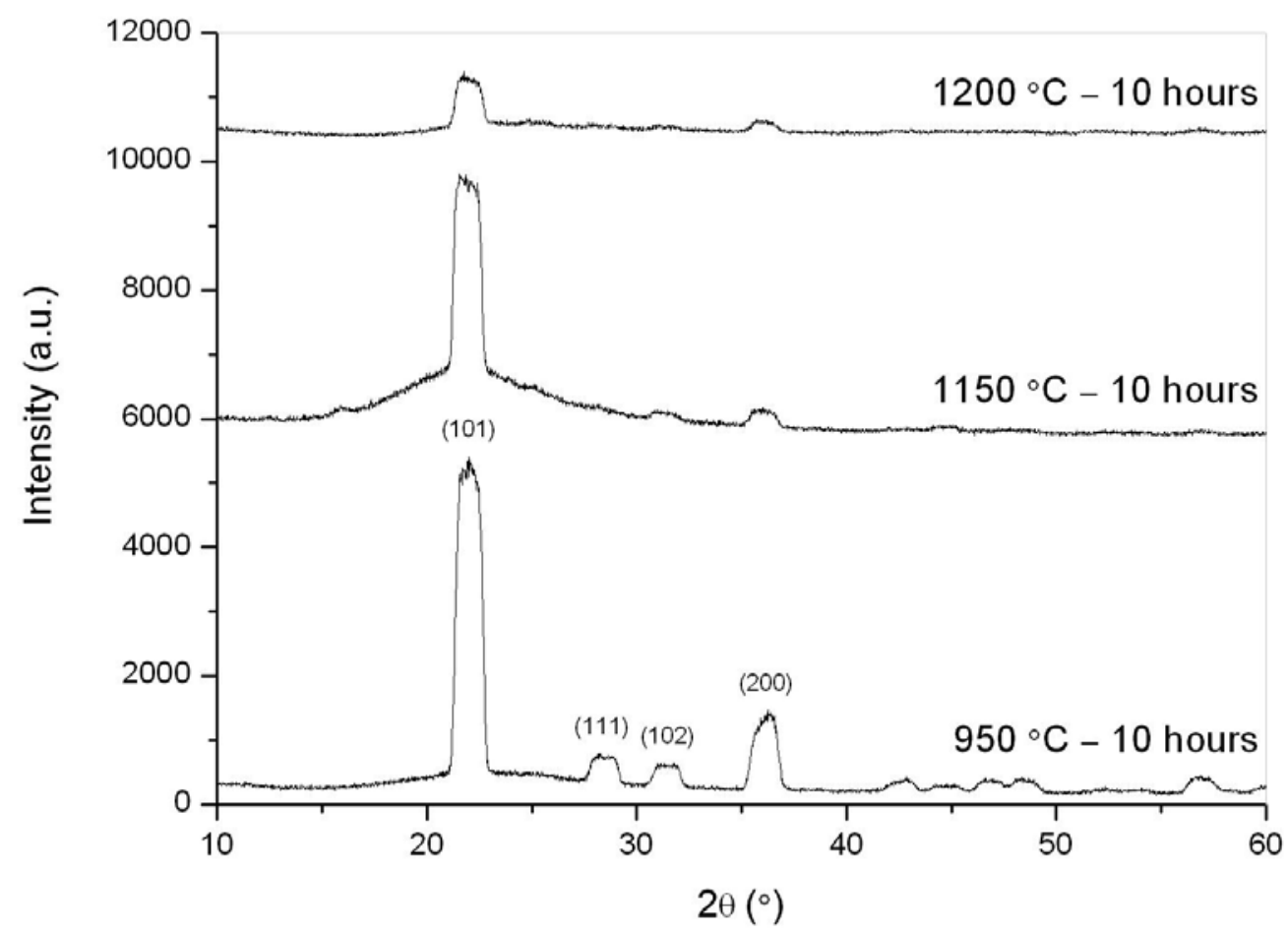

Figure 3.2 X-ray diffractometry (XRD) patterns of annealed Borofloat glass using $\mathrm{Cu} \mathrm{K \alpha}$ radiation. The samples were heat treated at $950^{\circ} \mathrm{C}, 1150^{\circ} \mathrm{C}$ and $1200^{\circ} \mathrm{C}$ for 10 hours. The diffraction pattern exhibits clear (101), (111), (102) and (200) peaks from $\alpha$-cristobalite.

The measured incubation times for nucleation and linear crystal growth rates in Borofloat glass between temperatures $660-850{ }^{\circ} \mathrm{C}$ are listed in Table 3.1. Approximate incubation times for the nucleation of cristobalite were measured to be 23 hours, 5 hours, 90 minutes, 30 minutes and 5 minutes; at $660{ }^{\circ} \mathrm{C}, 680^{\circ} \mathrm{C}, 700{ }^{\circ} \mathrm{C}$, 
$720{ }^{\circ} \mathrm{C}$ and $740{ }^{\circ} \mathrm{C}$ respectively. They are dependent on temperature and are the average times required to obtain thermodynamically stable nuclei. Above $750{ }^{\circ} \mathrm{C}$, the incubation times could not be measured accurately because of the slow heating near the operating temperature during the ramp-up. To mitigate the effects of any evaporation at higher temperatures, only the measured crystallisation rates between $660-850{ }^{\circ} \mathrm{C}$ were used in eq. (3.3) for determining $Q$. Experimental results are plotted in Figure 3.3(a) in the form of $u$ against $T$ taking values of $\Delta s_{\mathrm{r}} \leq 5$. For this range, $Q$ was calculated to be between $175-195 \mathrm{~kJ} \mathrm{~mol}^{-1}$ depending on the exact physical value of $\Delta s_{\mathrm{r}}$. These values are significantly closer to the activation energy for the diffusion of boron, rather than sodium, in silica [3.18]. In Borofloat, the melting entropy on crystallisation will be different from the situation in silica because of the higher entropy arising from the boron and sodium present in the material. In forming cristobalite in Borofloat glass, boron and sodium have to be rejected by the volume of material transforming into cristobalite. It is therefore reasonable to expect that the reduced melting entropy of Borofloat, $\Delta s_{\mathrm{r}}$, will be higher than 0.79 , that for silica. Therefore, the calculated activation energy for diffusion governing the transport of material across the crystal-liquid interface, $Q$, will be lower than $190 \mathrm{~kJ} \mathrm{~mol}^{-1}$ the value of $Q$ for which $\Delta s_{\mathrm{r}}$ is 0.79 .

The effect of $\Delta s_{\mathrm{r}}$ on the calculated linear growth rate is illustrated in Figure 3.3(b) for values $\geq 10$. If $\Delta s_{\mathrm{r}} \geq 10$, calculated $Q$ values would fall between $155-165 \mathrm{~kJ} \mathrm{~mol}^{-1}$. It can be clearly seen in Figure 3.3(b) that as $\Delta s_{\mathrm{r}} \rightarrow \infty$, the peak position, $T_{\max }$, tends towards $T_{\text {liq }}$ and the peak height dramatically increases. Quantitatively, $T_{\max }$ should be larger than $1000{ }^{\circ} \mathrm{C}$ for $\Delta s_{\mathrm{r}} \geq 10$ - contradicting the cross-sectional views in Figure 3.1 , where the penetration depth of cristobalite at $950^{\circ} \mathrm{C}$ and $970{ }^{\circ} \mathrm{C}$ are significantly 
higher than at $1000{ }^{\circ} \mathrm{C}$ after 10 hours. This inspection also supports the presumption that $\Delta s_{\mathrm{r}} \leq 5$ for Borofloat.

As Kelton has discussed in Appendix A of his review of crystal nucleation in liquids and glasses [3.19], there are a number of valid approximations to the free energy decrease per mole between the crystal and the liquid, $\Delta g$, and it is written in the full form

$$
\Delta g=\Delta s_{f}\left(T_{\text {liq }}-T\right)-\int_{T}^{T_{\text {inq }}} \Delta c_{p} d T^{\prime}+T \int_{T}^{T_{\text {iiq }}} \frac{\Delta c_{p}}{T^{\prime}} d T^{\prime}
$$

where $\Delta c_{p}=c_{p}^{\text {liq }}-c_{p}{ }^{c r y}$ is the difference between the molar heat capacities of the liquid (or glass), $c_{p}^{\text {liq }}$, and the crystal, $c_{p}{ }^{\text {cry }}$, at constant pressure. Here, the Turnbull approximation was chosen, in which it is assumed that $\Delta c_{p}$ is zero. Then eq. (3.12) becomes eq. (3.2).

For completeness, other models discussed by Kelton [3.19] were considered, namely the one in which $\Delta c_{p}$ is assumed to be constant to reach eq. (3.13) and the model of Hoffman [3.20] in which it is assumed that the difference in enthalpy between the liquid and solid phases vanishes at a temperature slightly below the glass transition temperature of the liquid to reach eq. (3.14).

$$
\Delta g=\Delta s_{f}\left(T_{\text {liq }}-T\right)-\Delta c_{p}\left[\Delta T-T \ln \left(\frac{T_{\text {liq }}}{T}\right)\right]
$$




$$
\Delta g=\Delta s_{f}\left(T_{\text {liq }}-T\right) \frac{T}{T_{l i q}}
$$

The heat capacity of the Pyrex at high temperatures was used to estimate that of the Borofloat. The heat capacity of Pyrex was formulated at temperatures above $600{ }^{\circ} \mathrm{C}$ [3.21] and the heat capacity of cristobalite was formulated at temperatures above $260{ }^{\circ} \mathrm{C}$ [3.22]. The difference in specific heat capacities, $\Delta c_{p}$, of the liquid glass and the cristobalite crystal was calculated for temperatures between $660^{\circ} \mathrm{C}$ and $850{ }^{\circ} \mathrm{C}$ and was found to be weakly temperature dependent. Therefore, the average of $\Delta c_{p}$ over this temperature range, $21.19 \mathrm{~J} / \mathrm{mol} \mathrm{K}$, was used in eq. (3.13) for the analysis of growth kinetics.

The upper bound on the estimate of $Q$ was always given by the Turnbull formulation (eq. (3.2)) regardless of the presumed value of $\Delta s_{r}$. The lower bound on the estimate of $Q$ was given by the $\Delta g$ formulation with constant $\Delta c_{p}$ assumption (eq. (3.13)) for $\Delta s_{r} \leq 1.5$ and by the Hoffman formulation (eq. (3.14)) for $\Delta s_{r} \geq 1.5$. However, the comparative analysis of these three models suggests that for $\Delta s_{r}>1$, the effect of these two formulations on the estimate of $Q$ will be at most $5 \%$ of its absolute value for the presumed value of $\Delta s_{r}$. 
Table 3.1 Measured incubation times for nucleation and linear crystal growth rates of cristobalite, $u$, in Borofloat glass for temperatures between $660-850{ }^{\circ} \mathrm{C}$.

\begin{tabular}{|c|c|c|}
\hline Temperature $\left({ }^{\circ} \mathrm{C}\right)$ & $\begin{array}{c}\text { Measured } \\
\text { Incubation } \\
\text { Times for } \\
\text { Nucleation }\end{array}$ & $\begin{array}{c}\text { Measured Linear } \\
\text { Crystal Growth } \\
\text { Rate, } u\left(\mu \mathrm{m} \mathrm{h}^{-1}\right)\end{array}$ \\
\hline 660 & $23 \mathrm{hr}$ & 0.20 \\
\hline 680 & $5 \mathrm{hr}$ & 0.24 \\
\hline 700 & $90 \mathrm{~min}$ & 0.41 \\
\hline 720 & $30 \mathrm{~min}$ & 0.67 \\
\hline 740 & $5 \mathrm{~min}$ & 0.83 \\
\hline 770 & - & 1.56 \\
\hline 800 & - & 2.90 \\
\hline 820 & - & 3.55 \\
\hline 850 & - & 5.18 \\
\hline
\end{tabular}




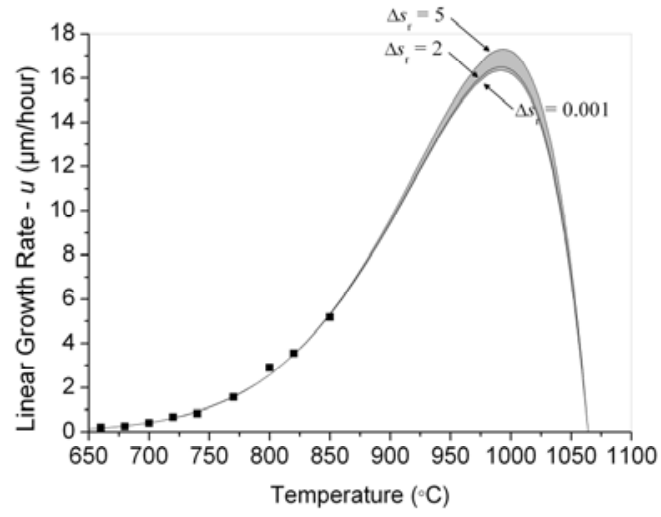

(a)

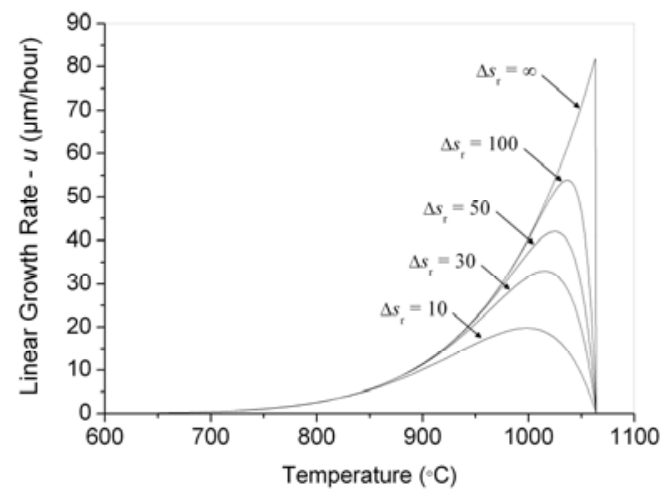

(b)

Figure 3.3 (a) Measured linear growth rates of cristobalite, $u$, in Borofloat glass shown as a function of temperature, $T$ along with calculated curves for $\Delta s_{\mathrm{r}} \leq 5$. In (b), the calculated curves are plotted for $\Delta s_{\mathrm{r}} \geq 10$ to illustrate its effect on wide range.

The above values of $Q$ are much higher than the values $\left(70-80 \mathrm{~kJ} \mathrm{~mol}^{-1}\right)$ reported recently for Pyrex by Jean and Fang using eq. (3.5) [3.8]. Their analysis leads to a lower bound estimate of $Q$, as it has been discussed in section 3.3.1. Cox and Kirby [3.7] followed a similar approach. Their empirical model was mathematically satisfactory, but failed to explain the physics of crystallisation. For comparison, their crystallisation data for Pyrex using eq. (3.3) for values of $\Delta s_{\mathrm{r}} \leq 5$ have been reanalysed. This reanalysis suggests a value of $Q$ for Pyrex of $145 \pm 15 \mathrm{~kJ} \mathrm{~mol}^{-1}$, a value notably higher than the activation energy required for the diffusion of sodium in Pyrex, which they showed to be $92 \mathrm{~kJ} \mathrm{~mol}^{-1}$ [3.7]. For comparison, the activation energy describing the temperature dependence of the viscosity of Borofloat between $660-850^{\circ} \mathrm{C}$, assuming an Arrhenius-type equation can be fitted to the data over this range, is calculated to be above $300 \mathrm{~kJ} \mathrm{~mol}^{-1}$ using the data quoted by the manufacturer [3.6] and the eq. (2.1) in Chapter 2. Therefore, it can be concluded that it is not correct to ascribe the value of $Q$ obtained for the growth of cristobalite in 
either Borofloat glass or Pyrex to either the transport of sodium or the activation energy for viscous flow. Other step(s) in the crystal precipitation, such as the diffusion of boron-containing species, are rate-limiting instead. Qualitatively, the boron connected to the glass network needs to be rejected out of the amorphous silica framework for further growth of cristobalite. This is a more difficult step to achieve than the transport of ionic species such as sodium which are not part of this three-dimensional framework.

\subsubsection{Microscopic examination of crystals}

By selectively etching the surrounding glass matrix in dilute HF solution, cristobalite crystals produced as a consequence of the devitrification can be highlighted for easy analysis and observation. Optical micrographs of cristobalite spherulites are shown in Figure 3.4 to illustrate their linear growth as a function of time. They are taken from samples heat treated at $700{ }^{\circ} \mathrm{C}$ for 20,30 and 40 hours and etched in BHF for 5

minutes. A scanning electron micrograph of cristobalite spherulite with substantially longer etching time is shown in Figure 3.5(a). This is taken from a sample heat treated at $700{ }^{\circ} \mathrm{C}$ for 20 hours and etched in BHF for 60 minutes. Continued etching would eventually let the spherulites detach from the surface, causing them to be released into the etchant solution. This would enable a crystal-free surface to be obtained, potentially useful for microfluidic applications [3.2].

The radiating needle-like, dendritic growth of cristobalite indicated self-similar growth and anisotropy in the crystal-melt interfacial energy. In other words, Mullins-Sekerka instabilities [3.23] favoured the pseudo-6-fold symmetrical growth of cristobalite crystals in the Borofloat glass matrix. This effect was particularly evident at lower temperatures of formation, such as in the example shown in Figure 3.5(b). 


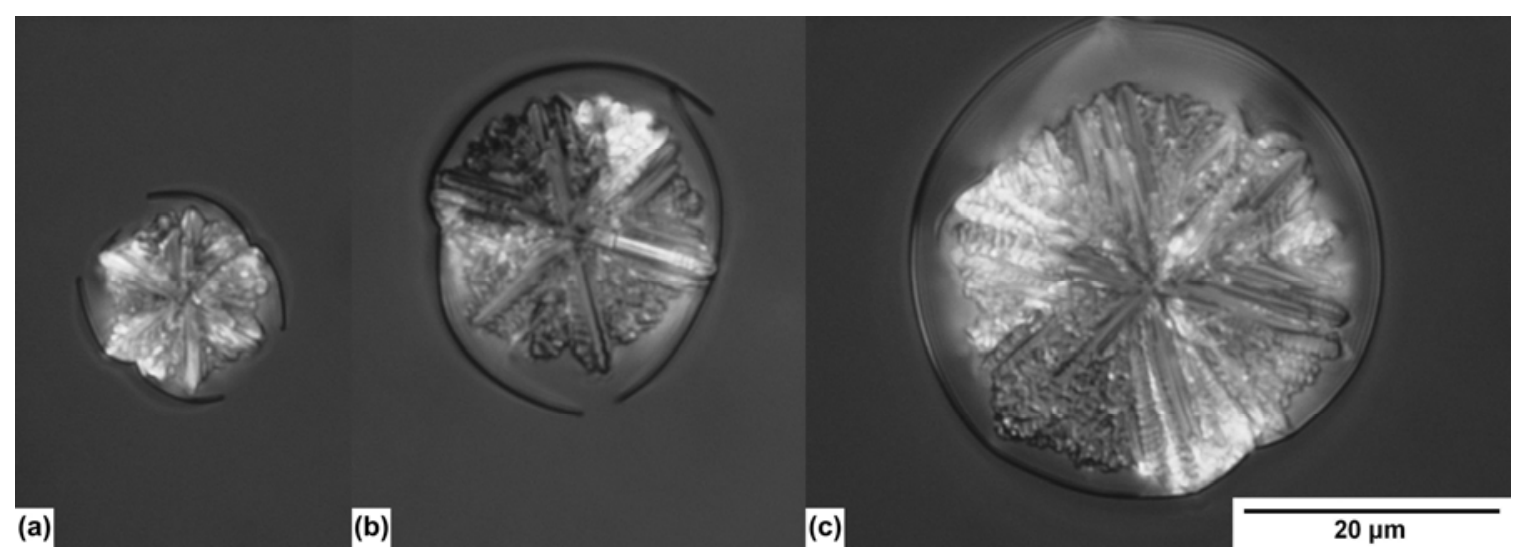

Figure 3.4 Cristobalite crystals in Borofloat glass heat treated at $700{ }^{\circ} \mathrm{C}$ for (a) 20 hours, (b) 30 hours and (c) 40 hours, etched in BHF for 5 minutes and examined in an optical microscope. The crystals in (a), (b) and (c) are from different glass samples.

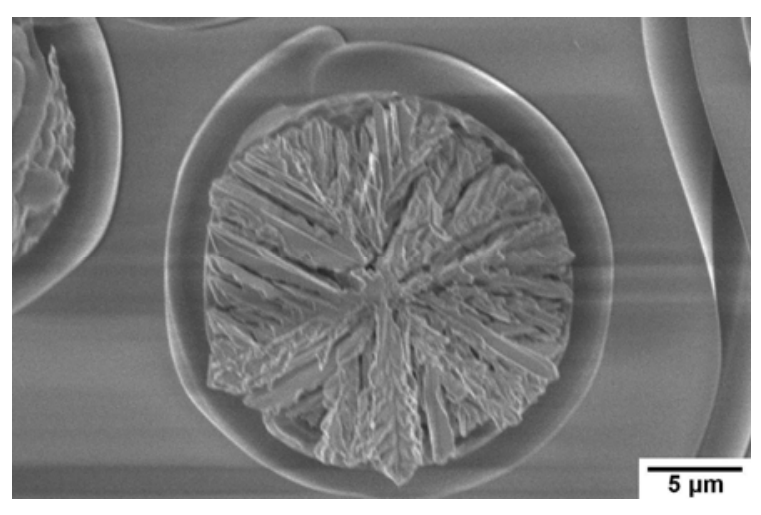

(a)

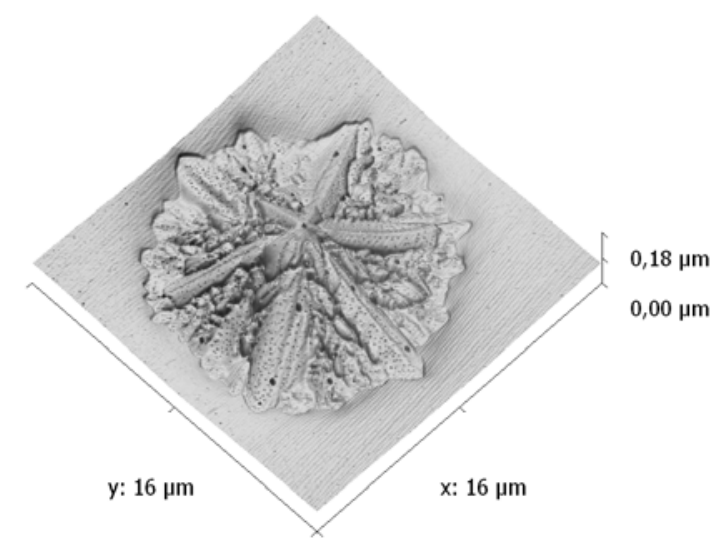

(b)

Figure 3.5 Cristobalite crystals in Borofloat glass heat treated at $700{ }^{\circ} \mathrm{C}$ for 20 hours: (a) etched in BHF for 60 minutes and examined in a scanning electron microscope, and (b) examined in an atomic force microscope without receiving any chemical etching. The crystals in (a) and (b) are from different glass samples.

The EDX analyses of the samples are shown in Figure 3.6, where their chemical compositions are studied. Figure 3.6(a) is a scan of glass matrix, where the sodium and aluminium peaks are apparent. Boron can not be detected by EDX because it is a 
light element. Figure 3.6(b) is a scan of cristobalite crystal in Borofloat glass heat treated at $700{ }^{\circ} \mathrm{C}$ for 20 hours and etched in BHF for 60 minutes, similar to the one in Figure 3.5(a). The surrounding matrix was etched to avoid its contribution to the spectroscopy of the crystal and the silicon-oxygen ratio was of the correct ratio expected for silica.

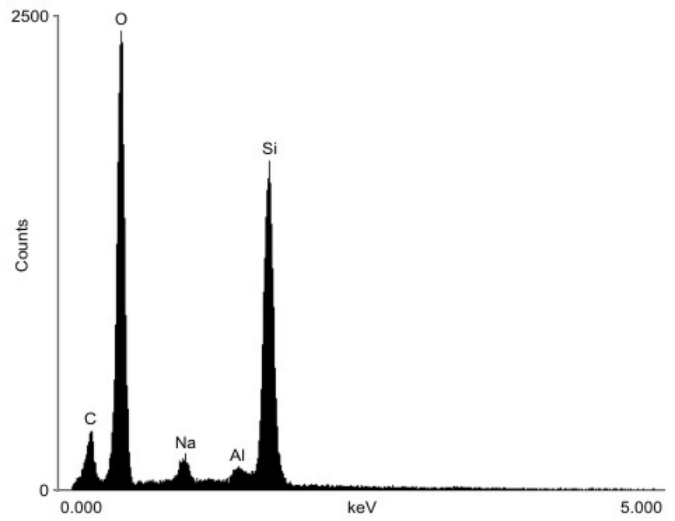

(a)

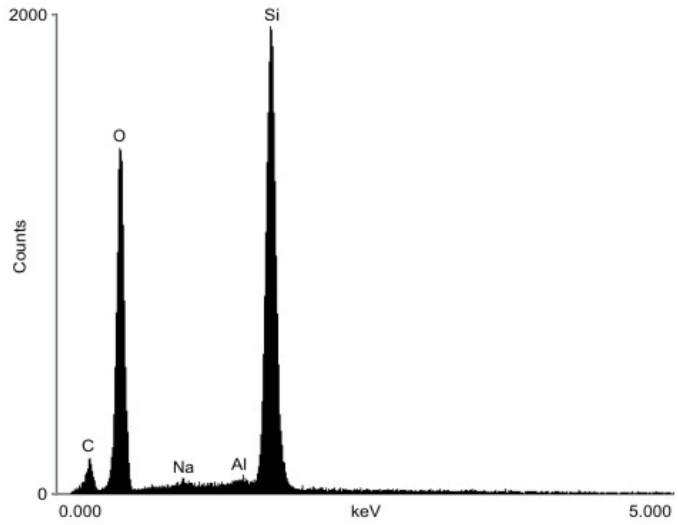

(b)

Figure 3.6 Energy dispersive X-ray (EDX) analyses of (a) glass matrix and (b) cristobalite crystal in Borofloat glass heat treated at $700{ }^{\circ} \mathrm{C}$ for 20 hours and etched in BHF for 60 minutes.

The difference in thermal expansions between the crystal and the surrounding matrix can be large [3.24], inducing thermal stresses in the system on cooling from the temperature range used for nucleation and growth of the crystals to room temperature through the glass transition temperature of the matrix. McMillan [3.24] quotes the coefficient of thermal expansion (CTE) of cristobalite as $5010^{-6}{ }^{\circ} \mathrm{C}^{-1}$ between $20^{\circ} \mathrm{C}$ and $300{ }^{\circ} \mathrm{C}$ and $27.110^{-6}{ }^{\circ} \mathrm{C}^{-1}$ between $20^{\circ} \mathrm{C}$ and $600{ }^{\circ} \mathrm{C}$. The CTE of cristobalite between $300{ }^{\circ} \mathrm{C}$ and $600^{\circ} \mathrm{C}$ was calculated as $5.7310^{-6}{ }^{\circ} \mathrm{C}^{-1}$. As an added complication, cristobalite crystals are known to change their crystal structure from the cubic $\beta$-cristobalite to tetragonal $\alpha$-cristobalite during this cooling [3.24]. 
This occurs at around $250{ }^{\circ} \mathrm{C}$ and is associated with a volume decrease of approximately $3.9 \%$ [3.3]. Therefore, it is assumed that the thermal expansion of cristobalite is dominated by $\beta$-phase at the higher temperature range $\left(300-600{ }^{\circ} \mathrm{C}\right)$ and by $\alpha$-phase at the lower temperature range $\left(20-300^{\circ} \mathrm{C}\right)$. When the glass matrix containing cristobalite crystals are cooled from the firing temperature, tensile stresses start to be accumulated around the cristobalite particles from the annealing point of Borofloat glass, $560{ }^{\circ} \mathrm{C}$. As mentioned in Chapter 2, the annealing point of glass is defined as the temperature at which stresses relax over a period of several minutes and the measured rate of cooling of the oven used in the experiments (about $5{ }^{\circ} \mathrm{C} \mathrm{min}^{-1}$ around $560{ }^{\circ} \mathrm{C}$ ) was slow enough to allow relaxation of stresses over such a time period. The CTE of the Pyrex was used to estimate that of the Borofloat and was quoted to be $3.710^{-6}{ }^{\circ} \mathrm{C}^{-1}$ between $20^{\circ} \mathrm{C}$ and $560^{\circ} \mathrm{C}$ [3.25]. In order to calculate the approximate stress values, it is assumed that the cristobalite crystals are spherical and have the same elastic properties as the glass matrix. Then, the maximum thermal stress between two phases, $\sigma$, can be calculated by the formula of Selsing [3.26]

$$
\sigma=\frac{2}{3} \frac{\mathrm{E}_{\mathrm{Glass}}}{1-v_{\mathrm{Glass}}}\left[\int_{20^{\circ} \mathrm{C}}^{250^{\circ} \mathrm{C}}\left(\alpha_{\alpha-\text { cri }}-\alpha_{\text {Glass }}\right) d T+\left(\frac{\Delta V}{3 V}\right)+\int_{250^{\circ} \mathrm{C}}^{560^{\circ} \mathrm{C}}\left(\alpha_{\beta-\text { cri }}-\alpha_{\text {Glass }}\right) d T\right]
$$

where $\mathrm{E}_{\text {Glass }}$ is Young's modulus of the glass and is $64 \mathrm{GPa}$ [3.6], $v_{\text {Glass }}$ is Poisson's ratio of the glass and is 0.2 [3.6], $\Delta V$ is the volume decrease during the phase change at the transformation temperature of $250^{\circ} \mathrm{C}$ and is 0.039 times the initial crystal volume, $V$ [3.3]. $\alpha_{\alpha-c r i}=5010^{-6}{ }^{\circ} \mathrm{C}^{-1}, \alpha_{\beta-c r i}=5.7310^{-6}{ }^{\circ} \mathrm{C}^{-1}$ and $\alpha_{\text {Glass }}=3.710^{-6}{ }^{\circ} \mathrm{C}^{-1}$ are used to calculate $\sigma$ as $1.295 \mathrm{GPa}$. In agreement with the literature [3.3], these stresses produced locally around cristobalite particles embedded in the borosilicate 
matrix were of the order of $\mathrm{GPa}$, sufficient to cause spontaneous fracture and cracking on the surfaces of the glass. An atomic force micrograph of a cristobalite crystal is shown in Figure 3.7(a), after annealing Borofloat glass at $740{ }^{\circ} \mathrm{C}$ for 10 hours. The crystal was embedded in the surrounding glass matrix and did not show any sign of cracking. However, it fractured during the next imaging sequence, presumably as a consequence of the extra force exerted on it by the scanning probe, to produce the micrograph in Figure 3.7(b).

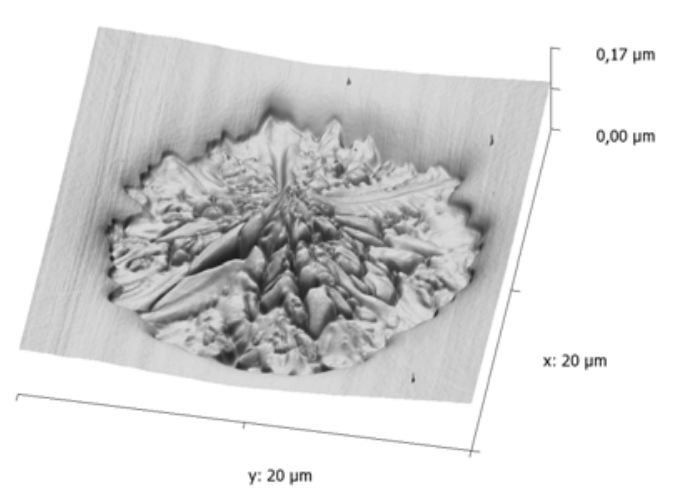

(a)

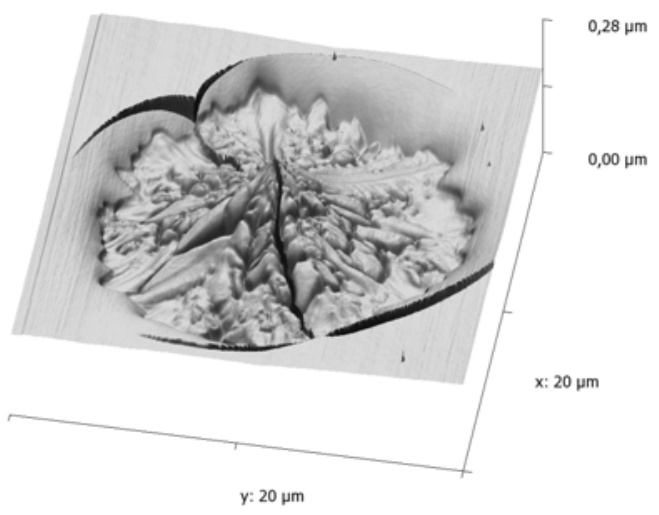

(b)

Figure 3.7 A cristobalite crystal in Borofloat glass heat treated at $740{ }^{\circ} \mathrm{C}$ for 10 hours and examined in an atomic force microscope without receiving any chemical etching. The crystal in (a) fractured during imaging to form (b), as a consequence of the level of stress in the crystal and the surrounding glass matrix.

\subsubsection{Interfacial effects on nucleation}

During high temperature annealing, the nucleation of cristobalite in silica glass is found to be highly dependent on the condition of the heterogeneous surface, while the growth is affected by the existence of catalysts in the firing environment [3.9, 3.27]. When a piece of borosilicate glass is annealed for a sufficiently long time on a silicon substrate at around $700{ }^{\circ} \mathrm{C}$, it is able to flow and wet the silicon and produce a defect-free contact [3.2]. Cristobalite crystals grown during the heat treatment at the 
contact region are found to be much smaller than those on the free surface of the glass - the presence of the silicon inhibits the nucleation of cristobalite because of the lack of water vapour and/or oxygen in the local environment [3.9, 3.27]. An example of this is shown in Figure 3.8(a) for Borofloat wafers after annealing at $700{ }^{\circ} \mathrm{C}$ for 20 hours and removal of the underlying silicon by immersion in TMAH solution.

Nucleation of cristobalite crystals can be prevented by covering the glass surface with a thin silicon nitride film prior to annealing. An optical micrograph of a Borofloat wafer, where the top side is coated with a $0.5 \mu \mathrm{m}$ thick silicon nitride film, is shown in Figure 3.8(b) after annealing at $700{ }^{\circ} \mathrm{C}$ for 20 hours.

Depending on the process parameters, the silicon nitride film may have tensile or compressive internal stress or may be stress-free after the deposition at $300{ }^{\circ} \mathrm{C}$ [3.28] and it requires further study to be able to comment on the internal stress of the asdeposited silicon nitride layer. However, the thermal expansion coefficient of the glass substrate is higher than that of the silicon nitride film [3.25] and heating the samples above $300{ }^{\circ} \mathrm{C}$ will stretch the deposited silicon nitride film. Therefore, it shattered at the beginning of the annealing process, presumably as combined result of the internal stress and the thermal expansion mismatch with the underlying Borofloat glass. Wherever the underlying glass was exposed to the air environment, the cristobalite crystals could nucleate and grow. However, the regions protected by the nitride film were less favourable sites for nucleation. Such nucleation behaviour has the potential to lead to spatially-selective devitrification of the glass surface, and hence to micron-scale engineering of the surface. However, the $0.5 \mu \mathrm{m}$ thick silicon nitride film failed to prevent nucleation of cristobalite when the annealing temperature and / or time were higher, and selective crystallisation behaviour was then lost. 


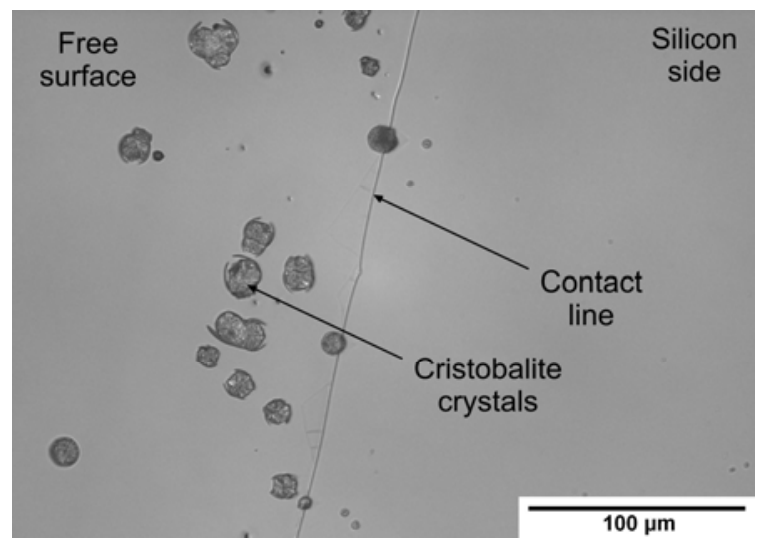

(a)

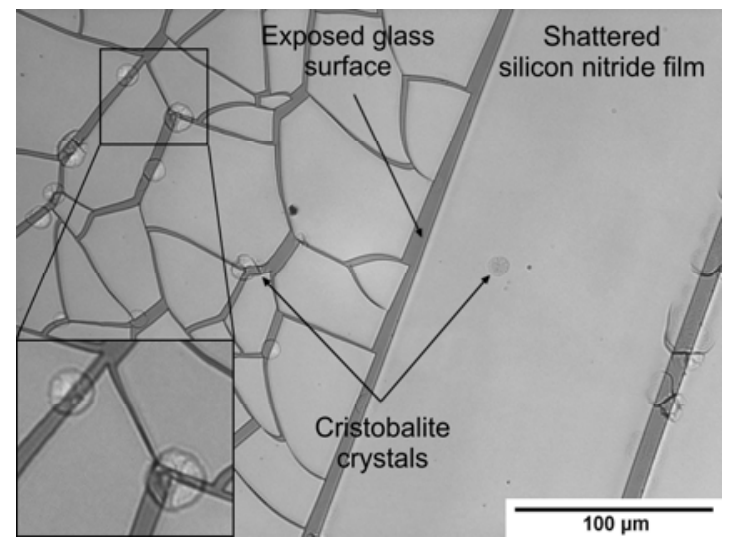

(b)

Figure 3.8 Cristobalite crystals grown at $700{ }^{\circ} \mathrm{C}$ after 20 hours in regions protected by (a) a silicon substrate and (b) a thin silicon nitride film.

\subsection{Effect of crystallisation on the reflow bonding}

An unintended aspect of the heat treatments required for the reflow bonding is the surface crystallisation of the glass arising from heterogeneous nucleation and growth of cristobalite crystals. The kinetics and morphology of this crystal growth has been studied but its effect on the reflow bonding needs to be considered. Therefore, the final cristobalite size for the annealing times required to achieve the bonding at different temperatures are plotted in Figure 3.9. As in Figure 2.4 of Chapter 2; the dashed black line refers to the scaling of the annealing time of 30 minutes at $800{ }^{\circ} \mathrm{C}$, the dotted black line refers to the annealing times where the bond formation starts and the solid black line refers to the annealing times that will allow strong bond formation between the borosilicate glass and the silicon substrate. The temperature / time heat treatments chosen to achieve bonding $\left(680^{\circ} \mathrm{C}\right.$ for 10 hours and (ii) - (iv) $700{ }^{\circ} \mathrm{C}$ for 10, 20 and 30 hours) are shown in Figure 3.9.

It is apparent from Figure 3.9 that the crystal size will be smaller if the bonding is performed at higher temperatures. This is because the activation energy describing the temperature dependence of the crystal growth is smaller than that of the viscosity. The hump above $740{ }^{\circ} \mathrm{C}$ occurs because of the slow heating near the operating 
temperature during the ramp-up and the start of crystal growth before the operating temperature is reached. It might be argued that performing the bonding at temperatures higher than $700{ }^{\circ} \mathrm{C}$ would require shorter annealing times and yield smaller crystals precipitated on the glass surface. However, due to practical reasons discussed in Chapter 2, the bonding is performed at lower temperatures $\left(680-700{ }^{\circ} \mathrm{C}\right)$ through long but still reasonable heat treatment times.

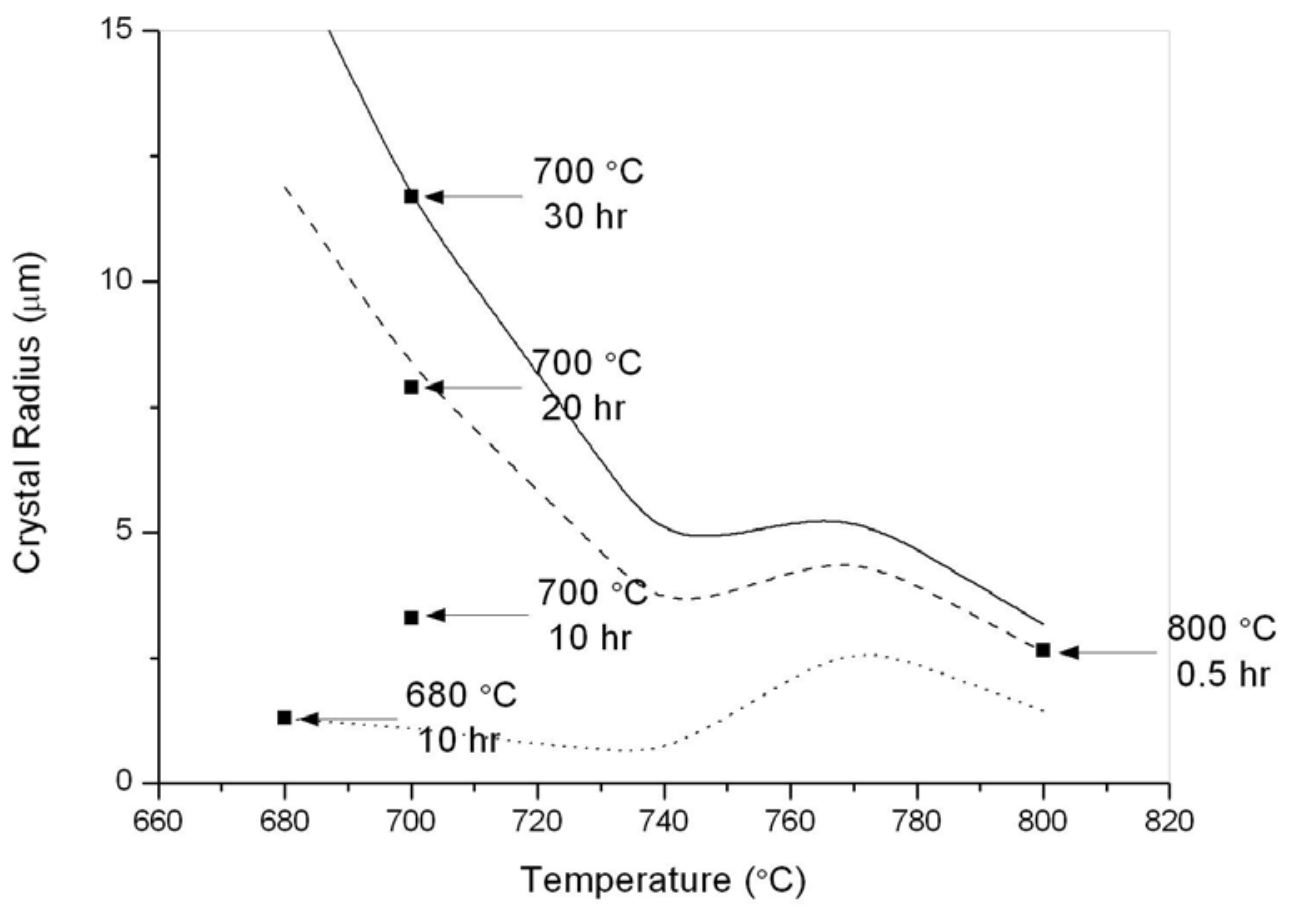

Figure 3.9 Cristobalite size for various thermal treatments required to achieve the reflow bonding. The dotted black line refers to the annealing times where the bond formation starts. The solid black line refers to the annealing times that will allow strong bond formation.

\subsection{Summary}

Theories of direct crystal growth have been used to model the heterogeneous nucleation and growth of cristobalite in Borofloat (borosilicate 8330) when fired in an 
air environment. Microscopic examination of the crystals reveals the significant effect of evaporation out of the melt surface at high temperatures. Analysis of the devitrification kinetics at lower temperatures suggests an activation energy of $185 \pm$ $10 \mathrm{~kJ} \mathrm{~mol}{ }^{-1}$, similar to that for the diffusion of boron in silica. The nucleation and growth of cristobalite spherulites on the surface of the Borofloat glass is inhibited if contact with air is prevented, either by deposition of a thin film or simply by covering the surface. The effect of unintentional devitrification of glass on the reflow bonding is discussed.

\section{References}

[3.1] M. J. Madou, Fundamentals of microfabrication (CRC Press, Boca Raton, 2002), pp 183-258, 467-534.

[3.2] B. Moğulkoç, H. V. Jansen, J. W. Berenschot, H. J. M. ter Brake, K. M. Knowles, and M. C. Elwenspoek, J. Micromech. Microeng. 19, 085027 (2009).

[3.3] D.-W. Shin, K. H. Auh, and K. M. Knowles, J. Ceram. Soc. Jpn. 103, 319 (1995).

[3.4] R. Müller, E. D. Zanotto, and V. M. Fokin, J. Non-Cryst. Solids 274, 208 (2000).

[3.5] E. D. Zanotto, and V. M. Fokin, Philos. Trans. R. Soc. A 361, 591 (2003).

[3.6] http://www.schott.com/borofloat/english, accessed 1 July 2010.

[3.7] S. M. Cox and P. L. Kirby, Nature 159, 162 (1947). 
[3.8] J.-H. Jean and Y.-C. Fang, J. Mater. Res. 16, 1752 (2001).

[3.9] N. G. Ainslie, C. R. Morelock, and D. Turnbull, Symposium on Nucleation and Crystallization in Glasses and Melts (The American Ceramic Society, Ohio, 1962), pp 97-107.

[3.10] R.H. Doremus, Glass Science (John Wiley and Sons, New York, 1994), p 91.

[3.11] D. Turnbull and M. H. Cohen, Modern aspects of the vitreous state, edited by J. D. Mackenzie (Butterworth \& Co. Ltd., London, 1960), pp 38-62.

[3.12] T. J. Rockett and W. R. Foster, J. Am. Ceram. Soc. 64, C148 (1981).

[3.13] T. J. Rockett and W. R. Foster, J. Am. Ceram. Soc. 49, 30 (1966).

[3.14] H. L. Schick, Chem. Rev. 60, 331 (1960).

[3.15] V. M. Fokin, M. L. F. Nascimento, and E. D. Zanotto, J. Non-Cryst. Solids 351, 789 (2005).

[3.16] M. J. Snyder, M. G. Mesko, and J. E. Shelby, J. Non-Cryst. Solids 352, 669 (2006).

[3.17] L. F. Oldfield and R. D. Wright, Glass Technol. 3, 59 (1962).

[3.18] K. Kawagishi, M. Susa, T. Maruyama, and K. Nagata, J. Electrochem. Soc. 144, 3270 (1997).

[3.19] K. F. Kelton, Solid State Phys. 45, 75 (1991).

[3.20] J. D. Hoffman, J. Chem. Phys. 29, 1192 (1958). 
[3.21] P. Richet, M. A. Bouhifd, P. Courtial, and C. Tequi, J. Non-Cryst. Solids 211, 271 (1997).

[3.22] P. Richet, Y. Bottinga, L. Denielou, J. P. Petitet, and C. Tequi, Geochim. Cosmochim. Acta 46, 2639 (1982).

[3.23] W. W. Mullins and R. F. Sekerka, J. Appl. Phys. 34, 323 (1963).

[3.24] P. W. McMillan, Glass-ceramics (Academic Press, London, 1964), pp 132-57.

[3.25] Y. S. Touloukian, R. K. Kirby, R. E. Taylor, and T. Y. R. Lee, Thermal expansion - nonmetallic solids: Thermophysical Properties of Matter - the TPRC data series vol. 13 (IFI/Plenum, New York, 1977), pp 1140-6, 1369-73.

[3.26] J. Selsing, J. Am. Ceram. Soc. 44, 419 (1961).

[3.27] F. E. Wagstaff and K. J. Richards, J. Am. Ceram. Soc. 49, 118 (1966).

[3.28] M. K. Gunde, and M. Maček, Appl. Phys. A 74, 181 (2002). 


\section{4}

\section{Characterisation of tube-}

\section{silicon assembly}

The connections between borosilicate glass $\left(\operatorname{Duran}^{\circledR}\right)$ tubes and silicon substrates for

MEMS-on-tube assembly are characterised in this chapter. The borosilicate glass tubes are designed to be used as an interface and package for wafer-level microfluidic devices. Initially, the strength of the resulting package has been tested by pressurising it to failure. Failure occurred in the glass and the silicon adjacent to the bond, rather than along the bond itself. In addition, the bond formed is hermetic. The only leakage when testing the hermeticity of these bonds over a period of one month was due to gas diffusion through the glass. An unintended aspect of the heat treatments used for the reflow bonding was surface crystallisation of the glass arising from heterogeneous nucleation and growth of cristobalite crystals. The bulk of the borosilicate glass remained unaffected by crystallisation. For sufficiently large cristobalite crystals microcracking occurred on the tube surface. Pressure test results indicated that the microcracking is not detrimental to the viability of this joining technology for microfluidic interconnections. 


\subsection{Introduction}

The reflow bonding requires heat treatment of the prepared Duran tubes at around $700{ }^{\circ} \mathrm{C}$ for at least 10 hours. During the heat treatment procedure heterogeneous nucleation and growth of crystals occur in the glass in addition to its flow at the interface to create the bond with the silicon wafer. Thermal stresses also develop within the bonded system as it is cooled down to room temperature. Such issues have to be addressed correctly since they can affect the performance of the bond, and therefore the performance of the packaged MEMS device. In addition, the limitations of the bond in terms of the maximum gas pressure to which the bonded assembly can be subjected and the extent to which the bond is hermetic both need to be established for any practical application.

\subsection{Devitrification of glass tubes}

Devitrification of borosilicate glass is known to occur at the bonding temperatures after suitable periods of time, the details of which are presented in Chapter 3. In this section, the devitrification of the Duran tubes as result of the reflow bonding is considered. The crystallisation found on the surface of the glass is clearly shown in the optical micrographs of the tube end after heat treatment at $700{ }^{\circ} \mathrm{C}$ for 20 hours in Figure 4.1(a) and Figure 4.1(b). Fine crystallisation and a network of cracks are apparent. Etching the glass in buffered HF solution for 5 min enables the crystals to be seen even more readily (Figure 4.1(c) and Figure 4.1(d)). Prolonged etching enables the three-dimensional morphology of the crystals to be determined using scanning electron microscopy.

The surface density of crystals could be reduced by careful cleaning of the glass tubes and leaching of the surface layer with HF prior to the heat treatment. The Borofloat wafers (made from the same glass composition as Duran) studied in Chapter 3 
produced cristobalite crystals of the same size as with the Duran tubes, but with a lower density of crystals. These experiments suggest that residual contamination of the tube surfaces by wax after the polishing process, for example, will help to increase the degree of surface crystallisation after heat treatment by acting as favoured positions for heterogeneous nucleation on the surface.

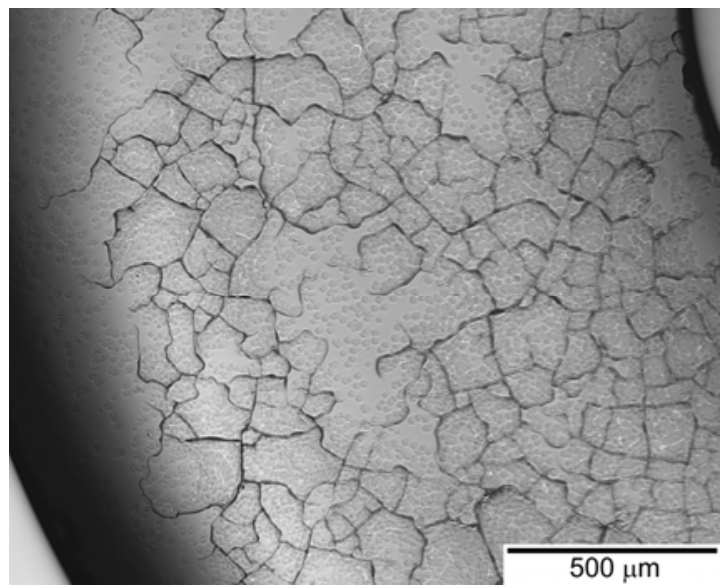

(a)

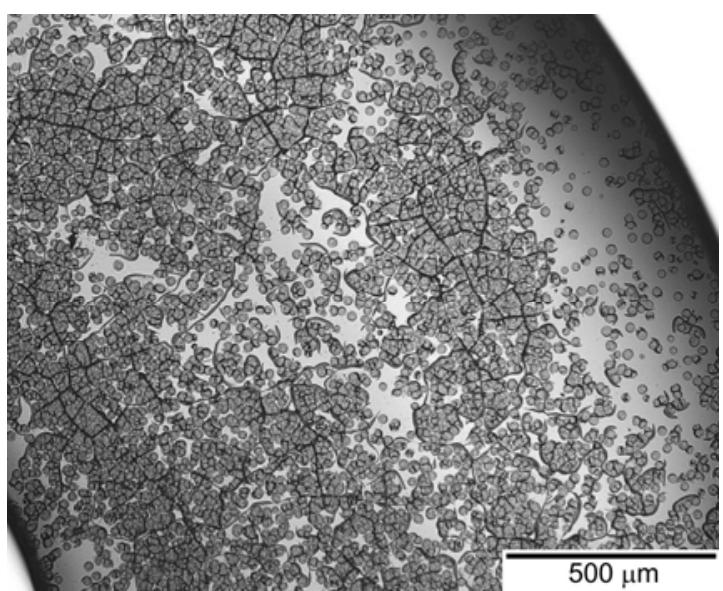

(c)

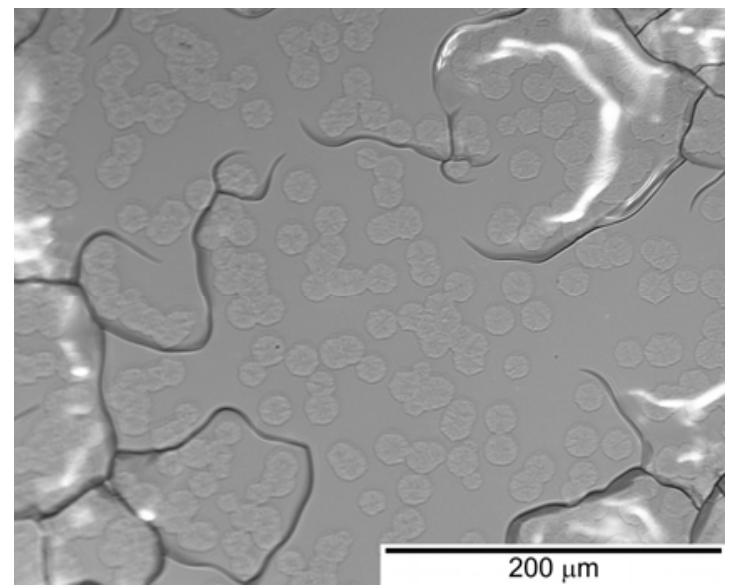

(b)

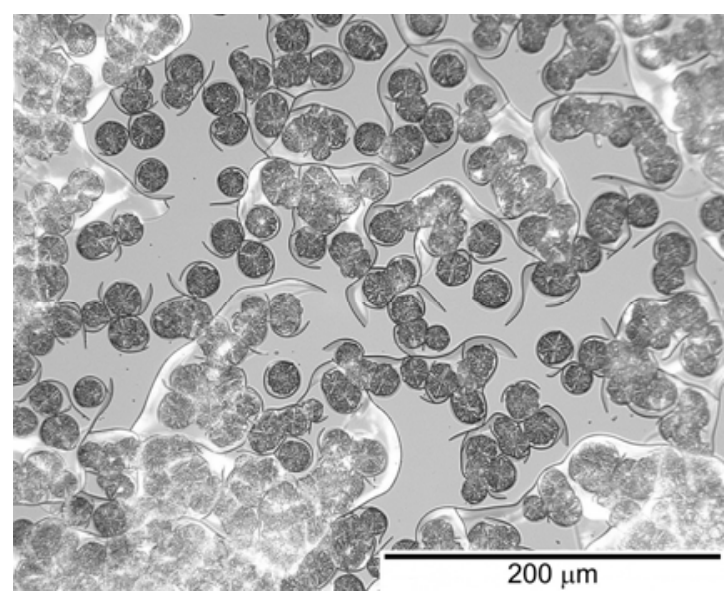

(d)

Figure 4.1 Crystals grown on the end of glass tube after annealing at $700{ }^{\circ} \mathrm{C}$ for 20 hours. 


\subsection{Thermal stresses between the borosilicate matrix and silica crystals}

In Chapter 3, it has been shown that the differences in thermal expansion between the crystal and the surrounding matrix can be large [4.1], inducing thermal stresses in the system on cooling to room temperature through the glass transition temperature from the temperature range used for nucleation and growth of the crystals.

Cracking of the surface evident in Figure 4.1 arises because of the magnitude of these thermal stresses and is explained in Chapter 3, section 3.3.3. Fortunately, the cracking seen is due to failure of the glassy material surrounding the cristobalite crystals and failure of the cristobalite crystals themselves, rather than interfacial debonding between the glass tubes and the silicon wafers, i.e., any cracking seen does not affect the integrity of the silicon-glass bond formed during the heat treatment. A further feature of cracking in two-phase ceramic/glass materials is the size of the ceramic particles: the larger the size of the particles, the more likely they are to induce the growth of cracks within the surrounding glass matrix [4.2].

\subsubsection{Cracks on the surface of the tube}

The radii of the largest crystals observed for the different heat treatments are shown in Table 4.1. Crystallisation was rare in the samples heat treated at $680{ }^{\circ} \mathrm{C}$ for 10 hours and was not accompanied by any cracking. However, samples heat treated for the same time or longer at $700{ }^{\circ} \mathrm{C}$ were accompanied by circumferential cracks in the matrix around the crystals, such as those seen in Figure 4.1 and Figure 4.2. The size of the largest crystals present at $700{ }^{\circ} \mathrm{C}$ for the three periods of heat treatment indicates a linear crystal growth rate of $0.41 \mu \mathrm{m} \mathrm{hr}^{-1}$. The increase seen in the number of crystals per unit area of surface as heat treatment time increases is consistent with the crystallisation process consisting of nucleation of crystals and their subsequent 
crystal growth as in the Johnson-Mehl-Avrami theory of crystal growth $[4.3,4.4,4.5$ and 4.6].

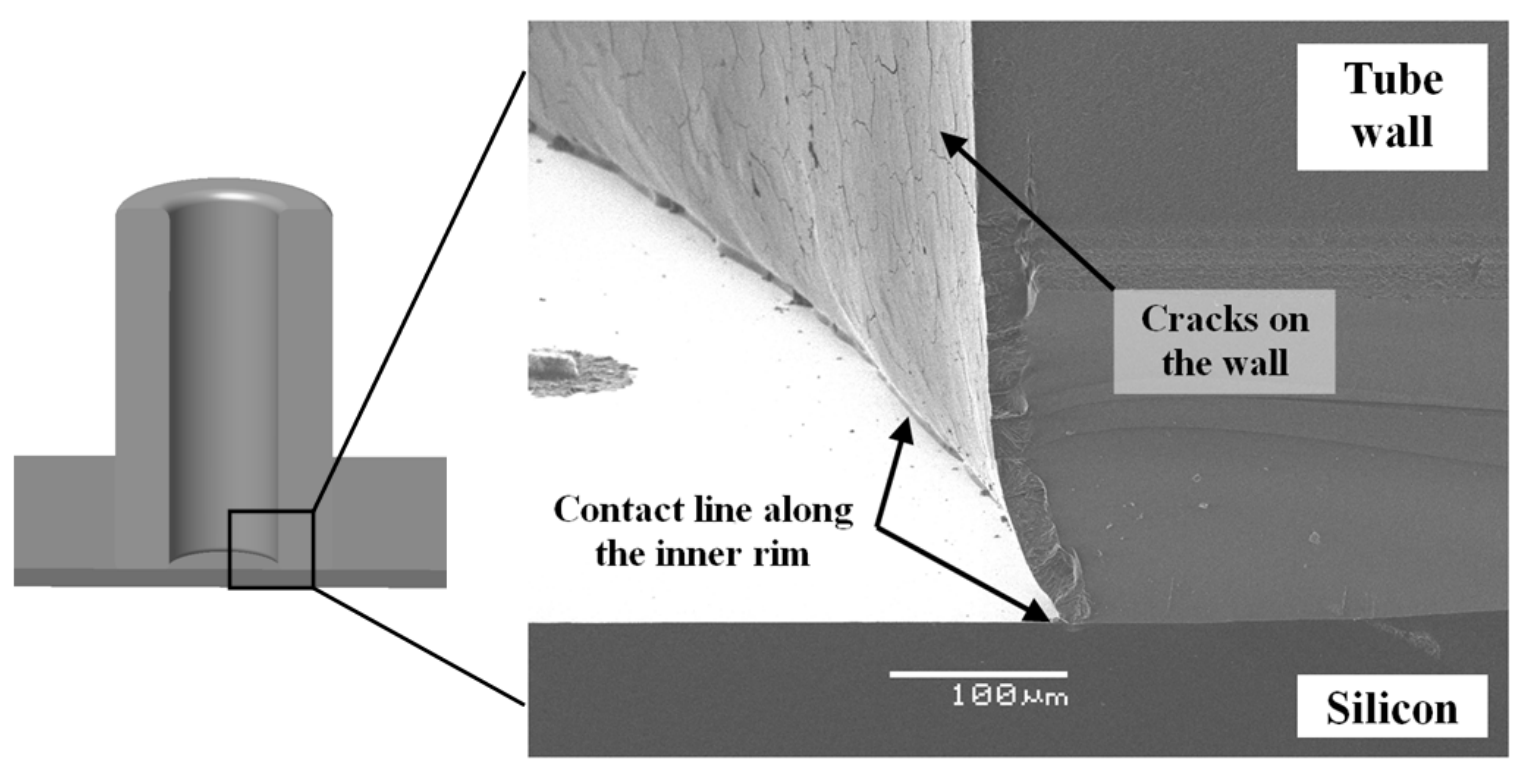

Figure 4.2 Cracks on the inner wall of a glass tube after bonding to silicon at $700^{\circ} \mathrm{C}$ for 30 hours.

Table 4.1 Cristobalite size for various thermal treatments.

\begin{tabular}{|c|c|c|c|}
\hline \multicolumn{4}{|c|}{ Radii of the crystals $(\mu \mathrm{m})$} \\
\hline $680^{\circ} \mathrm{C} ; 10 \mathrm{hr}$ & $700^{\circ} \mathrm{C} ; 10 \mathrm{hr}$ & $700^{\circ} \mathrm{C} ; 20 \mathrm{hr}$ & $700^{\circ} \mathrm{C} ; 30 \mathrm{hr}$ \\
\hline $1.2 \mu \mathrm{m}$ & $3.3 \mu \mathrm{m}$ & $7.9 \mu \mathrm{m}$ & $11.7 \mu \mathrm{m}$ \\
\hline
\end{tabular}

\subsubsection{Cracks at the glass-silicon interface}

In order to check the existence of crystallisation and cracks, the contact region of glass to silicon was observed. For this purpose, a Duran glass tube was bonded to a piece of silicon wafer by heating the tube-wafer assembly at $700{ }^{\circ} \mathrm{C}$ for 30 hours, 
after which it was put in tetramethylammonium hydroxide (TMAH) solution at $85^{\circ} \mathrm{C}$ to remove the silicon. A scanning electron micrograph of the end of the tube which had been in contact with the silicon is shown in Figure 4.3. Although the etch selectivity of silicon to glass is quite high for TMAH solution [4.7] during the etching of the $525 \mu \mathrm{m}$ thick silicon wafer, several hundred nanometres of glass was also etched from the surface. As a result, the crystals on the surface of the tube were rendered more visible than they would have been otherwise through selective etching of their surroundings. However, crystals in the contact region with silicon were protected until the silicon was completely dissolved. Therefore, their contrast and appearance is different in this scanning electron microscope picture.

The lower part of the micrograph in Figure 4.3 shows the inner wall of the glass tube, whereas the upper region shows the end of the tube previously in intimate contact with the silicon after bonding. A number of microstructural features are apparent: cracks and copious crystallisation on the inner wall of the tube, isolated small crystals in the contact region with silicon and a sharp transition in size of the crystals at the inner rim of the tube. The sizes of the cristobalite crystals on the inner wall of the tube are noticeably larger than those in the region in intimate contact with the silicon. One possible reason for this difference in behaviour is that glass in the contact region will not have a ready supply of water vapour and/or oxygen to assist devitrification [4.8] as mentioned previously in Chapter 3. In addition, the ends of the glass are likely to have been cleaned more thoroughly than the inner wall of the tube after the polishing process. Both these factors will help to delay nucleation of crystals in the contact region with the silicon, so that there were fewer crystals in the contact region and the largest crystals seen there were noticeably smaller than on the adjacent part of the inner wall.

There is a transition region at the inner rim where the cristobalite crystals change in size and where there is evidence of localised cracking. The crystals larger than $5 \mu \mathrm{m}$ in 
diameter were accompanied by circumferential cracks around them. Such observations have to be borne in mind when subjecting the tubes to pressures: in principle, these cracks have the potential act as points of failure and subsequent catastrophic crack propagation. It is also noteworthy that the size of the cristobalite crystals in the contact region is such that circumferential cracks around them are also likely to occur.

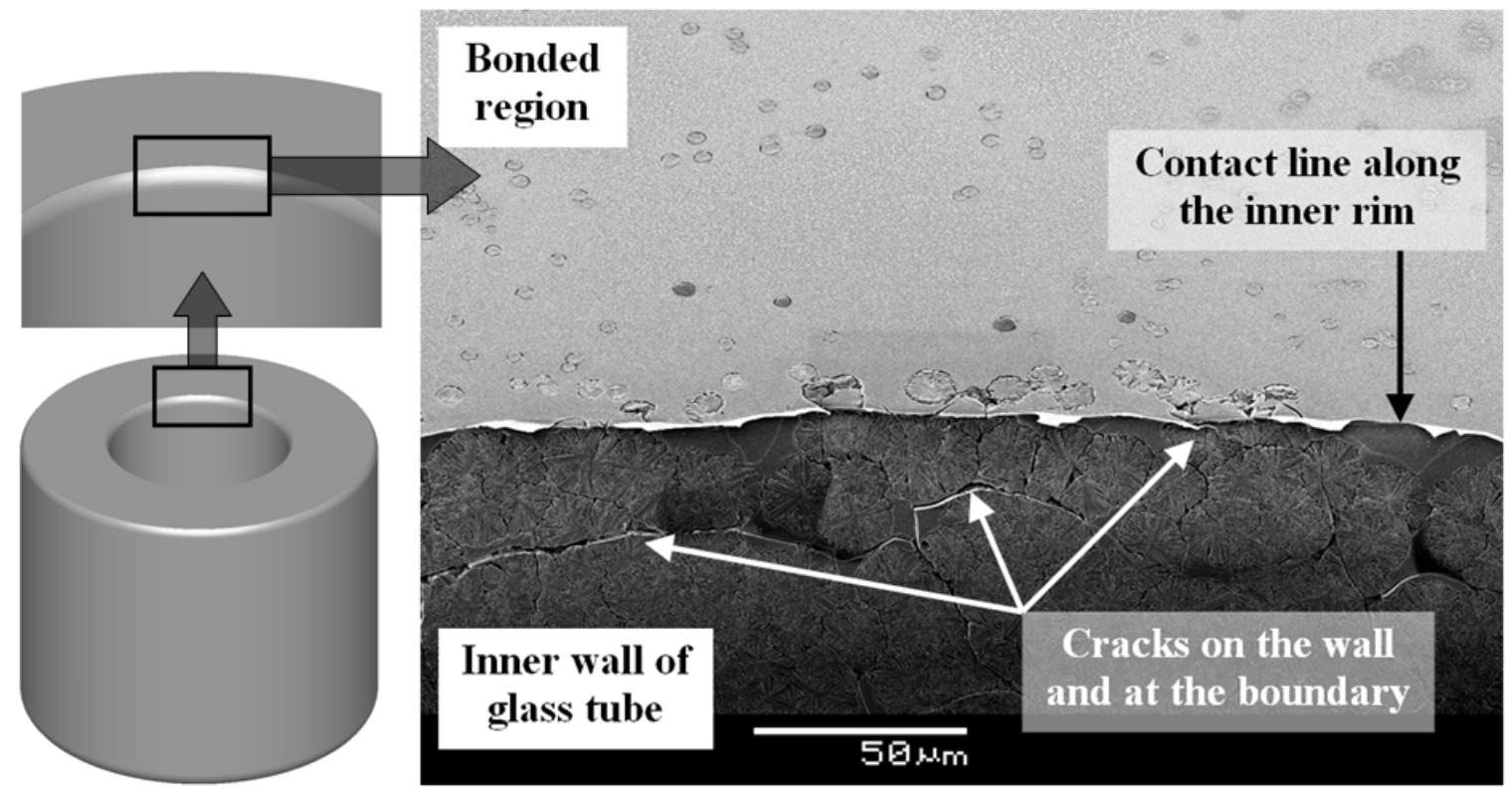

Figure 4.3 Cracks on the inner wall of the glass tube and crystals at the contact region to silicon after bonding at $700{ }^{\circ} \mathrm{C}$ for 30 hours and selective removal of the silicon in TMAH at $85{ }^{\circ} \mathrm{C}$.

\subsection{Thermal stresses between the borosilicate glass and silicon substrate}

Although crystallisation occurs on the surfaces of the glass tubes as a result of the heat treatments, the bulk of the glass remains unchanged and is still borosilicate glass. Therefore, it is appropriate to consider the magnitude of the thermal stress between borosilicate glass matrix and silicon arising from cooling the bonded assembly to 
room temperature after heat treatment. Similar to the calculations of thermal stresses between the borosilicate glass and the cristobalite crystals in Chapter 3, section 3.3.3; thermal stresses between the borosilicate glass tube and the bonded silicon assembly again start building up on cooling to room temperature from the annealing point of glass, $560{ }^{\circ} \mathrm{C}[4.9]$.

The coefficients of thermal expansion of Pyrex glass and silicon from $560^{\circ} \mathrm{C}$ down to room temperature are shown in Figure 4.4 [4.10]. Duran glass and Pyrex glass are known to have similar physical properties and matched average thermal expansion coefficient to silicon between $440{ }^{\circ} \mathrm{C}$ and $20{ }^{\circ} \mathrm{C}$ [4.10], so that stress induced after anodic bonding of silicon to Pyrex can be kept to a minimum [4.11]. Therefore, to a good approximation, the dominant contribution to the magnitude of the thermal stresses arises from cooling the assembly between $560^{\circ} \mathrm{C}$ and $440^{\circ} \mathrm{C}$. Taking the averages of the coefficients of thermal expansion over this temperature range to be $410^{-6}{ }^{\circ} \mathrm{C}^{-1}$ and $4.810^{-6}{ }^{\circ} \mathrm{C}^{-1}$ for silicon and Pyrex respectively, the thermal strain induced, $\varepsilon_{T}$, is $0.9610^{-4}$.

Estimates of the possible levels of thermal stress induced in the assembly can be made assuming all the strain is taken up by the glass. A simple one-dimensional calculation for the thermal stress developed in a glass rod constrained by silicon gives a tensile stress level $\sigma=\mathrm{E}_{\text {Glass }} \varepsilon_{T}$ [4.12], where $\mathrm{E}_{\text {Glass }}$ is Young's modulus of the glass. If $\mathrm{E}_{\mathrm{Glass}}$ is taken to be $64 \mathrm{GPa}$ [4.9], this gives a stress level prediction of $6 \mathrm{MPa}$. A worst-case scenario in three dimensions in which a Pyrex sphere is constrained by surrounding silicon [4.12] gives a tensile stress of $10 \mathrm{MPa}$ for a value of Poisson's ratio for the glass of 0.2 [4.9]. By contrast, the manufacturer's quoted bend strength for Borofloat glass is $25 \mathrm{MPa}$ using the coaxial double ring bending test on flat specimens according to DIN 52292-1 [4.9]. Thus, the level of thermal stress present in the Duran tubes after the bonding heat treatment is well below that likely to cause 
spontaneous fracture in the glass adjacent to the bond. This is consistent with the experimental observations.

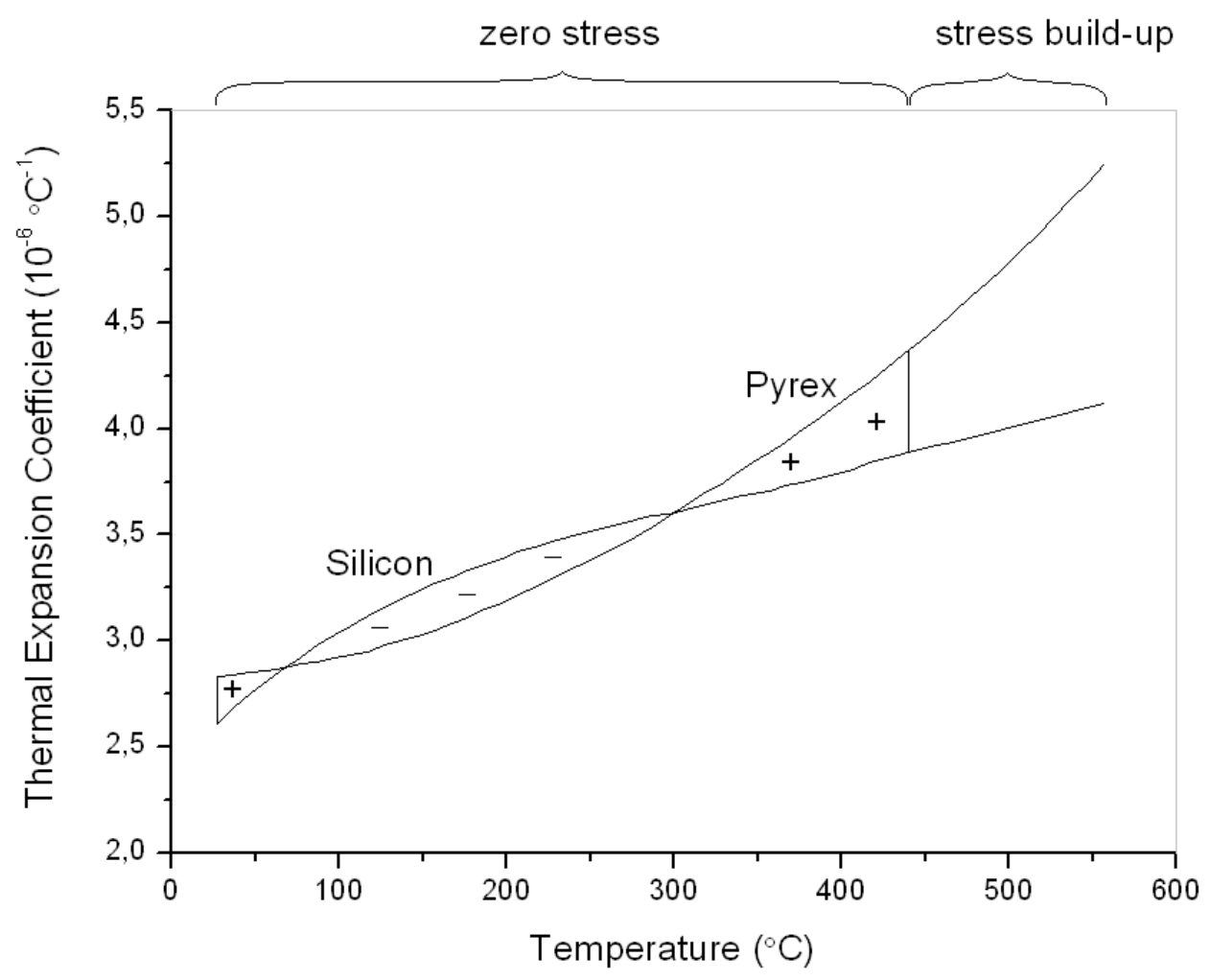

Figure 4.4 Coefficients of thermal expansion of Pyrex ${ }^{\circledR}$ glass and silicon from $560{ }^{\circ} \mathrm{C}$ to $20^{\circ} \mathrm{C}$.

\subsection{Bond strength}

To determine the mechanical strength of the bond between the borosilicate glass tubes and the silicon wafers, bonded tubes were connected to a water pump set-up by means of Swagelok connectors and pressurised [4.13, 4.14]. During pressurisation, the silicon bent, causing the borosilicate glass to be stretched along its contact boundary, along which both silicon and glass experience tensile stress. The pressure was 
increased until failure of the silicon-glass assembly; the burst pressure of the assembly was recorded and the mechanism of failure was established.

For each experiment, 10-15 tubes with the dimensions specified in Chapter 2, section 2.3 were bonded to silicon wafers as in section 2.4. The mean and standard deviations of the burst pressures of tubes bonded to $<100>$ SSP silicon wafers as a function of different heat treatments are shown in Table 4.2. It is apparent from this table that the bond strengths increase as a function of both temperature and time within the temperature/time regimes studied.

In the specimens bonded at $680{ }^{\circ} \mathrm{C}$ for 10 hours, fracture was observed in the glass in the vicinity of the contact region, leaving a residual layer of glass on silicon as shown schematically in situation I of Figure 4.5(a). A view of the surface of the silicon from such a fracture is shown in Figure 4.5(b), in which small voids arising from incomplete bonding are seen, typically along with a partly fractured silicon line near the outer rim of the tube. In addition, it can be seen that the contact line of glass to silicon is still continuing to be formed. As the bonding temperature and heat treatment time are increased to $700{ }^{\circ} \mathrm{C}$ and 30 hours respectively, all of the pressurised samples were found to fracture in the silicon plate, as shown schematically in situation II of Figure 4.5(a), and the bond was uniform. A view of the surface of such a ruptured silicon piece of silicon is shown in Figure 4.5(c), where there is evidence that the crack front was formed initially in the glass (leaving behind some traces of glass) before propagating into the silicon, causing its fracture. It is apparent from these observations that the heat treatment of $700{ }^{\circ} \mathrm{C}$ for 30 hours produces a good bond suitable for high pressure operation. 

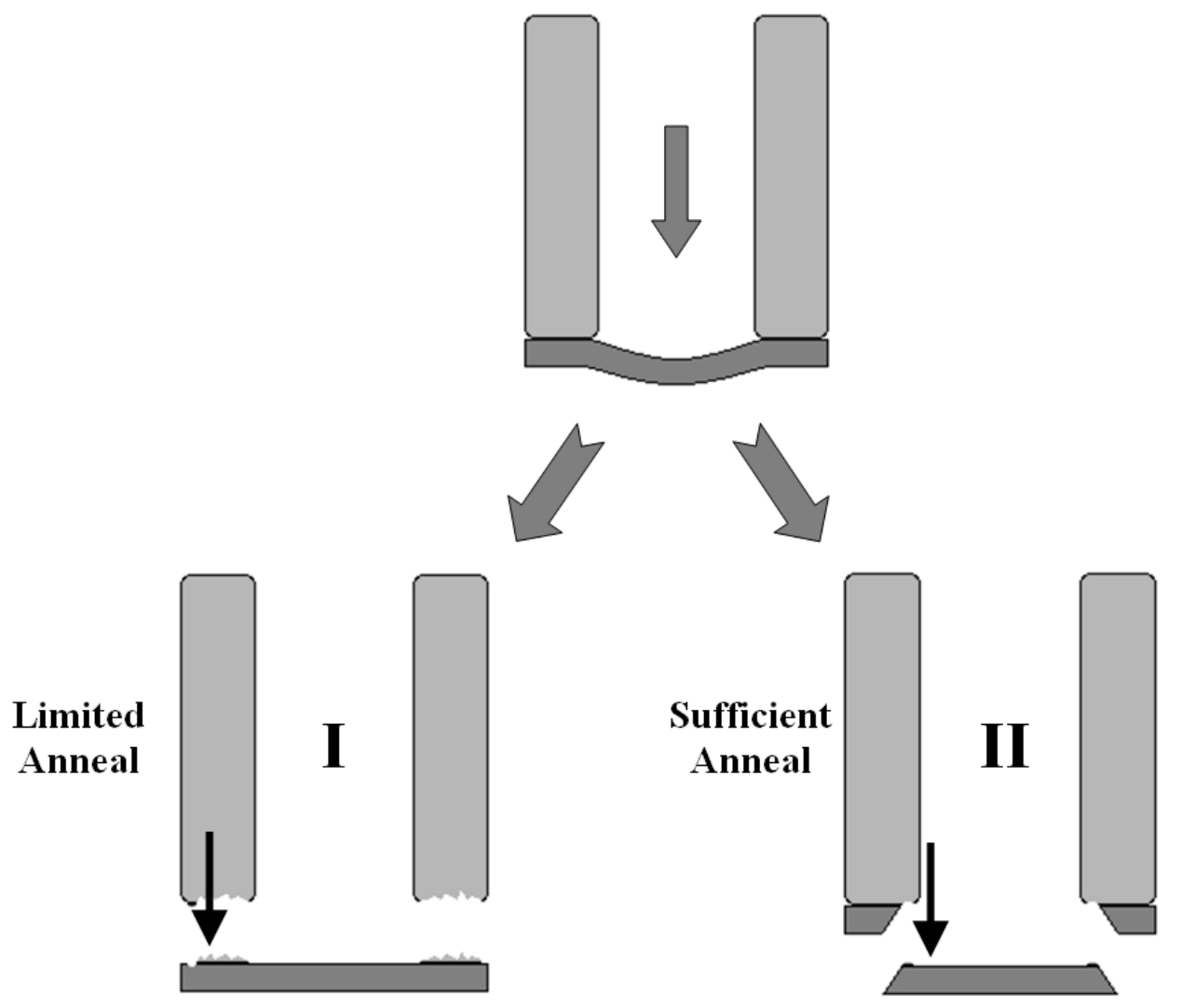

(a)

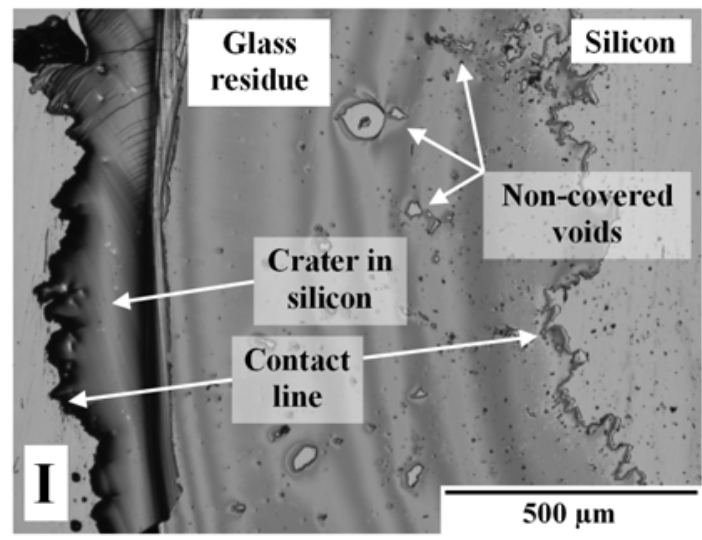

(b)

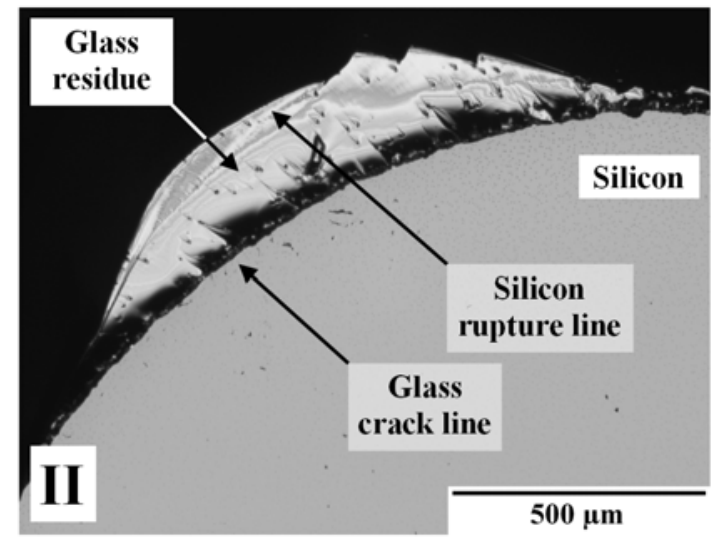

(c)

Figure 4.5 Fracture mechanisms for pressurised silicon-glass assemblies. (a) schematics of failure processes, (b) failure after bonding at $680{ }^{\circ} \mathrm{C}$ for 10 hours and (c) failure after bonding at $700{ }^{\circ} \mathrm{C}$ for 30 hours. 
Table 4.2 Burst pressures for $<100>$ SSP $525 \mu \mathrm{m}$ thick silicon wafers for different heat treatments.

\begin{tabular}{|c|c|c|c|}
\hline \multicolumn{3}{|c|}{ Burst pressure (MPa) } \\
\hline $680{ }^{\circ} \mathrm{C} ; 10 \mathrm{hr}$ & $700{ }^{\circ} \mathrm{C} ; 10 \mathrm{hr}$ & $700{ }^{\circ} \mathrm{C} ; 20 \mathrm{hr}$ & $700{ }^{\circ} \mathrm{C} ; 30 \mathrm{hr}$ \\
\hline $5.88 \pm 0.38$ & $6.55 \pm 0.32$ & $6.7 \pm 0.18$ & $7.3 \pm 0.28$ \\
\hline
\end{tabular}

Further burst pressure experiments were undertaken on bonds formed by heat treating at $700{ }^{\circ} \mathrm{C}$ for 30 hours, the results of which are displayed in Table 4.3. There are no significant differences between differently oriented or prepared wafers of a given thickness, although the wafer orientation affected the shape of the ruptured silicon piece as shown in Figure 4.6, where the fracture lines typically followed $\{110\}$ or $\{111\}$ directions. As expected, the thinner silicon wafers experienced lower burst pressures because the stress in the silicon wafer induced by the internal pressure scales inversely with the silicon wafer thickness. The results are consistent with this.

Table 4.3 Burst pressure values of various silicon substrates after heat treatment at $700{ }^{\circ} \mathrm{C}$ for 30 hours.

\begin{tabular}{|c|c|c|c|c|}
\hline \multicolumn{5}{|c|}{ Burst pressure (MPa) } \\
\hline$<100>$ SSP & $<100>$ DSP & $<111>$ SSP & $<100>$ SSP & $<110>$ DSP \\
$525 \mu \mathrm{m}$ & $525 \mu \mathrm{m}$ & $525 \mu \mathrm{m}$ & $380 \mu \mathrm{m}$ & $380 \mu \mathrm{m}$ \\
\hline $7.3 \pm 0.28$ & $7.46 \pm 0.2$ & $7.81 \pm 0.22$ & $5.0 \pm 0.13$ & $5.55 \pm 0.1$ \\
\hline
\end{tabular}




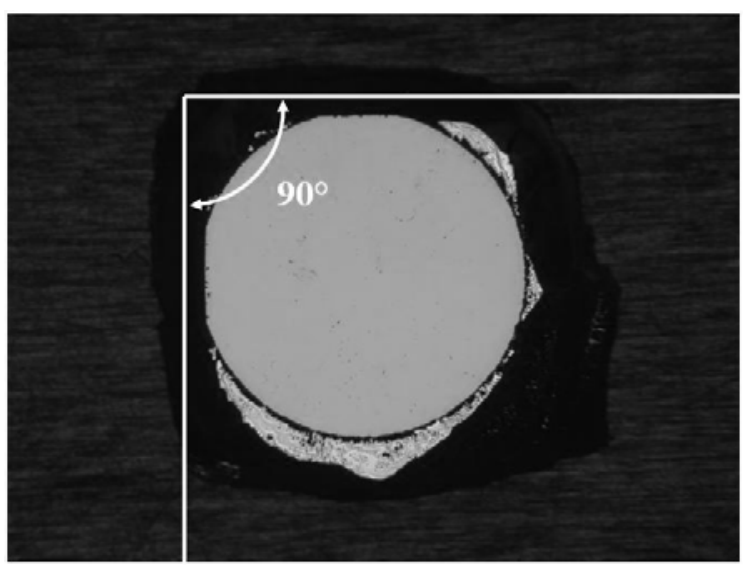

(a)

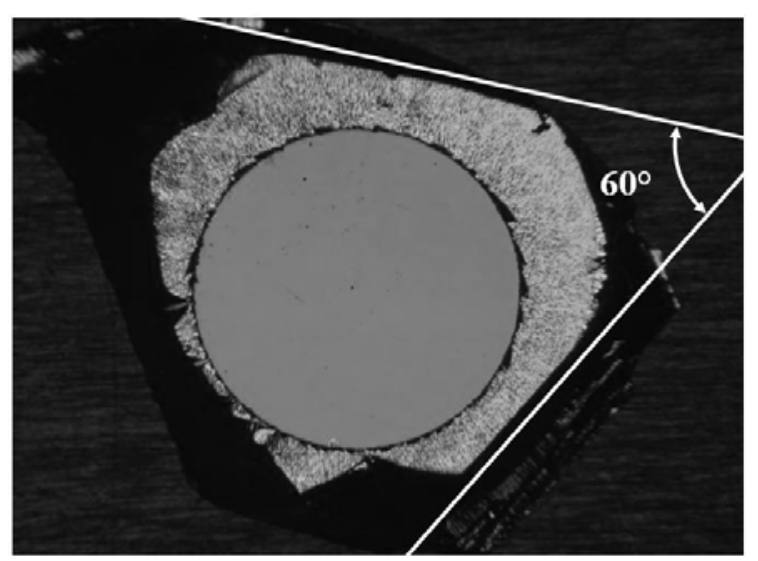

(b)

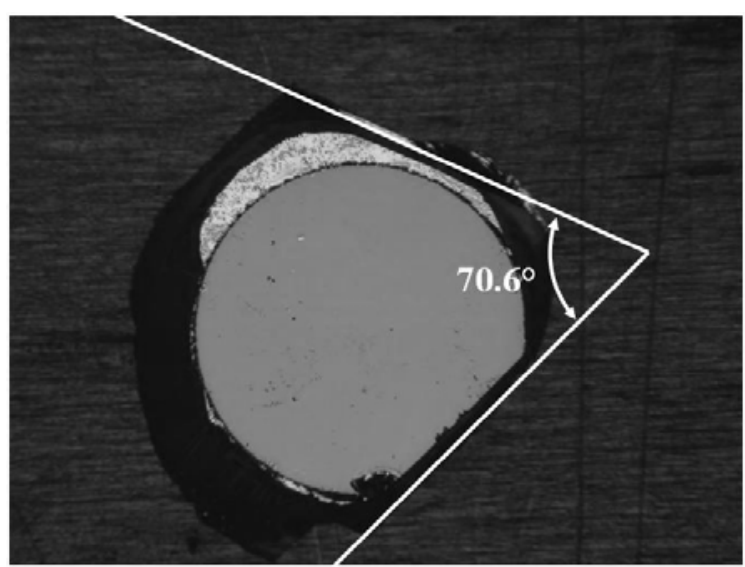

(c)

Figure 4.6 Ruptured silicon pieces of (a) $<100>$ oriented wafer showing 4 fold symmetry with fracture lines along $\{110\}$ planes, (b) $<111>$ oriented wafer showing 3 fold symmetry with fracture lines along $\{110\}$ planes and (c) $<110>$ oriented wafer showing 2 fold symmetry with fracture lines along $\{111\}$ planes.

More detailed investigation of the fracture surfaces after failure during the burst pressure tests confirmed that bonding at $680^{\circ} \mathrm{C}$ for 10 hours produced a bond of low quality, with incomplete coverage of the contact region by the glass. Failure occurred in the glass by propagation of flaws, as shown schematically in Figure 4.7(a). No evidence was found for preferential crack formation and propagation linked to the relatively few small cristobalite crystals seen within the vicinity of the silicon-glass interface. 
When bonding was undertaken at $700{ }^{\circ} \mathrm{C}$ for 30 hours, a good bond was obtained, without any residual voids at the silicon-glass interface. It was observed that failure occurred by crack propagation through cristobalite crystals in the borosilicate glass, entering the silicon at some point away from the crystals, as demonstrated schematically in Figure 4.7(b). An optical micrograph of the residual glass layer is displayed in Figure 4.8(a), where the crack propagation through the crystals is apparent. However, the scanning electron micrograph in Figure 4.8(b) presents the crack entering silicon at some point away from the crystals from an oblique view. Qualitatively, the increase in the burst pressure seen in Table 4.2 between bonds formed at $680{ }^{\circ} \mathrm{C}$ for 10 hours and those formed at $700{ }^{\circ} \mathrm{C}$ for 30 hours compares well with the percentage increase in the fully bonded area between the borosilicate glass and the silicon substrate. The presence of cristobalite crystals does not appear to affect adversely the strength of the borosilicate glass, although these crystals might help to determine where cracks are able to propagate from the glass into the silicon. 

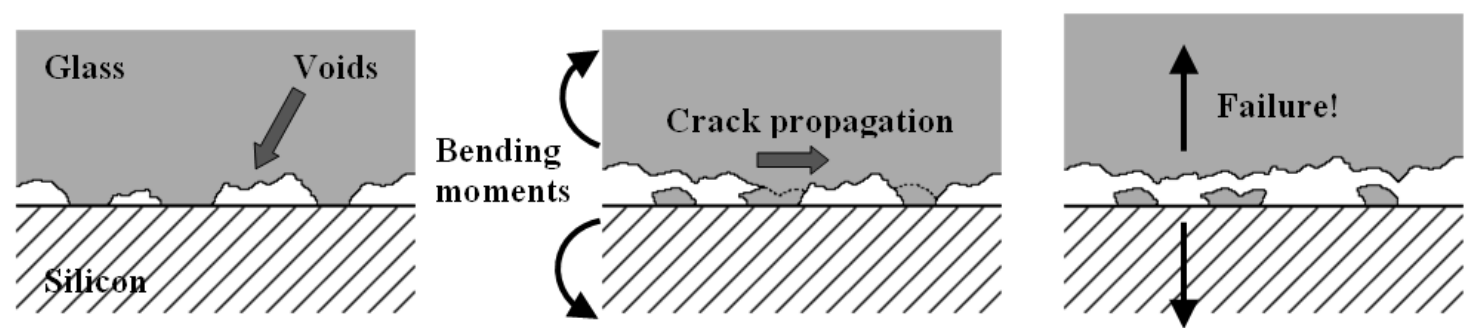

(a)
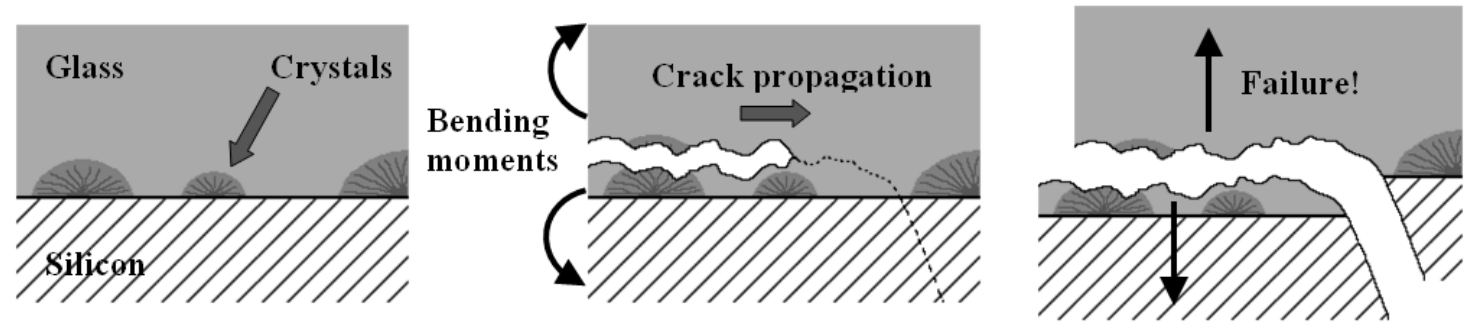

(b)

Figure 4.7 Fracture paths for bonded samples during burst pressure measurements. (a) after bonding at $680{ }^{\circ} \mathrm{C}$ for 10 hours and (b) after bonding at $700^{\circ} \mathrm{C}$ for 30 hours.

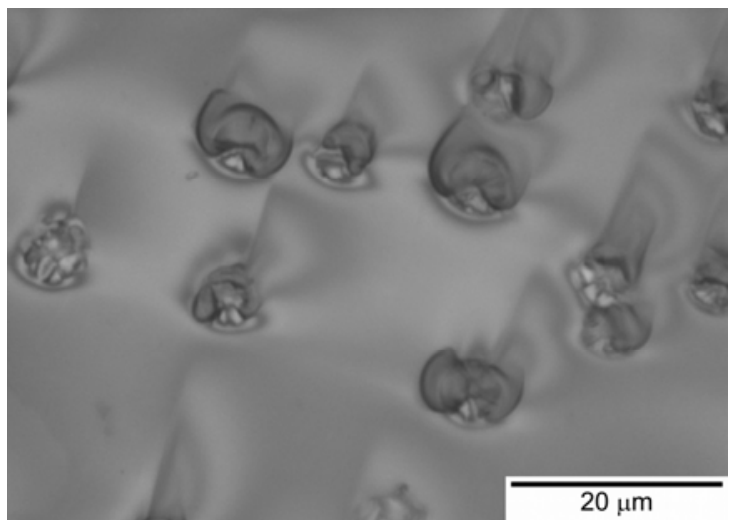

(a)

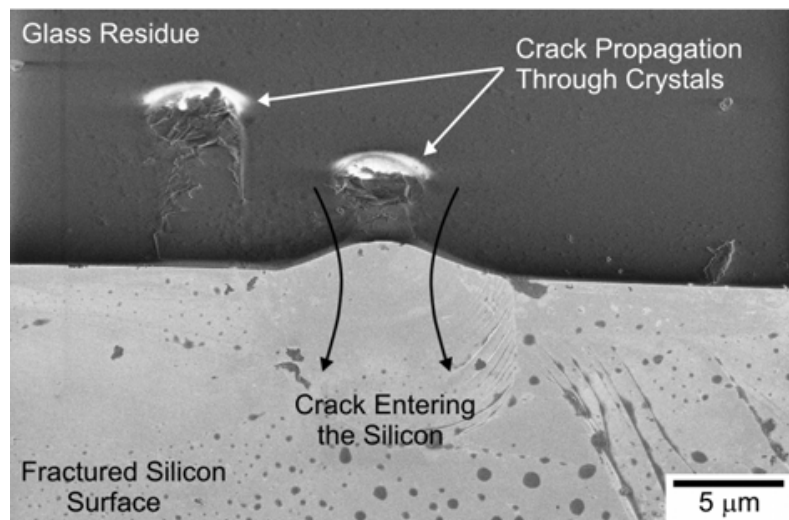

(b)

Figure 4.8 (a) Top view of the residual glass layer, where the crack propagates through the crystals. (b) Oblique view of a ruptured silicon piece, where the crack enters silicon at some point away from the crystals.

\subsection{Hermeticity}

A Leybold UL 500 helium leak detector was used to test the hermeticity of the bond. Tubes of $3 \mathrm{~mm}$ ID and $6 \mathrm{~mm}$ OD were bonded to silicon disks (produced by laser 
machining) and the tubes were connected to a flange, the sealing for which was provided by an O-ring. The flange was attached directly to the leak detector while the other side of the tube was pressurised with helium (Figure 4.9). No leak was found immediately after pressurising the bonded tube with helium. However, after about 48 hours, helium could be detected because of the diffusion of helium through the wall of the glass tube.

The escape of helium gas through a cylindrical tube as a function of time has been calculated using the theory outlined by Rogers et al. [4.15]. Owing to the cylindrical shape of the tube, an effective cross-sectional area has to be defined. In the early stage of the diffusion process the effective area, $A_{\text {eff }}$, can be calculated using the geometric mean of the inner and outer radii, $r_{i}$ and $r_{o}$ respectively, as shown in equation (4.1) below. However, in the later stage of the diffusion process, the effective area can be calculated using equation (4.2) below. The tube is pressurised with $2.3-2.5 \mathrm{MPa}$ of helium overpressure and the length of the tube contributing to the leak, $L$, (i.e., the section of the tube from silicon disk to O-ring seal) was measured to be $\sim 15 \mathrm{~mm}$.

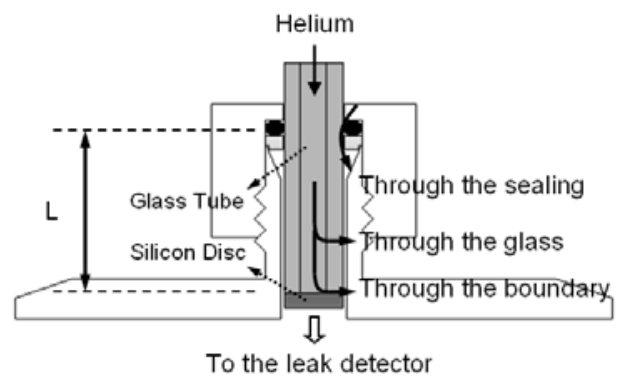

(a)

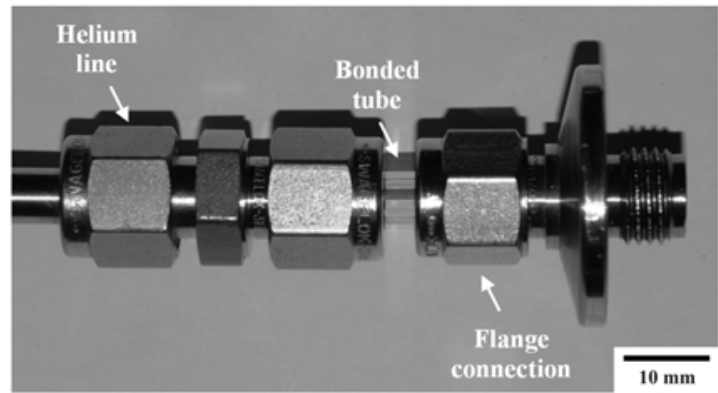

(b)

Figure 4.9 Schematic of the glass tube connected to leak detector. 


$$
\begin{gathered}
A_{\text {eff }}=2 \cdot \pi \cdot L \cdot \sqrt{r_{o} \cdot r_{i}} \text { for } t<0.45 \frac{\left(r_{o}-r_{i}\right)^{2}}{D} \\
A_{e f f}=\frac{2 \cdot \pi \cdot L \cdot\left(r_{o}-r_{i}\right)}{\ln \left(\frac{r_{o}}{r_{i}}\right)} \text { for } t \geq 0.45 \frac{\left(r_{o}-r_{i}\right)^{2}}{D}
\end{gathered}
$$

Following Rogers et al. [4.15] the rate of escape of gas with time, $\varphi(t)$, i.e., the rate of gas leakage, can be expressed in the form

$$
\varphi(t)=\frac{A_{e f f} \cdot D \cdot S \cdot P}{\left(r_{o}-r_{i}\right)} \cdot\left[1+2 \cdot \sum_{m=1}^{\infty} \cos (m \cdot \pi) \cdot e^{-\frac{m^{2} \cdot \pi^{2} \cdot D \cdot t}{\left(r_{o}-r_{i}\right)^{2}}}\right]
$$

in which $A_{e f f}$ is the effective cross-sectional area of the glass tube, $D$ is the diffusion coefficient of helium through the glass, $S$ is the solubility of helium in the glass, $P$ is the helium pressure inside the tube $(2.3 \mathrm{MPa})$ and $L$ is the length of the glass tube contributing to the leak.

Results of the leak rate measurements are plotted in Figure 4.10. The dashed line in Figure 4.10 represents the calculated leak rate with the shaded area corresponding to its error range. To plot this line, data of Rogers et al. [4.15] for Pyrex glass were used, (i.e. $D=0.910^{-8} \mathrm{~cm}^{2} \mathrm{~s}^{-1}$ with $\pm 10 \%$ error and $S=0.810^{-2}$ with $\pm 50 \%$ error) since the chemical composition of Duran glass and Pyrex are extremely similar, so that similar diffusivities and solubilities are expected. Although the error percentage in the reference data is quite high, there is quite a discrepancy between the calculated 
curve and the measurements (circles). The approximate measurement inaccuracy is displayed as error bars. The solid line in Figure 4.10 has been drawn by generating best fitting diffusion coefficient and solubility values (i.e. $D=0.410^{-8} \mathrm{~cm}^{2} \mathrm{~s}^{-1}$ and $S=510^{-2}$ ) to the measurement data, implying that the data suggest that the diffusion of helium through the glass has to be slower than expected with significantly higher solubility inside the glass. This difference between experimental behaviour and calculated prediction can be attributed to the thermal history of the glass as well as to the differences in the composition and the production methods of the different types of borosilicate glasses. No diffusion of helium through silicon at room temperature is reported and the shape of the leakage curve as a function of time is consistent with a developing diffusion process. Therefore, it is reasonable to state that no leak arises because of the boundary or through poor sealing from the environment. Contributions of other possible sources to the leakage of helium can also be ignored. 


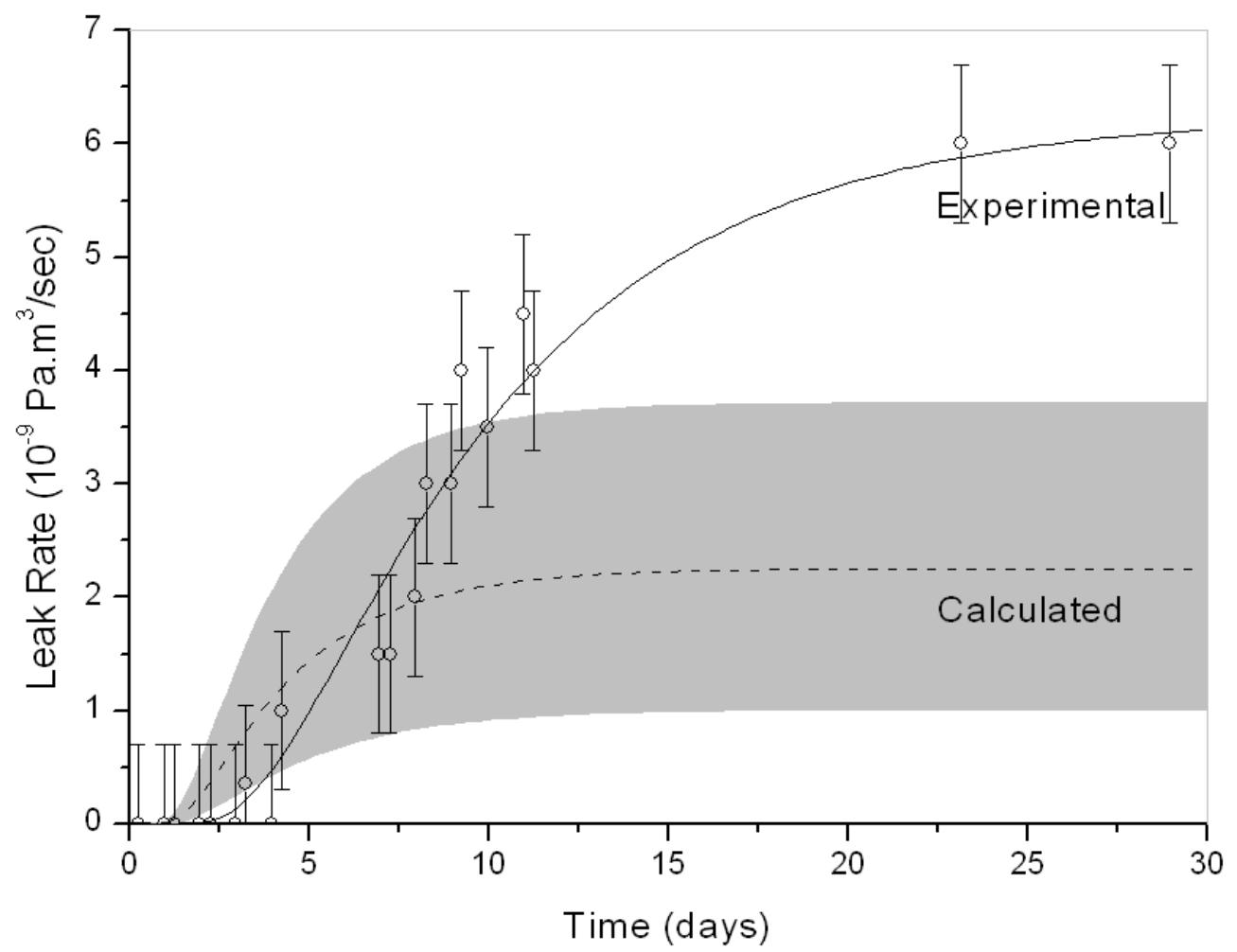

Figure 4.10 Leak rate as a function of time for experimental observations and calculated predictions.

\subsection{Summary}

Reflow bonding of Duran tubes to silicon wafers has been characterised as a fluidic interconnect and package technology for MEMS-on-tube assembly. The connections are produced by the high temperature heat treatment of borosilicate glass tubes after they are positioned on silicon wafers. The connections were hermetic and can be safely operated up to $7 \mathrm{MPa}$. The pressure is limited by the strength of the borosilicate glass and silicon rather than by the failure of the silicon-glass bond. As a consequence of the high temperature heat treatment used for bonding, surface devitrification has been observed on the borosilicate glass, causing fine cracks on the tube surface. However, the results shown indicate that the devitrification does not have a critical effect on the applicability of this technology. 


\section{References}

[4.1] P. W. McMillan, Glass-ceramics (Academic Press, London, 1964), pp 132-57.

[4.2] R. W. Davidge, and T. J. Green, J. Mater. Sci. 3, 629 (1968).

[4.3] W. A. Johnson, and R. F. Mehl, Trans. Am. Inst. Min. Metall. Eng. 135, 416 (1939).

[4.4] M. Avrami, J. Chem. Phys. 7, 1103 (1939).

[4.5] M. Avrami, J. Chem. Phys. 8, 212 (1940).

[4.6] M. Avrami, J. Chem. Phys. 9, 177 (1941).

[4.7] U. Schnakenberg, W. Benecke, and P. Lange, Proceedings of International Conference on Solid-State Sensors and Actuators (Transducers '91), pp 815-8 (1991).

[4.8] N. G. Ainslie, C. R. Morelock, and D. Turnbull, Symposium on Nucleation and Crystallization in Glasses and Melts (The American Ceramic Society, Ohio, 1962), pp 97-107.

[4.9] http://www.schott.com/borofloat/english, accessed 1 July 2010.

[4.10] Y. S. Touloukian, R. K. Kirby, R. E. Taylor, and T. Y. R. Lee, Thermal expansion - nonmetallic solids: Thermophysical Properties of Matter - the TPRC data series vol. 13 (IFI/Plenum, New York, 1977), pp 154-61, 1369-73.

[4.11] K. M. Knowles, and A. T. J. van Helvoort, Int. Mater. Rev. 51, 273 (2006).

[4.12] B. E. Gatewood, Thermal Stresses (McGraw-Hill, New York, 1957), pp 1-16. 
[4.13] I. Fazal, E. Berenschot, R. de Boer, H. Jansen, and M. Elwenspoek, Proceedings of International Conference on Solid-State Sensors, Actuators and Microsystems (Transducers ‘05), pp 936-9 (2005).

[4.14] I. Fazal, and M. C. Elwenspoek, J. Micromech. Microeng. 18, 055011 (2008).

[4.15] W. A. Rogers, R. S. Buritz, and D. Alpert, J. Appl. Phys. 25, 868 (1954). 


\section{Characterisation of the glass-silicon interface}

The interface of borosilicate glass tube-silicon joins formed after the reflow bonding is characterised in this chapter. The interface has been studied by scanning electron microscopy (SEM) and transmission electron microscopy (TEM). Amorphous borosilicate glass has been found to be fully intact with silicon. On occasion, cristobalite crystals trapped at the interface have been observed with cracks around them. In addition, compositional analysis of glass-silicon interface has revealed the formation of a thin amorphous silica layer adjacent to the silicon. 


\subsection{Introduction}

Reflow bonding of borosilicate glass tubes to silicon substrates has been achieved. The morphological changes in the glass have been studied and the limitations of the glass-silicon join in terms of strength and hermeticity have been established. While it is apparent from these observations that reflow bonding enables intimate contact to be made between the borosilicate glass and the silicon, the precise nature of the bond formed at the interface between these two materials is unknown. One possibility is that the native oxide film on the silicon substrate simply dissolves into the borosilicate glass to create a strong bond. A second possibility is that there is a modest degree of diffusion of materials between the silicon, the native silicon oxide and the borosilicate glass at $700{ }^{\circ} \mathrm{C}$ which helps to produce a strong chemical bond across the interface.

In this chapter, transmission electron microscopy (TEM) work of the borosilicate glass-silicon interface is undertaken after reflow bonding in order to establish the bonding mechanism. This is similar to the work performed by Helvoort et al. [5.1] for the borosilicate glass-silicon bonds formed by anodic bonding. The sample preparation suitable for TEM is described and the microscopic examination of the interface is presented. Compositional analysis across the interface is introduced and formation of an intermediate layer has been shown.

\subsection{Sample preparation}

In order to be able to extract any information by TEM, the specimens under inspection have to be thin so that they are electron transparent. Although it depends on the sample material, the microscopy conditions and the aim of the microscopy, the sample thickness should be typically lower than a couple of hundred nanometres to transmit sufficient electrons for an interpretable image [5.2]. 


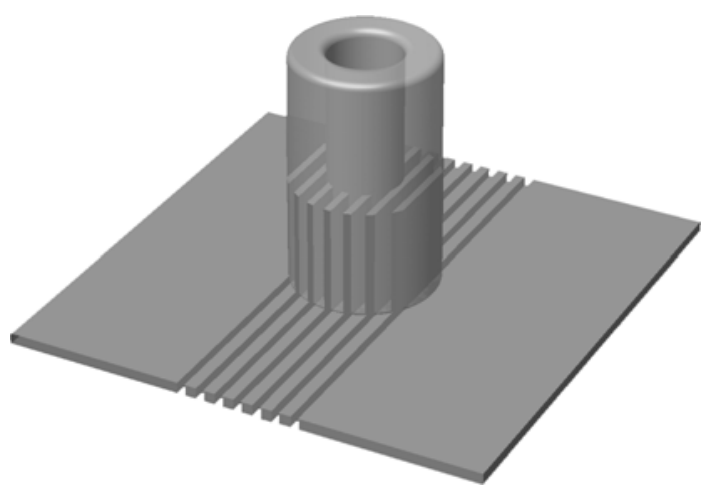

(a)

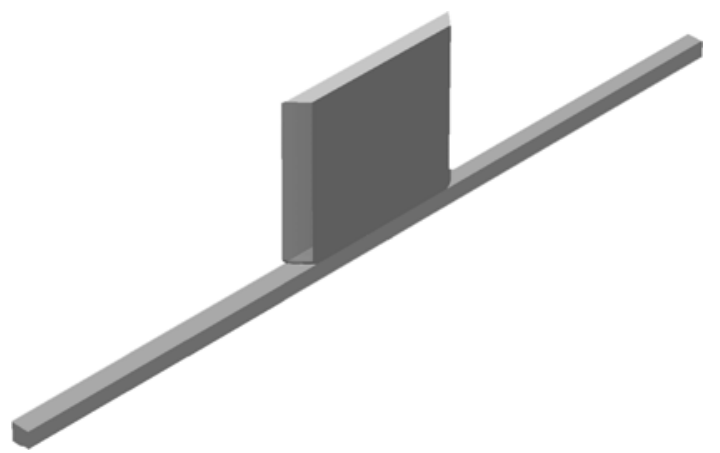

(c)

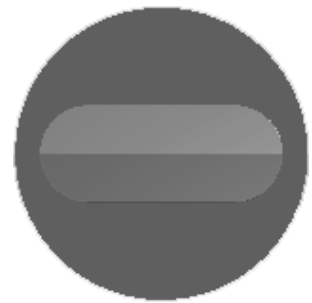

(e)

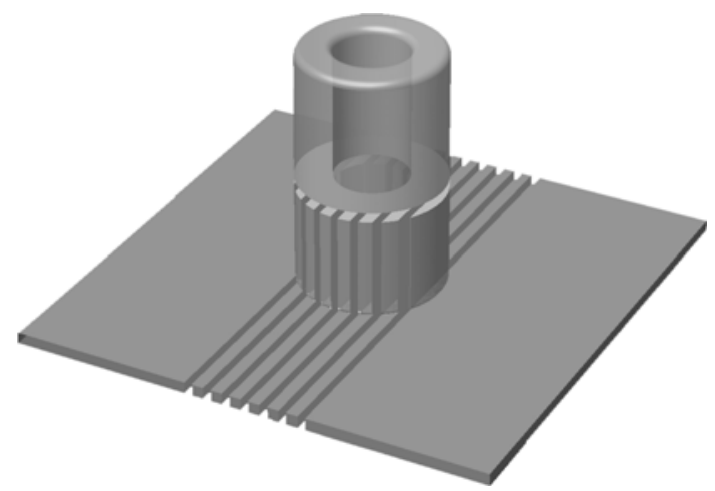

(b)

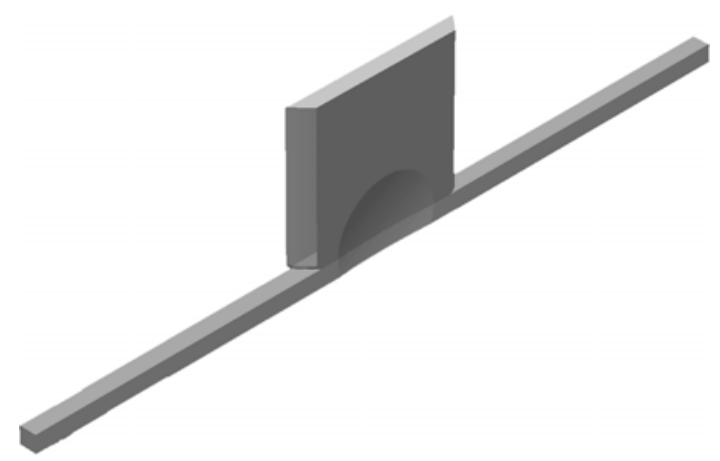

(d)

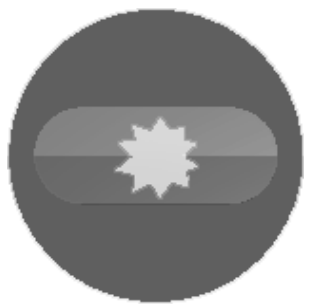

(f)

Figure 5.1 Schematic diagram of TEM specimen preparation by conventional methods.

For the sample preparation, Duran tubes are bonded to $<100>$ oriented SSP silicon wafers of 525 micron thick after the heat treatment at $700{ }^{\circ} \mathrm{C}$ for 30 hours. The details of the bonding process are given in Chapter 2. Two TEM specimen preparation routines have been used to examine the bond interface in cross-section. 
The first technique relies on conventional mechanical thinning and argon ion milling methods, while the second technique uses a focused ion beam (FIB) instrument. The preparation steps of the first technique are shown schematically in Figure 5.1. The bonded samples are initially sliced into slabs of $0.5-1 \mathrm{~mm}$ thick parallel to the length of the glass tube using a low speed diamond wheel saw (Figure 5.1(a)) and the slices are released by another perpendicular cut (Figure 5.1(b)). They are glued on a flat support and ground / polished to a thickness below $100 \mu \mathrm{m}$ using metallography turntables holding silicon carbide grinding paper starting with grit P600 and finishing with grit P2500 (Figure 5.1(c)). Scanning electron micrographs of samples after the grinding / polishing step are presented in Figure 5.2, where no defects on the interface are apparent except the features induced by grinding / polishing.

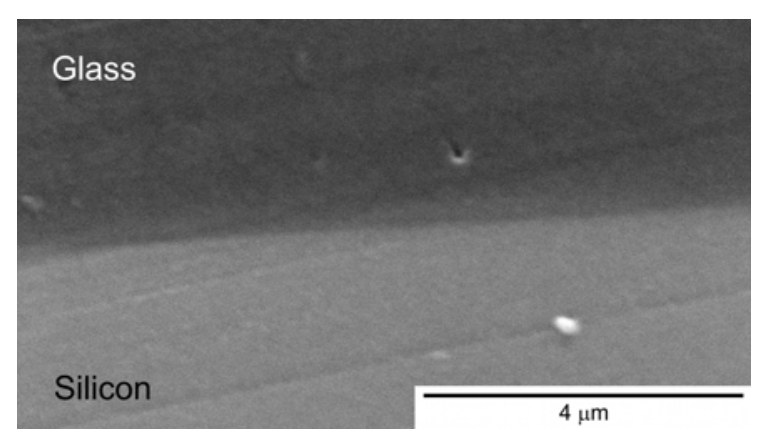

(a)

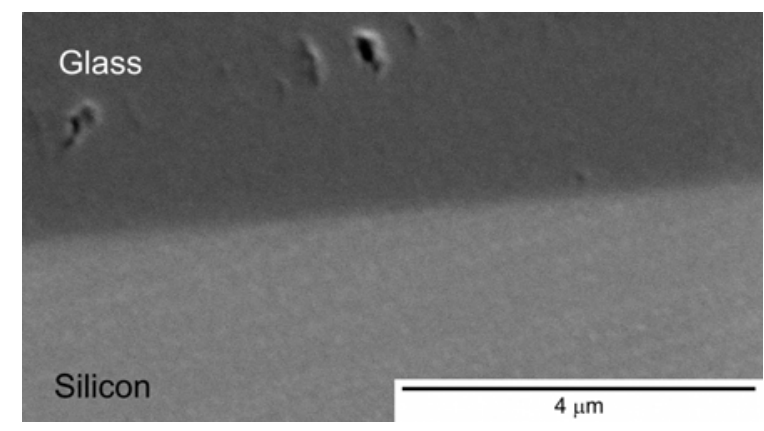

(b)

Figure 5.2 Scanning electron micrographs (Secondary Electron Image) of glass tube-silicon bonds after grinding / polishing steps. Some scratches and holes are visible in (a) and (b), which are caused during grinding

The samples prepared by standard methods are then dimpled to reduce the thickness to few tens of microns at the interface (Figure 5.1(d)). To achieve this, the sample is positioned on a rotating stage and a dish is ground at the interface by a metal wheel, which is rotating perpendicular to the stage and coated with diamond paste (Fishioni 1000 Dimpler) [5.2]. The following step is to glue each specimen slab on a $3 \mathrm{~mm}$ 
diameter copper $(\mathrm{Cu})$ grid with a single slot of $1 \times 2 \mathrm{~mm}$ (Figure 5.1(e)). The edges of the sample protruding out of the 3-mm Cu disk are cut with a scalpel. If the samples survive all previous steps, the final thinning is done by argon-ion miller with sample holder cooled to liquid-nitrogen temperature (Gatan Dual Mill). The area around the milled hole in the specimen (Figure 5.1(f)) should be electron transparent and can be used in TEM.

The second technique requires a dedicated tool, FIB instrument, to prepare suitable TEM specimens from the samples that are sliced and ground / polished. A typical way of using FIB is to prepare specimens having a uniform thickness from specific regions of interest. Using a beam of focused gallium ions in a FEI Helios Dual Mill system, two trenches, which are running across the glass-silicon interface, are cut next to each other thereby leaving a thin wall as in Figure 5.3(a). The sides of this thin wall are then trimmed away and it is attached to a half $\mathrm{Cu}$ support grid with the help of an in-situ probe manipulator. The sides of the specimen touching the support grid are locally coated with platinum to hold them together. The specimen is further thinned down with the ion beam to reach a suitable thickness. Its final state can be seen in Figure 5.3(b). The principles involved in both of the preparation techniques are discussed in detail by Williams and Carter [5.2]. 


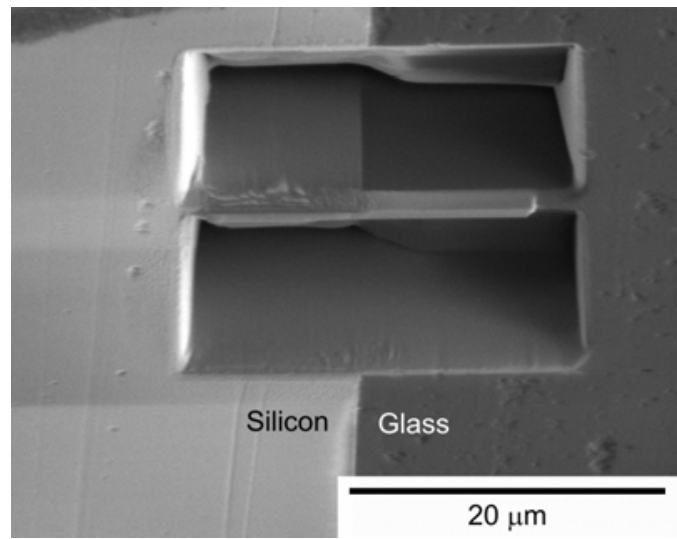

(a)

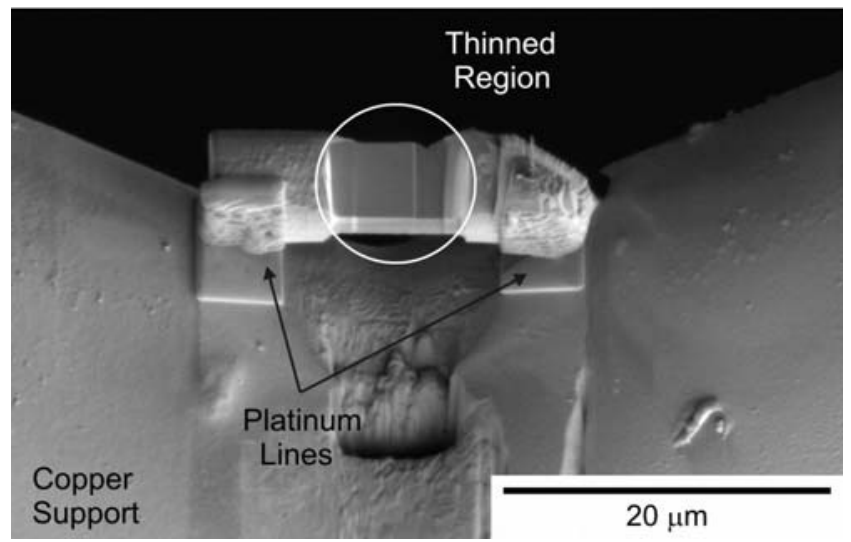

(b)

Figure 5.3 The stages of the TEM specimen preparation using a FIB instrument. (a) Two trenches are cut across the bond interface leaving a thin wall. (b) The slice is trimmed away at the sides, placed on a Cu support and further thinned to a suitable thickness.

\subsection{Microscopic examination of the bond interface}

To take the micrographs presented in this section, a JEOL 200CX TEM was used with a double tilt sample holder. A micrograph of the glass-silicon interface and its electron diffraction pattern are presented in Figure 5.4. This sample was prepared by conventional methods. The silicon was tilted to obtain a diffraction condition along [100] zone and to view the interface edge-on. The thickness fringes of silicon show the non-uniformity in the thickness of the specimen. The glass is shown to be in intimate contact with the silicon and the bond is observed to be good without any openings or voids at the interface. 


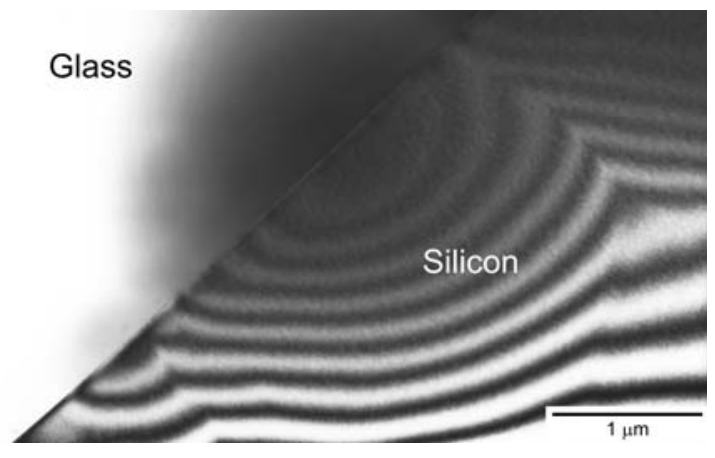

(a)

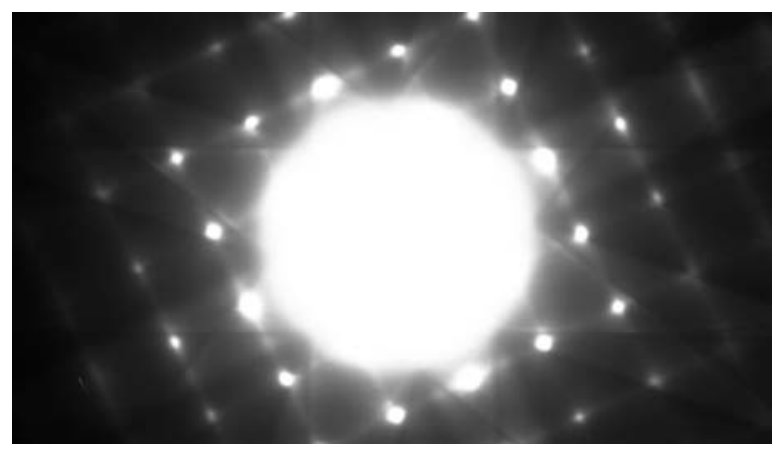

(b)

Figure 5.4 (a) Bright field TEM image of the glass-silicon interface. (b) Electron diffraction pattern of the interface after obtaining diffraction condition along [100] zone of the silicon.

In Chapter 4, section 4.3, the presence of cristobalite crystals across the bond interface was established. The crystals nucleate and grow in the beginning of the bonding process when the tube ends were not in intimate contact with silicon. After several hours of heat treatment, the interface between the glass tube and the silicon substrate is formed thereby trapping them in the contact region. The crystals are isolated, spread across the contact region and are of approximately $5 \mu \mathrm{m}$ diameter.

During the microscopy of samples prepared by conventional methods, several cristobalite crystals were encountered. They were embedded in the borosilicate glass matrix and cracks were induced around them. The crystal in Figure 5.5(a) has a crack along the surrounding glass matrix; however, the one in Figure 5.5(b) has a crack running along the interface. These cracks might have arisen from either the thermal stresses or the preparation procedure. Moreover, because of the electron beam damage, the crystals were very quickly amorphising during microscopy; this made it impractical to study their properties. The crystal in Figure 5.6 shows the loss of contrast difference after amorphisation. In addition, it is particularly important to highlight the effect of crystals at the silicon interface. Because the crystal distorted the interface with the silicon so that the silicon was no longer flat. 


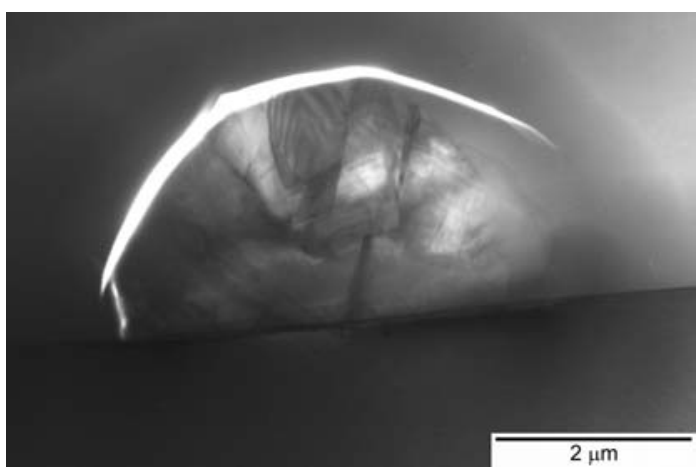

(a)

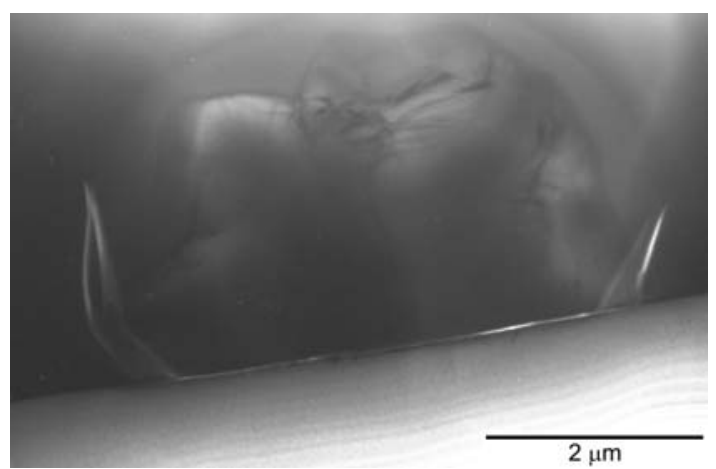

(b)

Figure 5.5 Cristobalite crystals of approximately $5 \mu \mathrm{m}$ diameter that are trapped at the glass-silicon interface.

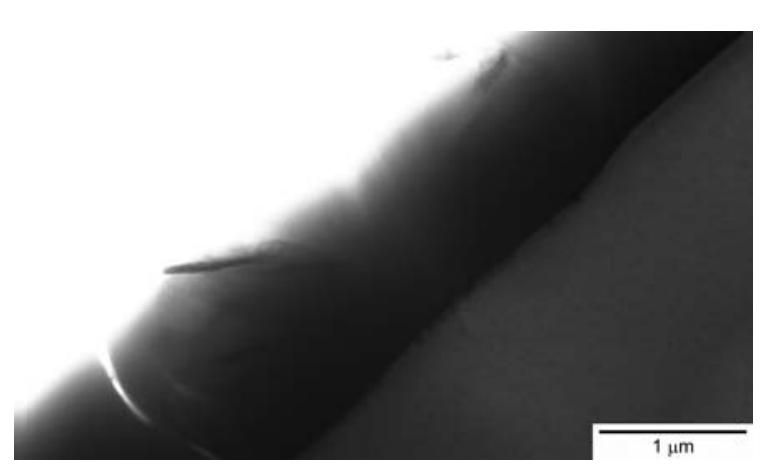

(a)

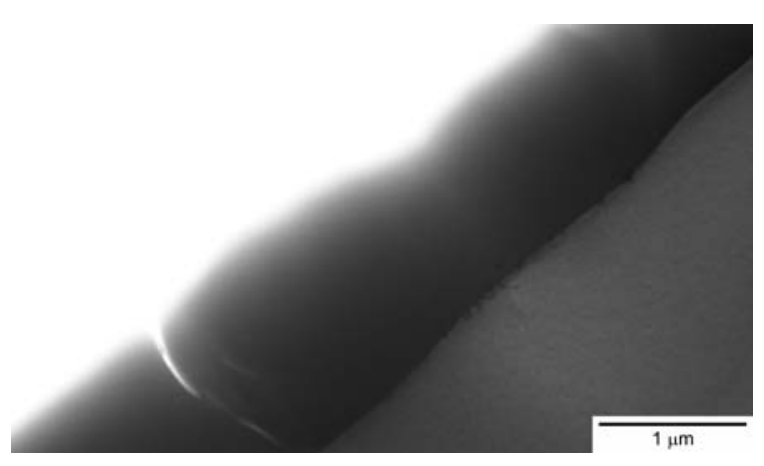

(b)

Figure 5.6 (a) Transmission electron micrograph of a cristobalite crystal trapped at the glass-silicon interface (a) before and (b) after amorphisation due to the beam damage.

FIB helps to prepare evenly flat samples which are particularly important to prevent the adverse effects of thickness variations. The Bright Field (BF) image and the Dark Field (DF) image of the edge of FIB prepared sample are shown in Figure 5.7. Within the resolution limits of these micrographs, no other contrast can be observed to suggest an intermediate layer formation. The thickness fringes of crystalline silicon converge along the interface indicating slight height difference adjacent to the line of 
contact due to difference in the erosion rates of glass and silicon during ion beam thinning.

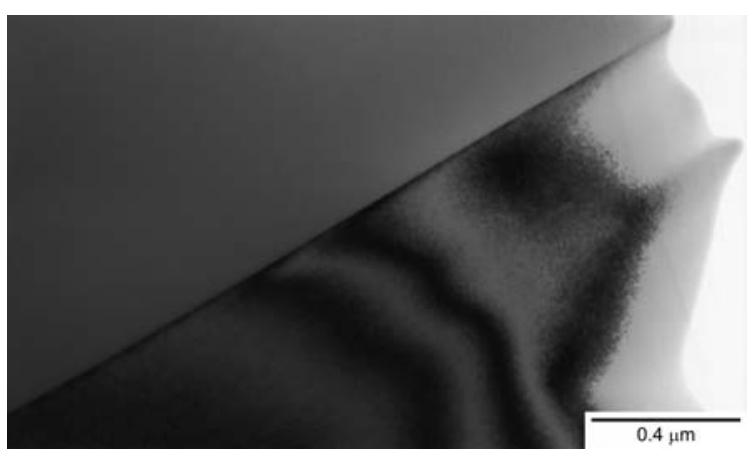

(a)

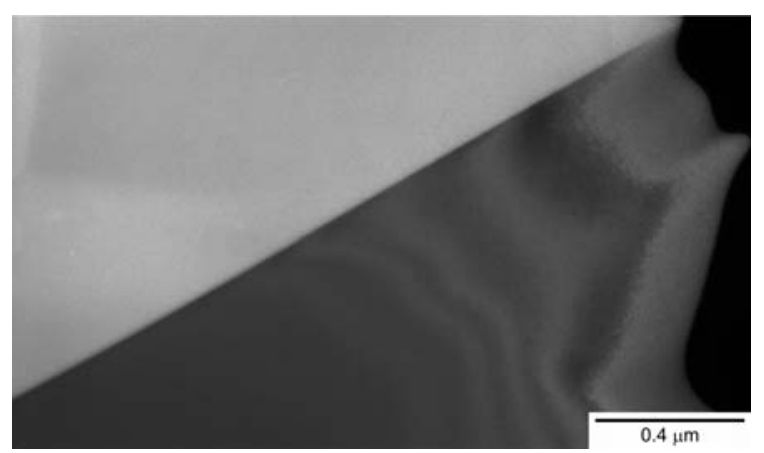

(b)

Figure 5.7 (a) Bright field and (b) dark field TEM image of the edge of the sample prepared by FIB.

\subsection{Chemical analysis of the bond interface}

To take the micrographs at higher magnification and do the chemical analysis presented in this section, a JEOL 2010F TEM was used. Again a double tilt sample holder was used to have the interface between glass and Si edge-on. In addition to the micrographs in previous section, higher resolution micrographs of specimens prepared by conventional methods were taken and are presented in Figure 5.8. These confirm that the glass is fully intact with the silicon even at the atomic scale, proving the success of the reflow bonding process. In the amorphous phase no other phases or a mixture of amorphous phases is apparent. 


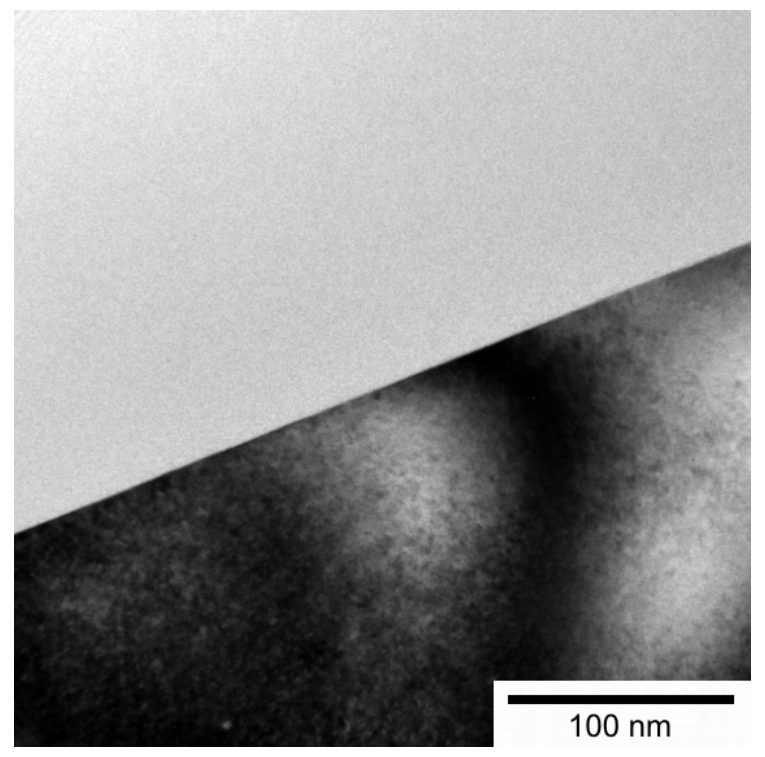

(a)

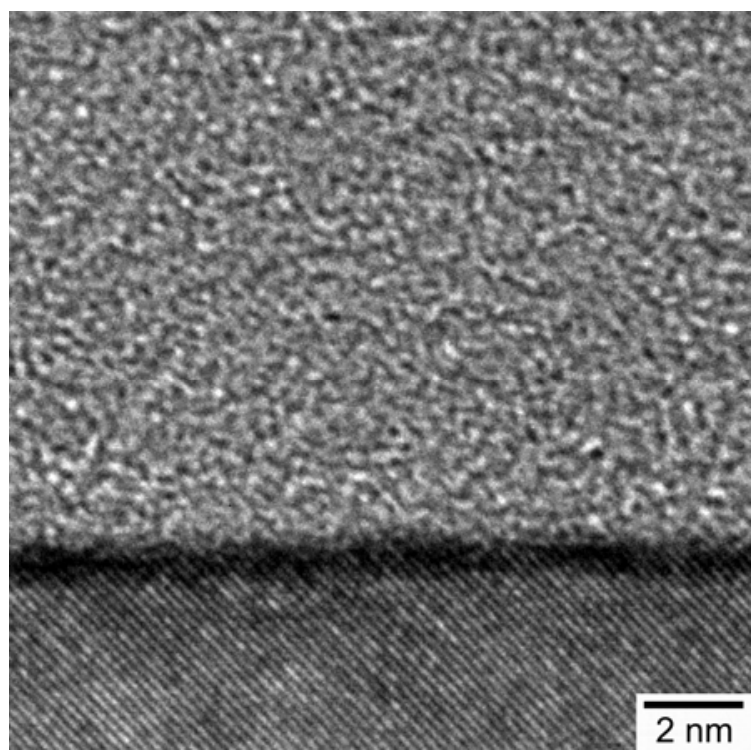

(b)

Figure 5.8 (a) Bright field and (b) high resolution transmission electron micrographs of the glass-silicon interface at higher magnifications.

In order to be able to comment on the presence of amorphous intermediate layers and possible diffusion of materials between the silicon and the glass, electron-energyloss spectrometry (EELS) [5.1,5.2] was carried out across the interfacial region at different locations with different specimen thicknesses. The spectra were measured with an electron beam of $0.7 \mathrm{~nm}$ diameter. A very thin area of the specimen was used to determine its thickness and energy resolution of the system. This was approximately $1.2 \mathrm{eV}$. The loss region containing the $\mathrm{Si}-\mathrm{L}_{2}, 3$ and $\mathrm{B}-\mathrm{K}$ edges was used as it is the most instructive area of the spectra for this material system [5.1]. The results of spot scans are plotted in Figure 5.9. The spectra shows that boron is absent in the amorphous region immediately adjacent to the silicon. The transition from reaction layer to bulk glass spectrum was at $10-20 \mathrm{~nm}$ and varied a little along the interface. In the thinnest specimen area no boron could be detected up to $60 \mathrm{~nm}$ from the interface. This could be a specimen preparation artefact. Therefore, it is 
reasonable to state that an amorphous silica layer of $10-20 \mathrm{~nm}$ thick is formed between the borosilicate glass and the silicon after the reflow bonding. These values compare well with the amount of oxide layer that will grow on silicon when annealed at $700{ }^{\circ} \mathrm{C}$ for $10-20$ hours [5.3]. The reaction layer could not be imaged by energy filtered TEM (EFTEM) due to the weak boron signal on the tail of the Si-L2, 3 edge. Energy dispersive spectroscopy (EDX) did not give conclusive results, as the signal was weak because of the thin specimen and the elements of interest were light.

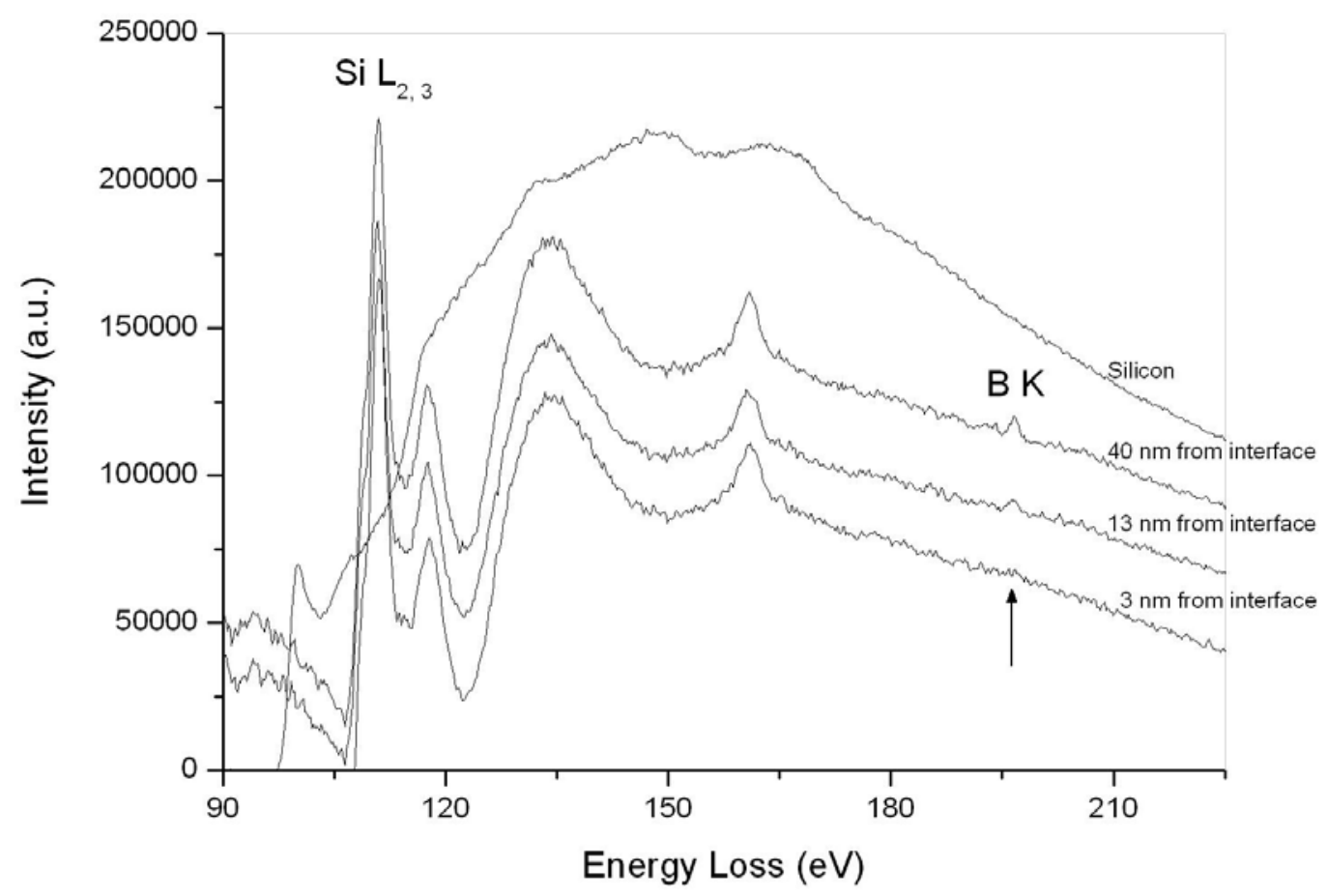

Figure 5.9 Electron-energy-loss spectra from the interfacial region of glass-silicon bonds.

\subsection{Summary}

The bonding has been characterised by electron microscopy. Two types of sample preparation for TEM are described in detail. SEM and TEM of the interface revealed 
that glass is in intimate contact with silicon. The joins did not have any voids, openings or intermediary porous layers. Cristobalite crystals, which are nucleated before the glass-silicon contact is formed, are trapped at the interface and occasionally encountered during microscopy of the bond interface.

Higher resolution microscopy of the joins confirmed that the glass is intact with silicon at atomic scale. EELS scans are taken from the interfacial region. The results revealed the formation of thin amorphous silica layer between the borosilicate glass and the silicon, which could have simply formed by the oxidation of silicon during reflow bonding. Overall, the characterisation of the reflow bonding process by microscopical techniques shows that the joining technology is robust.

\section{References}

[5.1] A. T. J. van Helvoort, K. M. Knowles, R. Holmestad, and J. A. Fernie, Phil. Mag. 84, 505 (2004).

[5.2] D. B. Williams, and C. B. Carter, Transmission Electron Microscopy: A Textbook for Materials Science (Springer, New York, 2009), pp 10-1, 173-92.

[5.3] B. E. Deal, and A. S. Grove, J. Appl. Phys. 36, 3770 (1965). 


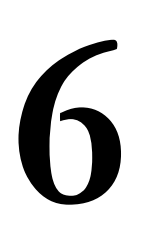

\section{Incorporation of in-plane} electrical interconnects

The incorporation of in-plane electrical interconnects to reflow bonding has been studied in this chapter. After joining the tubes to silicon substrates, the electrically conductive lines will allow probing into the volume confined by the tube. Therefore methods of fabrication of electrical interconnects, which would survive the bonding and not alter the quality of the bond interface, are investigated. 


\subsection{Introduction}

The borosilicate glass tubes are presented as fluidic interconnects to wafer-level microfluidic devices, where reflow bonding is the joining technology of glass tubes to silicon substrates. The connections can be operated at high pressures and are inherently hermetic. However, integrated microfluidic devices incorporate a lot of functionality which usually require electrical interconnects for sensing and actuation. Typical mechanical applications are microvalves, pumps and flow sensors [6.1]. Integrated devices for chemical and biological analysis, optical sensing elements, cooling of electronics [6.2] and manipulation of fluids through electrowetting or electrophoresis [6.3] are other applications that might require electrical interconnects. Therefore, in this chapter, the incorporation of in-plane electrical interconnects to reflow bonding is investigated.

The electrical lines start outside the tube and run through the bond interface allowing access to the volume encapsulated by the tube as depicted in Figure 6.1. The connections should be able to survive the bonding process and preserve the bond quality. The fabricated interconnects should stay conductive and should not produce any direct leak paths or cause reduction in the package strength. 


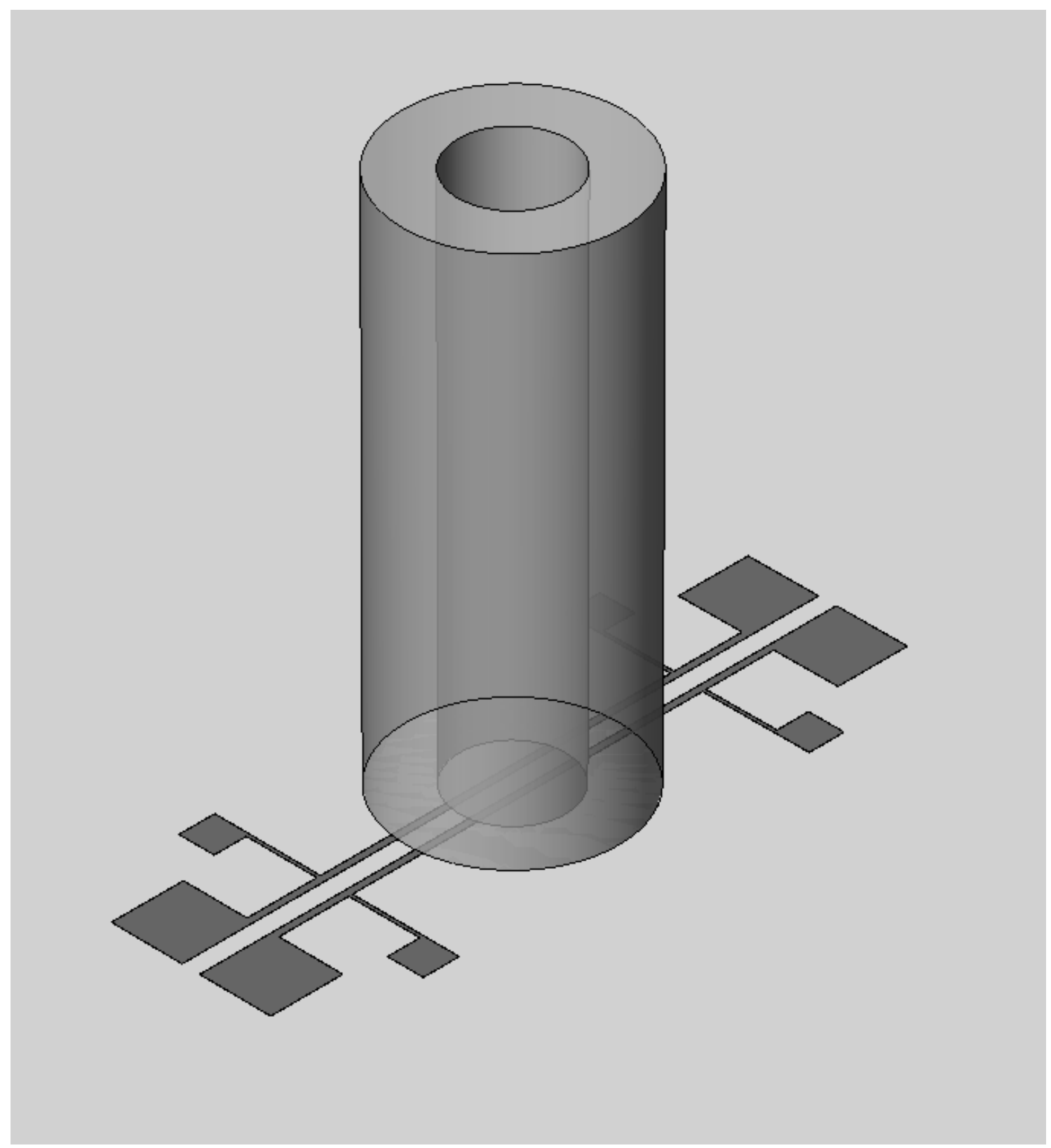

Figure 6.1 Schematic representation of incorporation of in-plane electrical interconnects.

\subsection{Fabrication}

Two types of in-plane electrical interconnects are fabricated for integration to reflow bonding of the glass tubes. The first design is to fabricate boron doped lines in an n-type substrate and the second one is to deposit metal lines. The mask consists of 
two sets of nine different structures with varying parameters. An example is shown in Figure 6.2 labelling the structural parameters. The length of the metallic lines, L, is 10 $\mathrm{mm}$ and always kept the same. The line widths, w, of 100, 200 and $500 \mu \mathrm{m}$ are tested with separations, $\mathrm{r}$, of 200, 500 and $1000 \mu \mathrm{m}$. The glass tubes are bonded to one set of the lines, while the second set acted as a reference point for comparison.
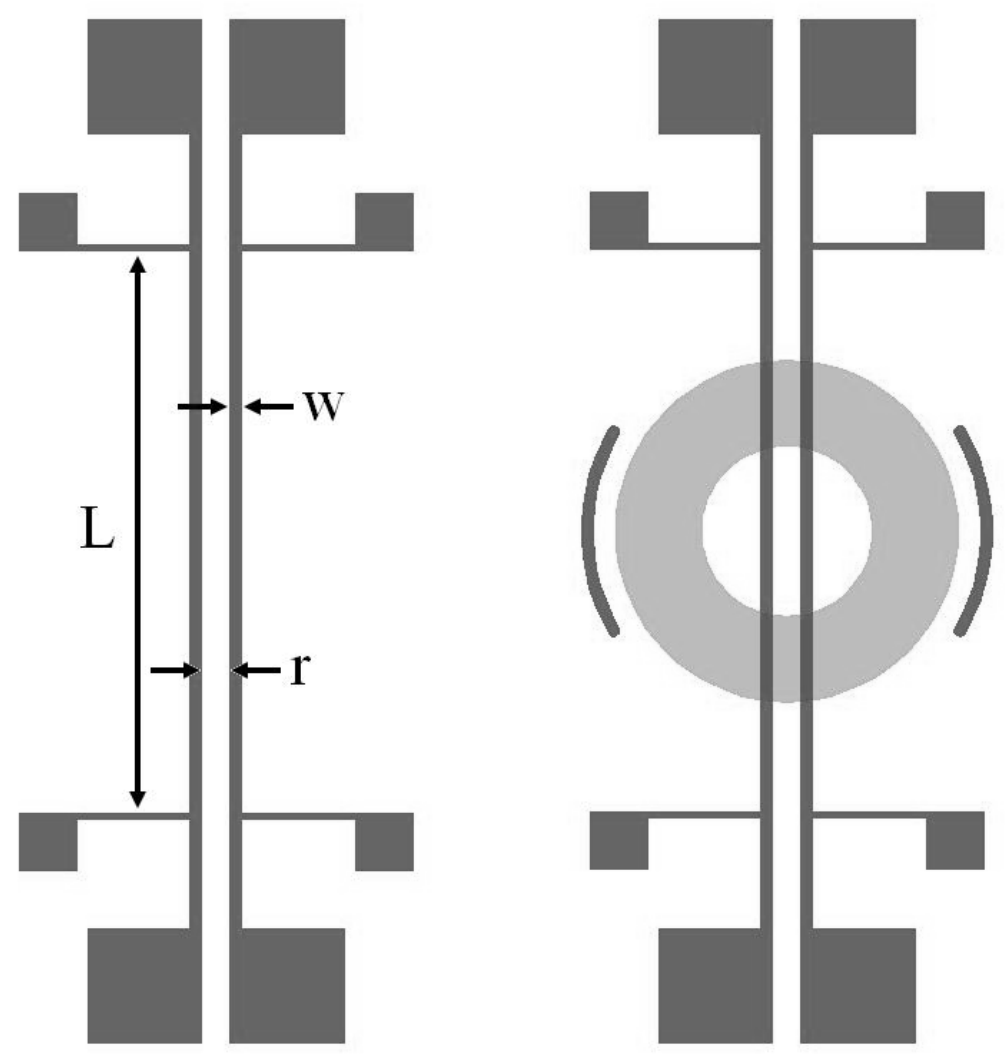

Figure 6.2 Top view of one of the structures in the mask design.

\subsubsection{Doped lines}

Schematics of the fabrication of boron doped lines are displayed in Figure 6.3(a). The selected substrate wafers are lightly n-type doped, $<100>$ oriented, single side 
polished (SSP) wafers of 380 micron thick. The first step is to grow $2 \mu \mathrm{m}$ thick silicon oxide by wet thermal oxidation in a tube oven. Secondly, this oxide layer is patterned in buffered hydrofluoric acid (BHF) using a hard baked photoresist mask. After removing the photoresist in $100 \%$ nitric acid $\left(\mathrm{HNO}_{3}\right)$, the doping can be performed in a tube oven.

Boron nitride wafers were used as solid sources and placed in the wafer boat to face the silicon wafers. During the high temperature diffusion, the boron evaporates in the form of boron trioxide from the solid source and is transferred directly to the surface of the silicon wafer [6.4]. This process is constant-source diffusion as the dopant concentration is held constant at the surface during the diffusion process and is referred as solid source doping (SSD) in this text. After the doping, wells of $\mathrm{p}^{+}$-type are created in junction with the n-type substrate.

SSD was performed at $1000{ }^{\circ} \mathrm{C}, 1050{ }^{\circ} \mathrm{C}$ and $1100{ }^{\circ} \mathrm{C}$ for 60 minutes. After the doping, there was boron-containing residue on the doped regions and it needed to be removed during the removal of the wet thermal oxide mask. Therefore, the following post-doping cleaning was performed. The samples were initially dipped in 50\% HF for 2 minutes. The wet thermal oxide mask was completely removed but the doped regions were not hydrophobic. Therefore the wafers were briefly oxidised at $800^{\circ} \mathrm{C}$ for 30 minutes and etched for another 2 minutes in 50\% HF. After this procedure, the whole silicon surface was clean and hydrophobic. The step heights between the protected and the boron doped regions were measured by Dektak profiler to be approximately $30 \mathrm{~nm}, 50 \mathrm{~nm}$ and $100 \mathrm{~nm}$ for the wafers treated for 60 minutes at $1000{ }^{\circ} \mathrm{C}, 1050{ }^{\circ} \mathrm{C}$ and $1100{ }^{\circ} \mathrm{C}$ respectively. 

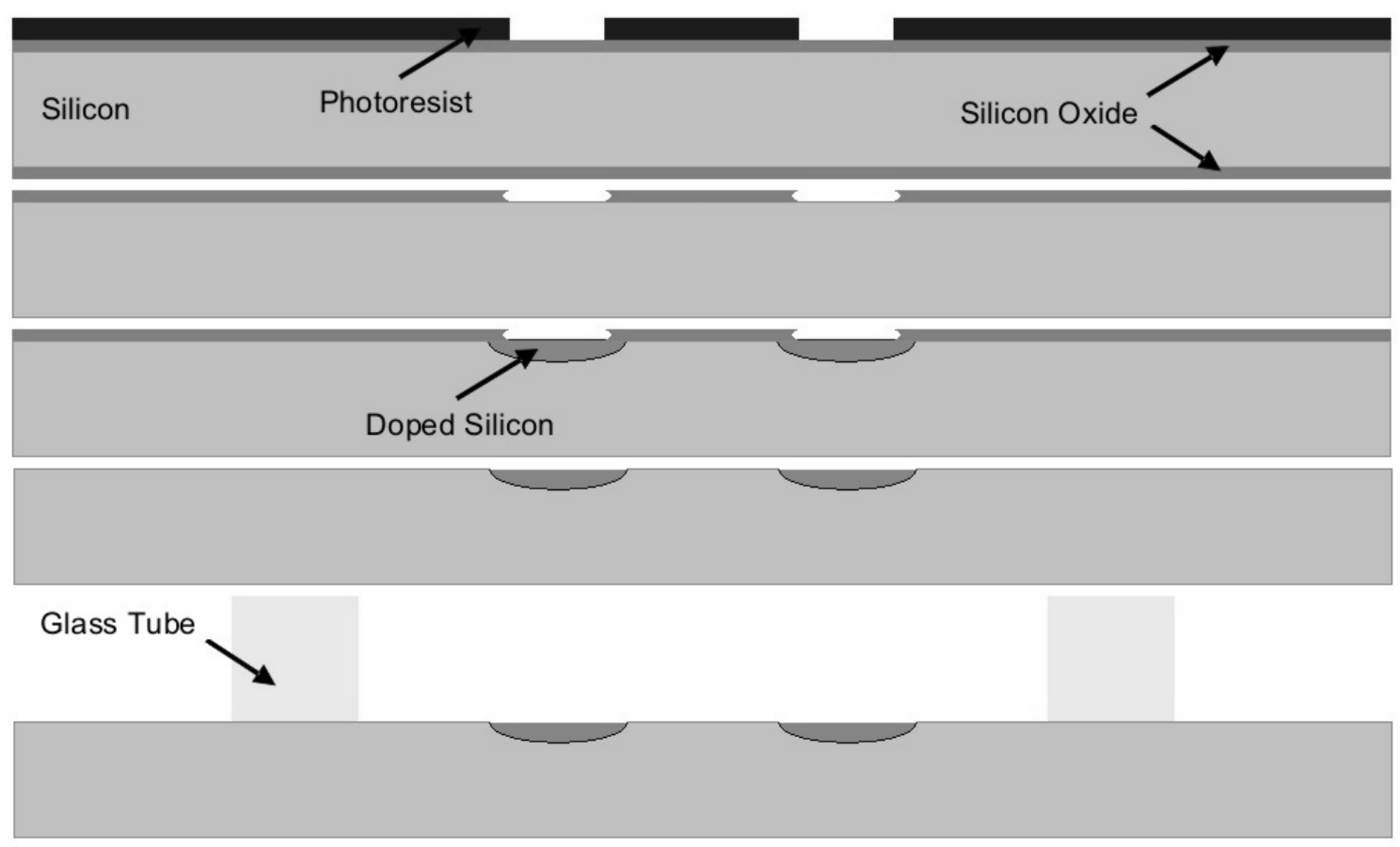

(a)
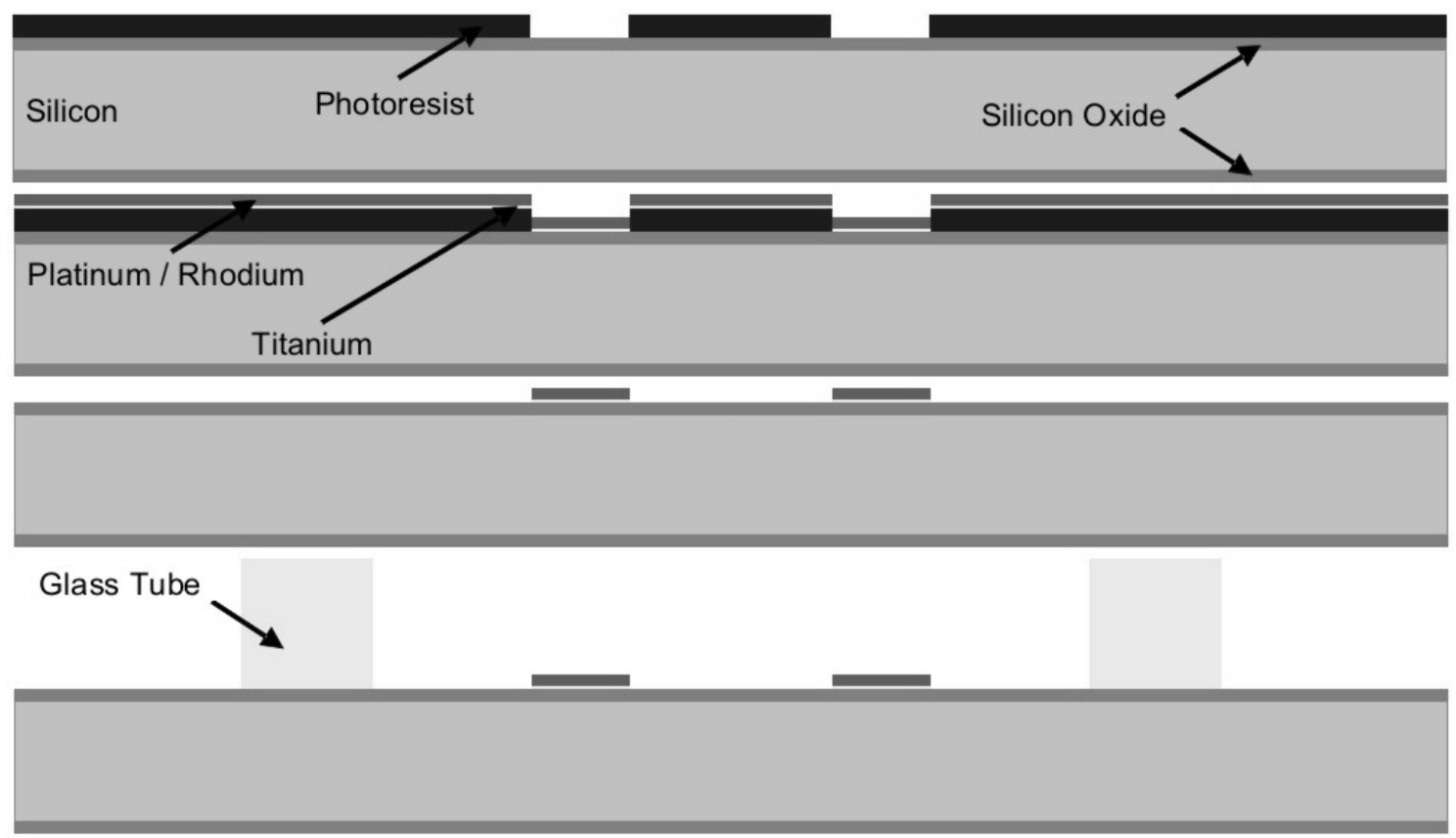

(b)

Figure 6.3 Schematics of the fabrication of (a) boron doped and (b) metallic lines. 


\subsubsection{Metallic lines}

The schematics of the fabrication of metallic lines are displayed in Figure 6.3(b). The selected substrate wafers are $<100>$ oriented, single side polished (SSP) wafers of 525 micron thick. The first step is to grow $310 \mathrm{~nm}$ thick silicon oxide by dry thermal oxidation in a tube oven. This oxide layer will act as a diffusion barrier between the metals and the silicon substrate to prevent formation of silicide [6.5]. After the standard lithography of the oxidised wafers, the metal lines are sputtered in Argon plasma. Before starting sputtering, the deposition chamber is pumped below $210^{-6}$ mbar and the deposition pressure is set to $6.610^{-3}$ mbar regulating the Argon flow. In all of the samples, $10 \mathrm{~nm}$ thick Titanium is deposited on $\mathrm{SiO}_{2} / \mathrm{Si}$ stack as the adhesion layer (or the bond layer) as it is known to react directly with silicon oxide [6.5]. The second metallic layer is the functional layer and it is chosen to be either platinum or rhodium due to their high melting temperature and resistance to oxidation. The thickness of the platinum layer was about $310 \mathrm{~nm}$ and the thickness of the rhodium layer was about $270 \mathrm{~nm}$.

In the last step, the photoresist mask is lifted off to release the metallic interconnects. For effective removal of the photoresist layer, the wafers were put in acetone and isopropanol at $50{ }^{\circ} \mathrm{C}$ in ultrasonic bath for half an hour each and left to dry in open air.

\subsection{Results and discussion}

After the fabrication of both designs, the electrical resistance of the structures were measured and the tube bonding was performed in air as explained in Chapter 2 to test the performance and integrability of each design to the reflow bonding [6.6].

The electrical resistance of these lines were measured both before and after the tube bonding. The lines, which experienced the free surface during the reflow bonding, 
could be distinguished from the ones to which tubes were bonded. The hermeticity of every bonded tube was tested by a helium leak detector. The bond surface between the glass tube and the silicon was sprayed with helium gas to check the existence of apparent leaks. If the detector read a signal, the maximum leak rate was obtained by continuously spraying helium to the leaky region. The last step of characterisation was to measure the burst pressures of the bonded tubes to check if the in-plane electrical interconnects caused any reduction in the strength of the package and change in the fracture behaviour of the silicon membranes.

The effects of the structural parameters and the design approaches will be discussed in light of these test results. If all the results were positive and the connections survived the bonding process without altering the bond quality, the integration can be called successful.

\subsubsection{Electrical resistivity}

The electrical resistances of the fabricated structures were measured with four-point probe method either by obtaining current-voltage curves or simply by multimeter measurements. The electrode configuration is exampled in Figure 6.2, where the connections on the side were used to apply current and the connections on the ends were used to measure the voltage drop.

The electrical resistances of the doped lines were measured in the dark to minimize photocurrents. The junction depths of the diffused layers were measured by the groove-and-stain method [6.4]. The resistance of $10 \mathrm{~mm}$ long doped lines before the bonding with respect to the line width is plotted in Figure 6.4. The sheet resistances and the junction depths of these samples are presented in Table 6.1. The deviation of the measurements was less than $5 \%$ of the value shown for each measurement. The accuracy was limited by the uniformity of the process, rather than the measurement equipment. The real resistance values can be calculated by multiplying the sheet 
resistance by the $2 \mathrm{D}$ aspect ratio of the structure, i.e. the ratio of the length of the structures to its width.

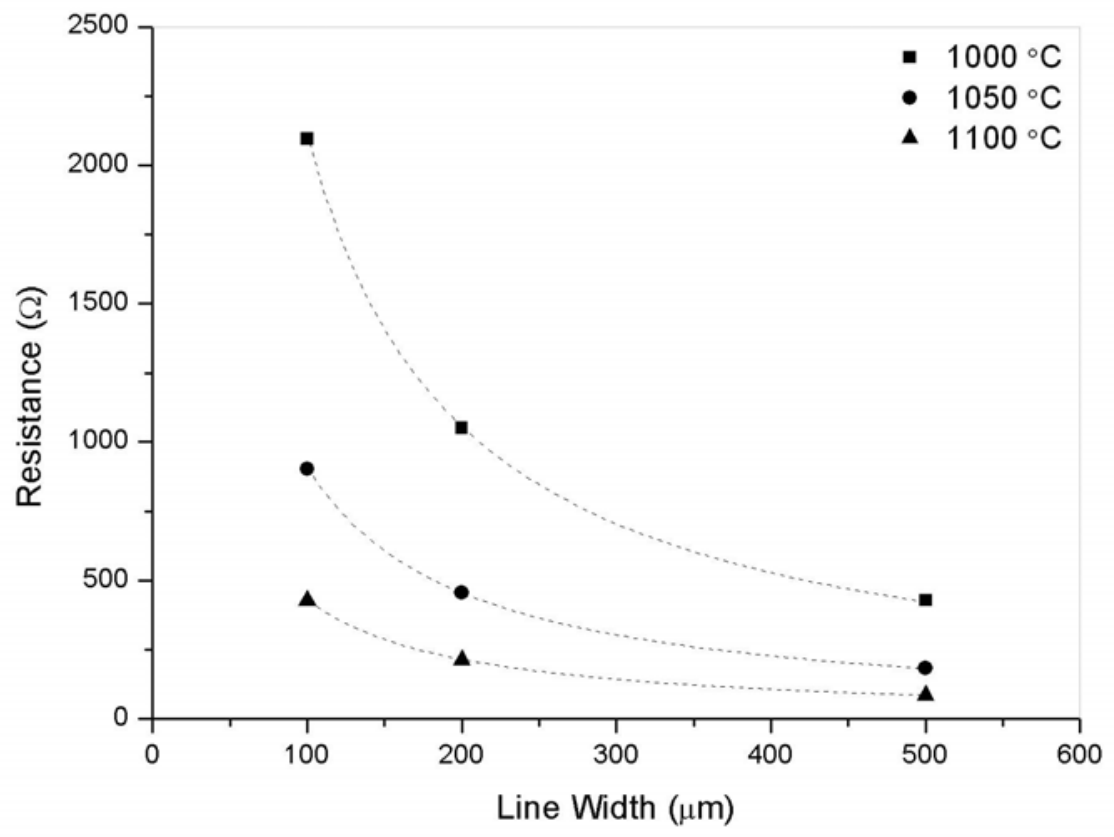

Figure 6.4 Electrical resistances of $10 \mathrm{~mm}$ long boron doped lines at different temperatures with respect to the line widths.

Table 6.1 Sheet resistances and junction depths of boron doped lines at different temperatures.

\begin{tabular}{|c|c|c|c|}
\hline & $1000^{\circ} \mathrm{C} ; 60 \mathrm{~min}$. & $1050^{\circ} \mathrm{C} ; 60 \mathrm{~min}$. & $1100^{\circ} \mathrm{C} ; 60 \mathrm{~min}$. \\
\hline Sheet res. $(\Omega / \square)$ & 21.1 & 9.1 & 4.3 \\
\hline Junc. depth $(\mu \mathrm{m})$ & 0.9 & 1.7 & 2.8 \\
\hline
\end{tabular}


The SSD process is constant-source diffusion because the surface dopant concentration remains the same during the high temperature diffusion and is determined by the solid-solubility limit of boron in silicon [6.4]. For temperatures higher than or equal to $1000{ }^{\circ} \mathrm{C}$, the solid-solubility limit of boron is higher than $10^{20}$ atoms $\mathrm{cm}^{-3}[6.7,6.8,6.9]$. During diffusion of high dopant levels, the impurity concentration is higher than the intrinsic-carrier concentration of silicon and the diffusion coefficient of boron becomes dependent on its local concentration. Therefore, the dopant concentration profile deviates from complementary error function curves and extra measure has to be taken to calculate the junction depth. This effect has been studied in detail by Fair [6.10] and formulated as follows:

$$
\begin{gathered}
x_{j}=2.45\left(\frac{N_{0} D_{i} t}{n_{i}}\right)^{0.5} \\
N_{0}=9.2510^{22} \exp \left(-\frac{0.73}{k T}\right) \\
D_{i}=3.17 \exp \left(-\frac{3.59}{k T}\right) \\
n_{i}=\left(1.510^{33} T^{3} \exp \left(-\frac{1.21}{k T}\right)\right)^{0.5}
\end{gathered}
$$

where $x_{j}$ is the junction depth [6.10] in $\mathrm{cm}, N_{0}$ is the surface concentration and the solid-solubility limit of boron in silicon [6.7] in $\mathrm{cm}^{-3}, D_{i}$ is the intrinsic diffusion coefficient of boron in silicon [6.10] in $\mathrm{cm}^{2} \mathrm{sec}^{-1}, t$ is the high temperature diffusion 
time in sec, $n_{i}$ is the intrinsic-carrier concentration of silicon [6.11] in $\mathrm{cm}^{-3}, k$ is the Boltzmann constant in $\mathrm{eV} \mathrm{K}^{-1}$ and $T$ is the diffusion temperature in $\mathrm{K}$.

If the values of eq. (6.2), (6.3) and (6.4) are substituted in eq. (6.1) for temperatures of $1000{ }^{\circ} \mathrm{C}, 1050{ }^{\circ} \mathrm{C}$ and $1100{ }^{\circ} \mathrm{C}$ and time of 60 minutes, the corresponding junction depths can be calculated as $0.84,1.55$ and 2.72 microns. These values are quite close to the experimental measurements displayed in Table 6.1, especially considering that the diffusion coefficient of boron will be changing more than a factor of ten during the diffusion process between $1000^{\circ} \mathrm{C}$ and $1100{ }^{\circ} \mathrm{C}$ [6.12].

After the analysis of the SSD process, the electrical resistance of the doped lines were measured after the reflow bonding was performed at $700^{\circ} \mathrm{C}$ for 30 hours. The bonding was performed in air environment and therefore the silicon wafers were oxidised about 20-30 $\mathrm{nm}$ [6.13]. Such an oxide layer was thick enough to insulate the test probes from the diffused layer and alter the resistance measurements. Therefore, the wafers were dipped in dilute HF solution after the tube bonding in order to remove the surface oxide layer before the actual resistance measurements. The measurement results after the tube bonding showed that the resistance values increased about 3\% on average. However, the accuracy of the doping process was only better than $5 \%$ and therefore, it can be stated that the increase in the electrical resistance of the doped lines after the bonding was within the error range, i.e. less than $5 \%$.

The metallic lines were deposited on silicon dioxide to form $\mathrm{Pt} / \mathrm{Ti} / \mathrm{SiO}_{2} / \mathrm{Si}$ and $\mathrm{Rh} / \mathrm{Ti} / \mathrm{SiO}_{2} / \mathrm{Si}$ stacks. Titanium was used as the adhesion layer as it is known to react with silicon oxide to form continuous and smooth coverage [6.5]. The thickness of the titanium layer was about $10 \mathrm{~nm}$. The thicknesses of the functional layers were about $310 \mathrm{~nm}$ and $270 \mathrm{~nm}$ for platinum and rhodium respectively. The electrical resistance of $10 \mathrm{~mm}$ long metallic lines before the bonding with respect to the line 
width is plotted in Figure 6.5. The sheet resistances of these samples are presented in Table 6.2. The deviation of the measurements was less than $2 \%$ of the mentioned value. The accuracy was limited by the uniformity of the process, rather than the measurement equipment. The sheet resistance of the rhodium stack was slightly less than the platinum stack, while both of them were about one tenth of the lowest sheet resistance of the boron-doped lines.

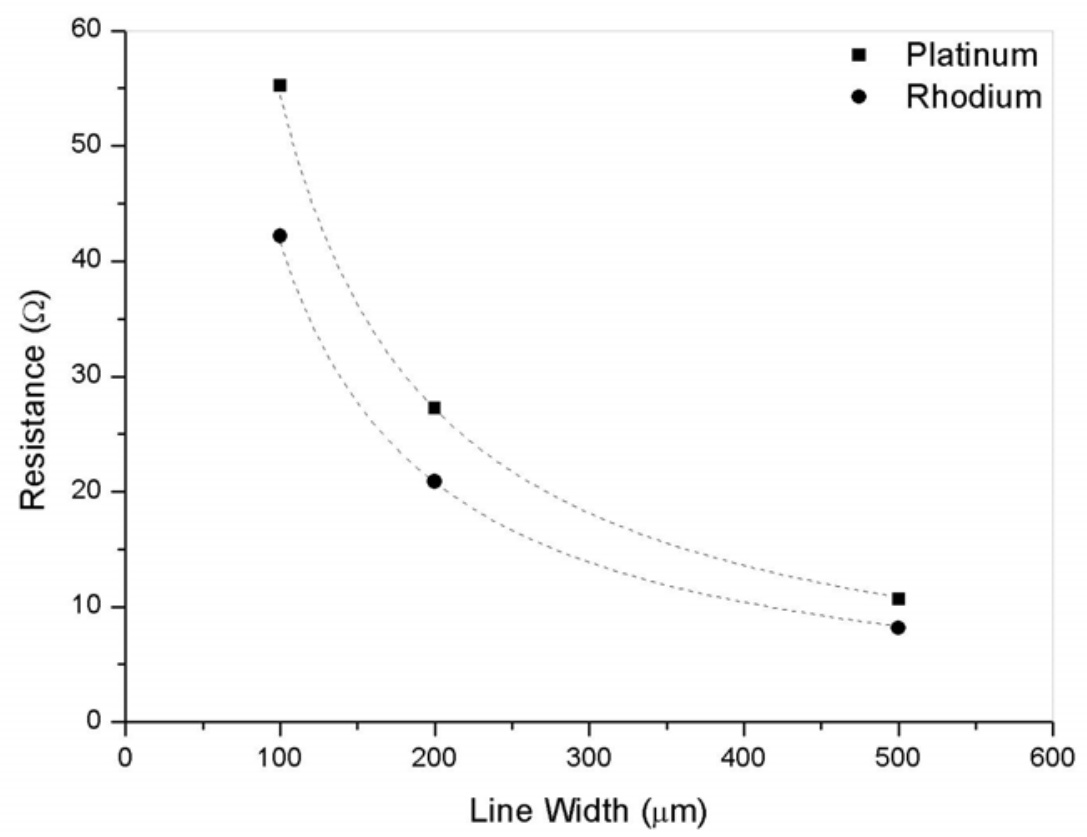

Figure 6.5 Electrical resistances of $10 \mathrm{~mm}$ long metallic lines with respect to the line widths. 
Table 6.2 Sheet resistances of metallic lines as deposited.

\begin{tabular}{|c|c|c|}
\hline & Platinum & Rhodium \\
\hline Sheet res. $(\boldsymbol{\Omega} / \square)$ & 0.54 & 0.42 \\
\hline
\end{tabular}

The electrical resistance of the metallic lines were measured again after the reflow bonding was performed at $700^{\circ} \mathrm{C}$ for 30 hours. The bonding was performed in air environment and therefore oxygen was present in the environment during high temperature annealing. The sheet resistivity of each stack is presented in Table 6.3.

Table 6.3 Sheet resistances of metallic lines after the tube bonding.

\begin{tabular}{|c|c|c|}
\hline & Platinum & Rhodium \\
\hline Sheet res. $(\boldsymbol{\Omega} / \square)$ & 0.47 & $7000-8000$ (without tubes) \\
& & $1000-2000$ (with tubes) \\
\hline
\end{tabular}

The platinum lines stayed conductive and their resistance has slightly decreased, presumably due to healing of the defects and grain growth [6.14]. An atomic force micrograph (AFM) of the surface of platinum layer after the bonding is displayed in Figure 6.6(a). The grain growth and hillock formation in the platinum layer are clearly visible in the topography. The scanning electron micrograph (SEM) of the cross-sectional view of the stack in Figure 6.6(b) indicates the porosity of the large grains. 
When Olowolafe et al. [6.15] and Kreider et al. [6.16] investigated the post-deposition annealing (PDA) of $\mathrm{Pt} / \mathrm{Ti} / \mathrm{SiO}_{2} / \mathrm{Si}$ stack at high temperature, they observed that the platinum layer on the surface remained unreacted even if oxygen was present in the annealing ambient. In agreement with their results, energy dispersive $\mathrm{x}$-ray analysis in the scanning electron microscope confirmed that the platinum layer was not oxidised. Relevantly, the base thickness of the platinum layer is observed to remain constant after the annealing at $700{ }^{\circ} \mathrm{C}$ in air environment.

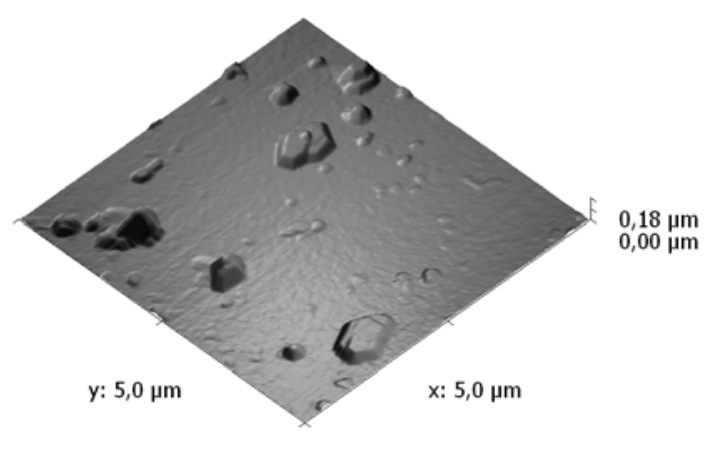

(a)

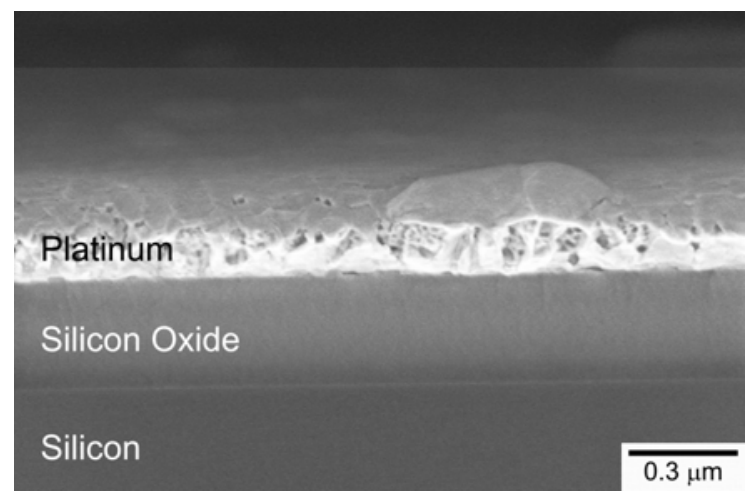

(b)

Figure 6.6 The platinum layer is annealed at $700{ }^{\circ} \mathrm{C}$ for 30 hours in air environment for the tube bonding. (a) The surface is examined in an atomic force microscope and (b) the cross-section is examined in a scanning electron microscope.

The rhodium lines lost their conductivity and their resistance strongly increased. In the presence of oxygen, rhodium starts to oxidise above $600{ }^{\circ} \mathrm{C}$ [6.17]. At and above $700{ }^{\circ} \mathrm{C}$, the oxide layers grow on the surface in the form of $\mathrm{Rh}_{2} \mathrm{O}_{3}$ which is a stable product until around $1000{ }^{\circ} \mathrm{C}$ [6.17]. Although, the lines on which the tubes were bonded showed a lower resistivity, their sheet resistance were higher than $1000 \Omega / \square$. An AFM of the surface of rhodium layer after the bonding is displayed in Figure 6.7(a) with a SEM of the cross-sectional view of the stack in Figure 6.7(b). Energy 
dispersive $\mathrm{x}$-ray analysis in the scanning electron microscope confirmed that the rhodium layer was oxidised. The base layer thickness of the rhodium layer was measured to be $580 \mathrm{~nm}$, which is higher than twice its initial thickness. The reason is ascribed to the weight gain during oxidation.

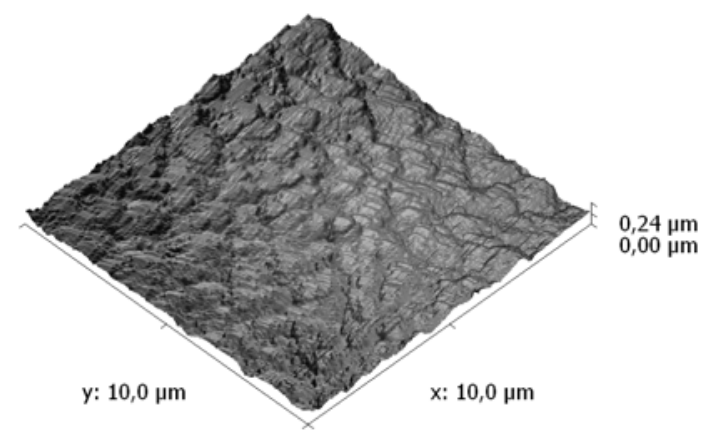

(a)

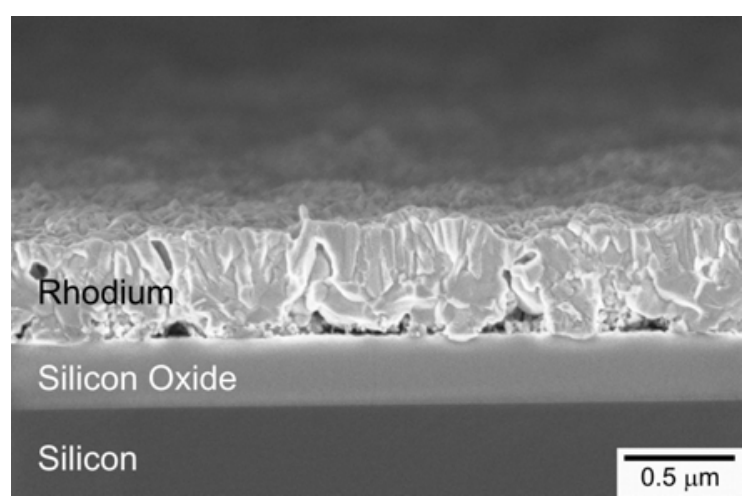

(b)

Figure 6.7 The rhodium layer is annealed at $700{ }^{\circ} \mathrm{C}$ for 30 hours in air environment for the tube bonding. (a) The surface is examined in an atomic force microscope and (b) the cross-section is examined in a scanning electron microscope.

\subsubsection{Hermeticity}

The hermeticity of every bonded tube was tested by a Leybold UL 500 helium leak detector. The open side of the tubes was connected to the detector through a flange and pumped down to the background pressure of $0.5 \mathrm{~Pa}$. The bond between the glass tube and the silicon was sprayed with helium gas. If there was an apparent leak, helium molecules could migrate through direct paths and the detector read a signal as long as it is above $10^{-9} \mathrm{~Pa} \mathrm{~m}^{3} \mathrm{sec}^{-1}$. The maximum signal was obtained by continuously spraying helium to the leaky region and the leak rates were recorded. As the result of described leak test, all of the tubes bonded to the boron doped electrical interconnects were found to be hermetic. In other words, the helium leak detector did not read any signal and the doped lines did not cause any instant leak above 
$10^{-9} \mathrm{~Pa} \mathrm{~m}^{3} \mathrm{sec}^{-1}$. However, all of the tubes bonded to the metallic electrical interconnects were found to be leaking. The maximum level of flux was measured to be about $10^{-6} \mathrm{~Pa} \mathrm{~m}^{3} \mathrm{sec}^{-1}$ for $\mathrm{Pt} / \mathrm{Ti} / \mathrm{SiO}_{2} / \mathrm{Si}$ stack and $310^{-6} \mathrm{~Pa} \mathrm{~m}^{3} \mathrm{sec}^{-1}$ for $\mathrm{Rh} / \mathrm{Ti} / \mathrm{SiO}_{2} / \mathrm{Si}$ stack. No correlation between the structural parameters of the lines and the leak values could be found.

\subsubsection{Bond strength}

The electrical interconnects running through the bond interface might reduce the maximum pressure to which the assembly can be subjected and cause change in the fracture behaviour of the silicon membranes. Therefore, the burst pressure of every bonded tube was tested to measure the effect of in-plane electrical interconnects on the strength of the package. As explained in previous chapters, the bonded glass tubes were connected to a water pump set-up and pressurised until the failure of the assembly to record the burst pressure values and establish the mechanism of failure.

The burst pressures of the silicon-glass assembly containing the boron doped electrical interconnects were measured and the results are shown in Table 6.4. All of the pressurised samples were found to fracture in the silicon plate. The values are similar to those obtained by testing non-processed 380 micron thick silicon wafers [6.6]. The step between the protected and the doped regions were completely filled by the softened glass and the fracture mechanism of the silicon substrates with boron doped lines was the same as non-processed substrates. Therefore, the doped lines can be said to cause no reduction in the strength of the bonds or the mechanism failure of the assembly. 
Table 6.4 Burst pressures of $<100>$ single side polished silicon wafers of $380 \mu \mathrm{m}$ thick, containing boron doped lines at different temperatures, after the tube bonding.

\begin{tabular}{|l|c|c|c|}
\hline & $1000^{\circ} \mathrm{C} ; 60 \mathrm{~min}$. & $1050^{\circ} \mathrm{C} ; 60 \mathrm{~min}$. & $1100^{\circ} \mathrm{C} ; 60 \mathrm{~min}$. \\
\hline Burst pressures $(\mathrm{MPa})$ & $5.71 \pm 0.16$ & $5.71 \pm 0.18$ & $5.66 \pm 0.1$ \\
\hline
\end{tabular}

The burst pressure of the silicon-glass assembly containing the metal electrical interconnects were measured and the results are shown in Table 6.5. All of the pressurised samples were found to fracture in the silicon plate. The burst pressures of the samples containing platinum lines are similar to those obtained by testing non-processed 525 micron thick silicon wafers [6.6]. However, it is good to notice that the burst pressures of the samples containing rhodium lines are more scattered and lower than non-processed wafers.

Table 6.5 Burst pressures of $<100>$ single side polished silicon wafers of $525 \mu \mathrm{m}$ thick, containing different types of metallic lines, after the tube bonding.

\begin{tabular}{|l|c|c|}
\hline & Platinum & Rhodium \\
\hline Burst pressures $(\mathrm{MPa})$ & $7.53 \pm 0.53$ & $6.79 \pm 0.74$ \\
\hline
\end{tabular}

During the $\mathrm{PDA}$ of $\mathrm{Pt} / \mathrm{Ti} / \mathrm{SiO}_{2} / \mathrm{Si}$ stack, the thin titanium layer at the interface can oxidise [6.15]. The oxidation of the titanium bond layer can lead to coalescence of the platinum layer and the loss of adhesion was observed with surface roughening in the platinum layer [6.16]. In agreement with the literature, the platinum layer peeled off the underlying substrate. A scanning electron micrograph of partly stripped platinum 
layer is shown in Figure 6.8(a) from an oblique view. This is the edge of the sample, of which the cross section was presented in Figure 6.6(b). Another example is displayed in Figure 6.8(b), which is the surface of a ruptured silicon piece containing platinum lines. The crack initiated in the glass tube near its inner rim before propagating into the silicon and the neighbouring platinum layers at the interface stayed on the fracture surface of the glass tube. The loss of adhesion of the platinum layer after the annealing was the reason of apparent leaks discussed in the previous section.

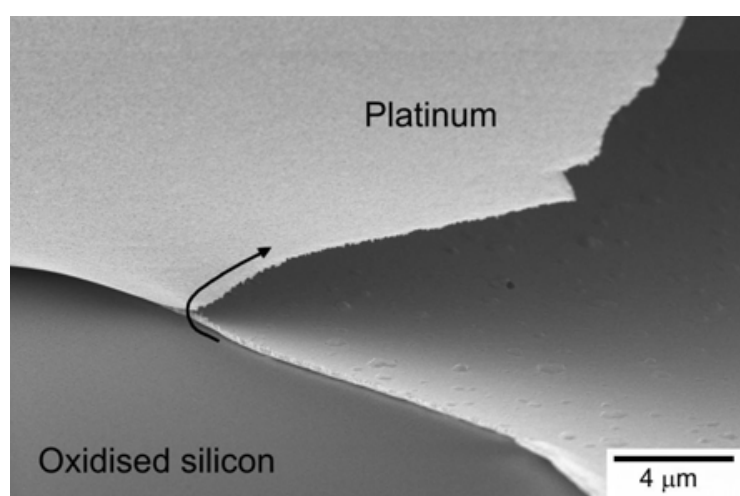

(a)

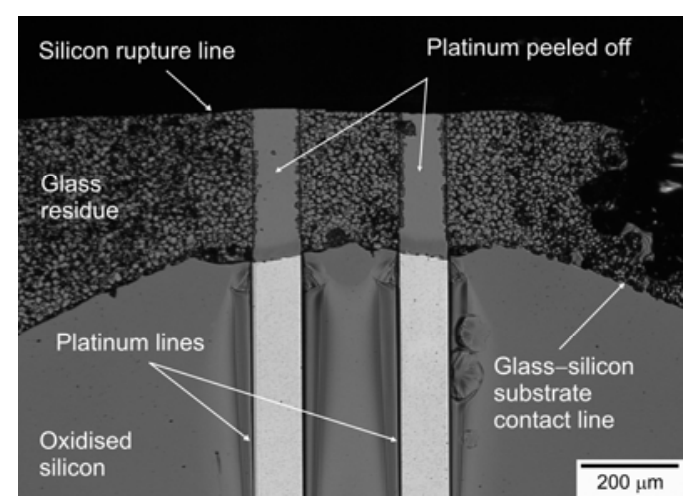

(b)

Figure 6.8 (a) Oblique view of the platinum layer, which is peeled off the silicon substrate after annealing at $700{ }^{\circ} \mathrm{C}$ for 30 hours in air environment. (b) Top view of the edge of a fractured silicon plate containing platinum lines after the tube bonding and burst pressure test. The lines at the glass tube-silicon interface are stripped off the silicon piece during the fracture of pressurised assembly.

During the PDA of $\mathrm{Rh} / \mathrm{Ti} / \mathrm{SiO}_{2} / \mathrm{Si}$ stack, the rhodium layer was oxidised [6.17] and thickened from $270 \mathrm{~nm}$ to $580 \mathrm{~nm}$. Just as with the platinum lines, the rhodium lines lost their adhesion to the underlying silicon substrates. In addition, the rhodium lines at the glass tube-substrate wafer interface were cracked. The oxidation and the cracking behaviour of these lines are thought to have altered the electrical resistance 
measurements and the stiction problem after the annealing is the reason of apparent leaks discussed in the previous section.

\subsection{Summary}

The incorporation of electrical interconnects to reflow bonding is required for probing to the volume encapsulated by the tube and is therefore investigated. Two types of electrical lines were tested for integrability to tube bonding. The first design was to fabricate boron-doped lines in an n-type substrate. The sheet resistances between $5-20 \Omega / \square$ were obtained after doping. The conductivity of the lines did not change after the reflow bonding. The doped lines did not cause any leakage or reduction in the strength of the tube-silicon assembly.

The second design was to deposit metal lines. Platinum or rhodium metallic lines were deposited on oxidised silicon using titanium adhesion layer to form $\mathrm{Pt} / \mathrm{Ti} / \mathrm{SiO}_{2} / \mathrm{Si}$ or $\mathrm{Rh} / \mathrm{Ti} / \mathrm{SiO}_{2} / \mathrm{Si}$ stack. The sheet resistance of both types of metal were about $0.5 \Omega / \square$ after deposition. After the reflow bonding, the resistivity of platinum lines slightly reduced while the rhodium lines lost their conductivity. Both types of metallic interconnects caused direct leak paths through the bond interface. Although the presence of these metallic lines did not considerably affect the strength of the glass tube-silicon join, both types of metals lost adhesion to the underlying silicon substrate after the post-deposition annealing for the reflow bonding. In the light of these results, it was concluded that the doping process is easily integrable to the reflow bonding, as they survive the bonding process and preserve the bond quality. 


\section{References}

[6.1] P. Gravesen, J. Branebjerg, and O. S. Jensen, J. Micromech. Microeng. 3, 168 (1993).

[6.2] D. Erickson, and D. Li, Anal. Chim. Acta 507, 11 (2004).

[6.3] T. M. Squires, and S. R. Quake, Rev. Mod. Phys. 77, 977 (2005).

[6.4] R. C. Jaeger, Introduction to microelectronic fabrication: Modular series on solid state devices-vol. 5, edited by G. W. Neudeck and R. F. Pierret, (AddisonWesley, Reading, MA, 1993) pp 49-83.

[6.5] M. Liehr, F. K. LeGoues, G. W. Rubloff, and P. S. Ho, J. Vac. Sci. Technol. A 3, 983 (1985).

[6.6] B. Moğulkoç, H. V. Jansen, J. W. Berenschot, H. J. M. ter Brake, K. M. Knowles, and M. C. Elwenspoek, J. Micromech. Microeng. 19, 085027 (2009).

[6.7] A. Armigliato, D. Nobili, P. Ostoja, M. Servidori, and S. Solmi, Semiconductor Silicon 1977, pp 638-47.

[6.8] G. L. Vick, and K. M. Whittle, J. Electrochem. Soc. 116, 1142 (1969).

[6.9] R. B. Fair, Semiconductor Silicon 1977: Proceedings of the Third International Symposium on Silicon Materials Science and Technology, edited by H. R. Huff, E. Sirtl, pp 968-87.

[6.10] R. B. Fair, J. Electrochem. Soc. 122, 800 (1975).

[6.11] F. J. Morin, and J. P. Maita, Phys. Rev. 96, 28 (1954). 
[6.12] S. Matsumoto, Y. Ishikawa, Y. Shirai, S. Sekine, and T. Niimi, Jpn. J. Appl. Phys. 19, 217 (1980).

[6.13] B. E. Deal, and A. S. Grove, J. Appl. Phys. 36, 3770 (1965).

[6.14] D.-S. Lee, D.-Y. Park, H.-J. Woo, S.-H. Kim, J. Ha, and E. Yoon, Jpn. J. Appl. Phys. 40, L1 (2001).

[6.15] J. O. Olowolafe, R. E. Jones Jr., A. C. Campbell, R. I. Hegde, C. J. Mogab, and R. B. Gregory, J. Appl. Phys. 73, 1764 (1993).

[6.16] K. G. Kreider, and G. Gillen, Thin Solid Films 376, 32 (2000).

[6.17] L. A. Carol, and G. S. Mann, Oxid. Met. 34, 1 (1990). 


\section{7}

\section{Example applications of}

\section{MEMS-on-tube assembly}

Examples of applications of borosilicate glass tubes as package or fluidic interconnects are given in this chapter. Numerous micro- and nano-devices built on MEMS-on-tube assembly are presented and the concept of long term encapsulation of MEMS structures under vacuum or selected gas environments is explained. 


\subsection{Introduction}

Reflow bonding of glass tubes to silicon wafers was studied as it presents great potential for various microsystems applications. As explained in the previous chapters, the connections were tested to be hermetically sealed and can be safely operated at high pressures. The tubes are directly connectable to Swagelok connectors, hence to the macro-world and test equipment, allowing to interpret it as a package for the so-called MEMS-on-tube assembly. Therefore, this patented technology provides successful interconnection to the wafer level devices manufactured by conventional methods of microfabrication.

Typical applications are the interfacing of fabricated microfluidic devices using this mask-less and adhesive free process. From another perspective, its ability to hermetically seal the silicon substrates can potentially provide a long term vacuum encapsulation if the bonding is done under vacuum conditions.

\subsection{Microfluidic devices}

Many microfluidic devices can be built on MEMS-on-tube assembly. The functional layers can be manufactured in planar substrates using lithographic processes and the tubes can be used to interface the printed micrometre nanometre sized features. Several applications such as particle filtering and gas separation using microsieves or dense inorganic membranes were demonstrated by Unnikrishnan et al. [7.1, 7.2]. A glass tube bonded to $90 \mu \mathrm{m}$ thick silicon microsieve with pores of $5 \mu \mathrm{m}$ in diameter is shown in Figure 7.1 for illustration of an assembled particle filter. A scanning electron micrograph of another glass tube bonded to silicon microsieve that supports a $50 \mathrm{~nm}$ thick $\mathrm{SiO}_{2}$ membrane is shown in Figure 7.2, where the cylindrical shaped silica membrane enables selective permeation for gas separation. Other examples are 
to mount check valves on the tube ends [7.1] or to interface fabricated microneedles for drug delivery or preparation of emulsions [7.2].

Louwerse et al. [7.3] drew attention to the possibility of stacking modular components in the bonded glass tubes to build a miniaturised propulsion unit for microsatellites as shown in Figure 7.3. The nozzle of the microthruster was fabricated by planar processes and the glass tube was bonded to act as a package for integration of the required components as well as an interface for the flow of propellant.

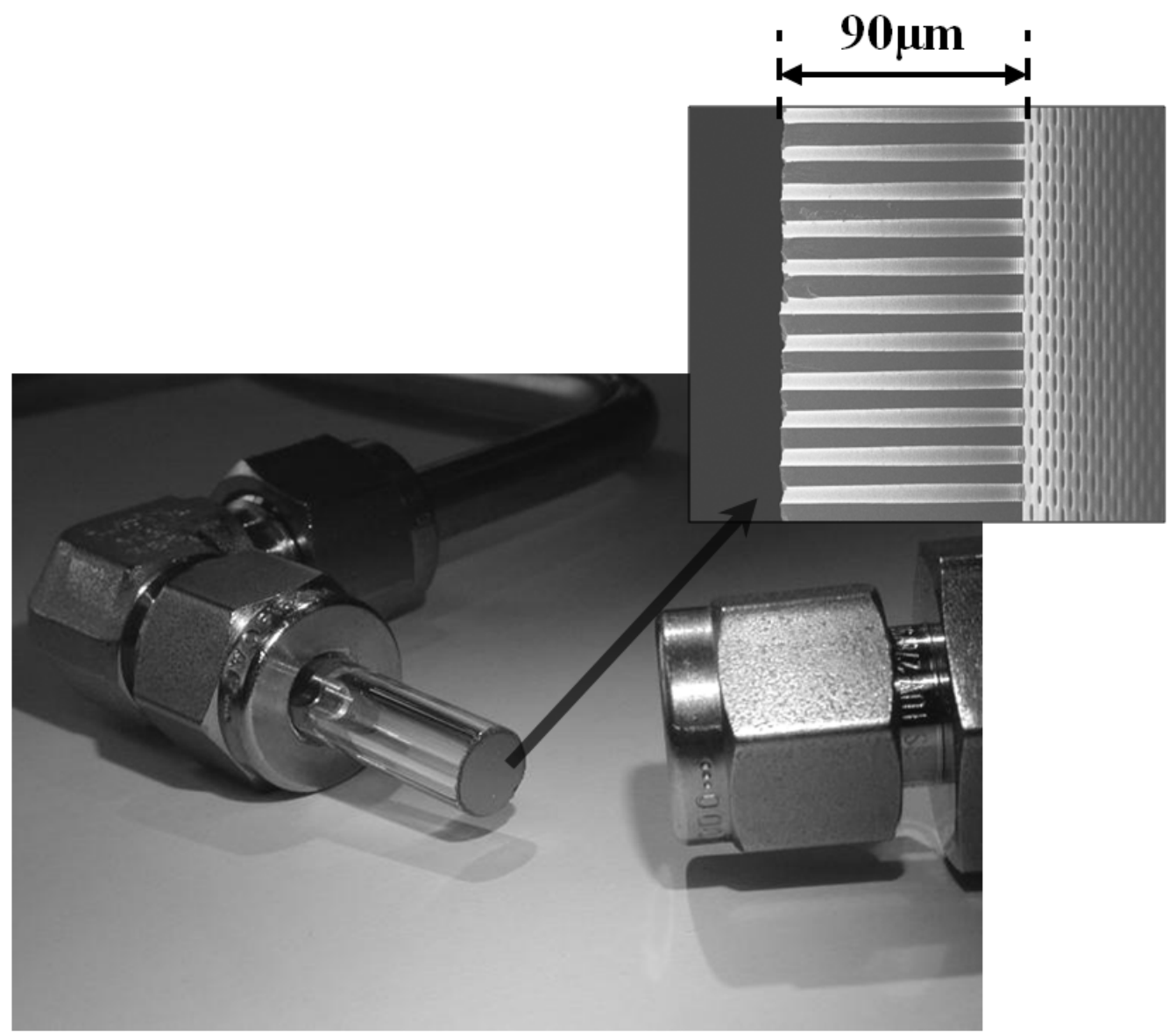

Figure 7.1 A glass tube bonded to $90 \mu \mathrm{m}$ thick silicon microsieve with pores of $5 \mu \mathrm{m}$ in diameter and coupled to Swagelok connectors. The close-up shows the cross-section of microsieve to be used as a particle filter [7.1]. 


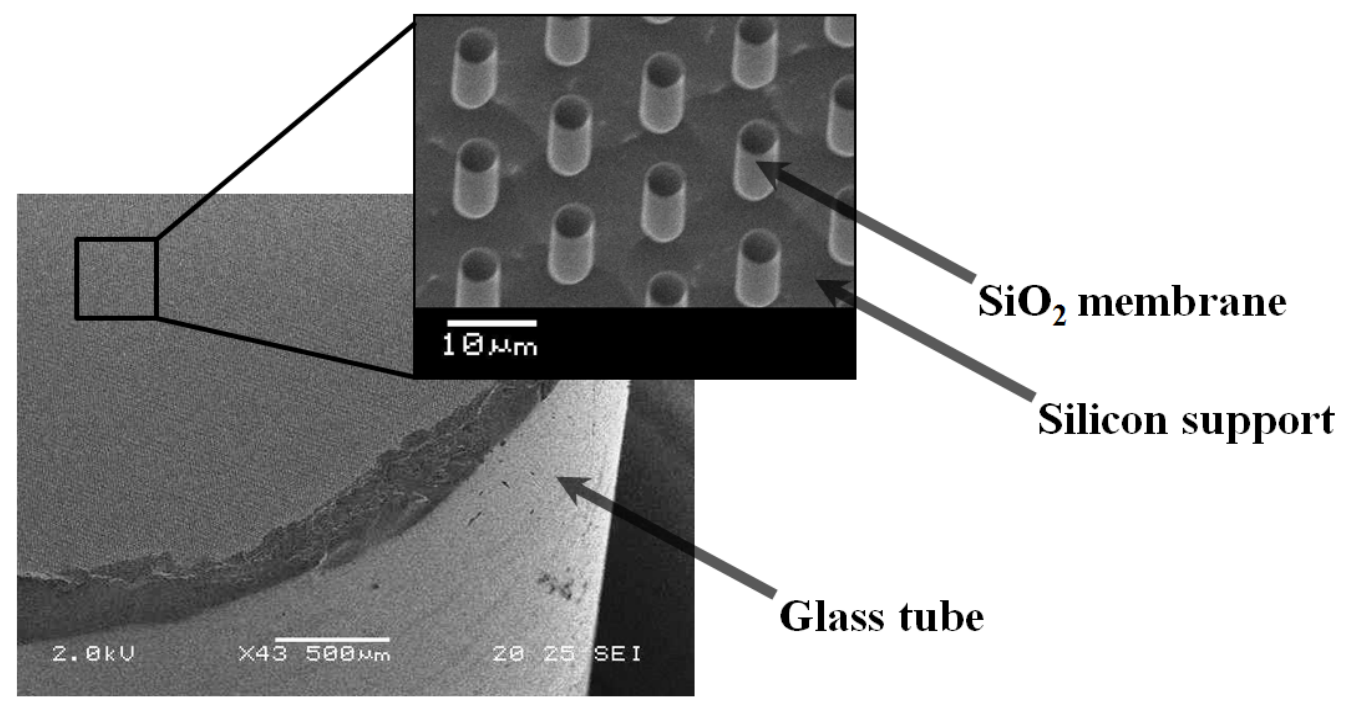

Figure 7.2 A glass tube bonded to a silicon microsieve, which supports a $50 \mathrm{~nm}$ thick corrugated $\mathrm{SiO}_{2}$ membrane. The close-up details the cylindrical shaped silica membrane and the silicon support [7.1].

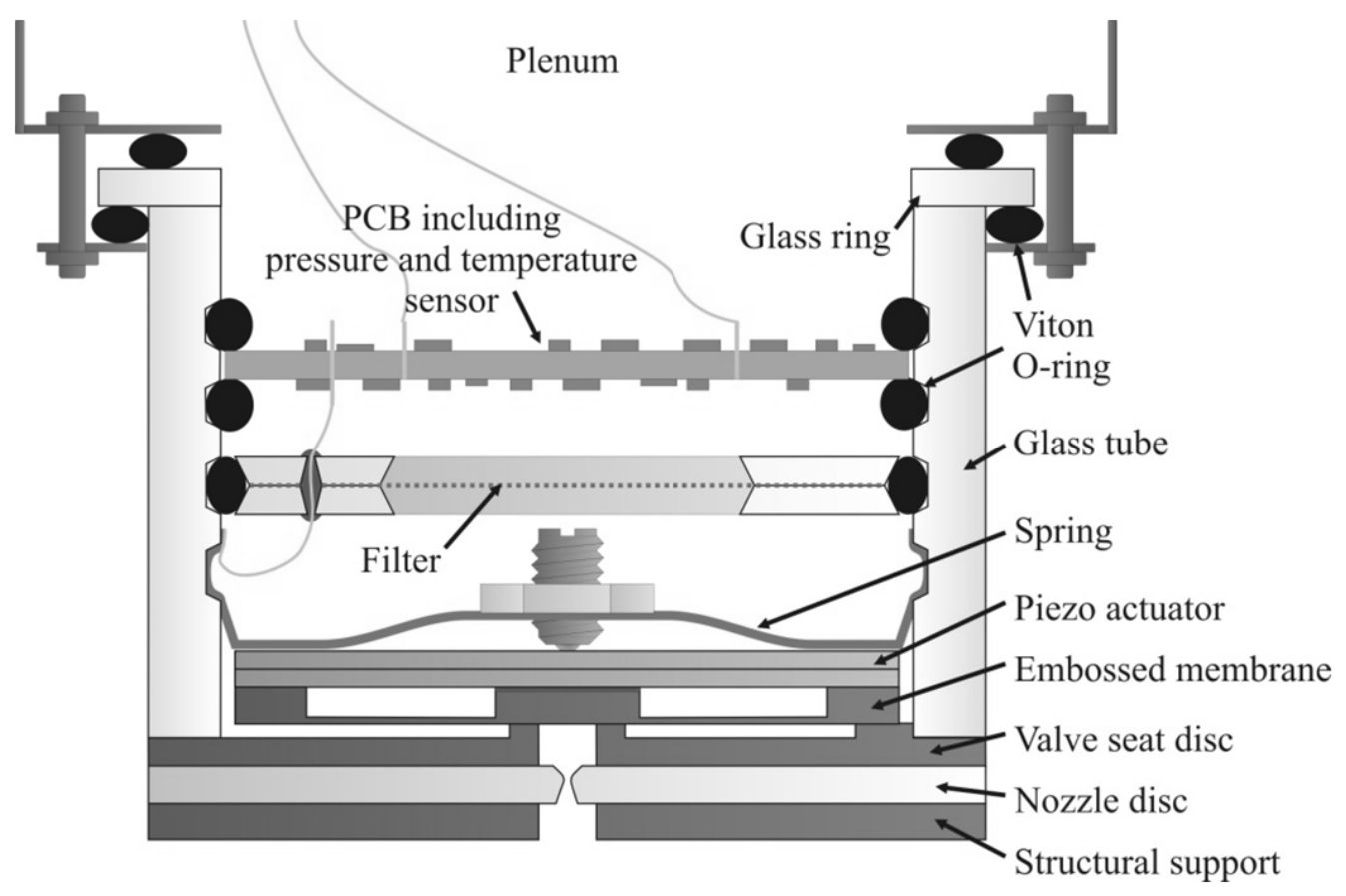

Figure 7.3 Schematic of a miniature thruster system designed for propulsion of microsatellites. The glass tube is bonded to the microfabricated nozzle to act as a package for the integration of modular parts [7.3]. 


\subsection{Long-term vacuum encapsulation}

If the bonding is done in a vacuum oven and the glass tube or ring is placed between two pieces of smooth silicon, the volume inside the tube can still be pumped down before the rise of the temperature. That is allowed by the direct paths on the tube ends which do not possess the qualities to have direct bonding or pre-bonding at room temperature.

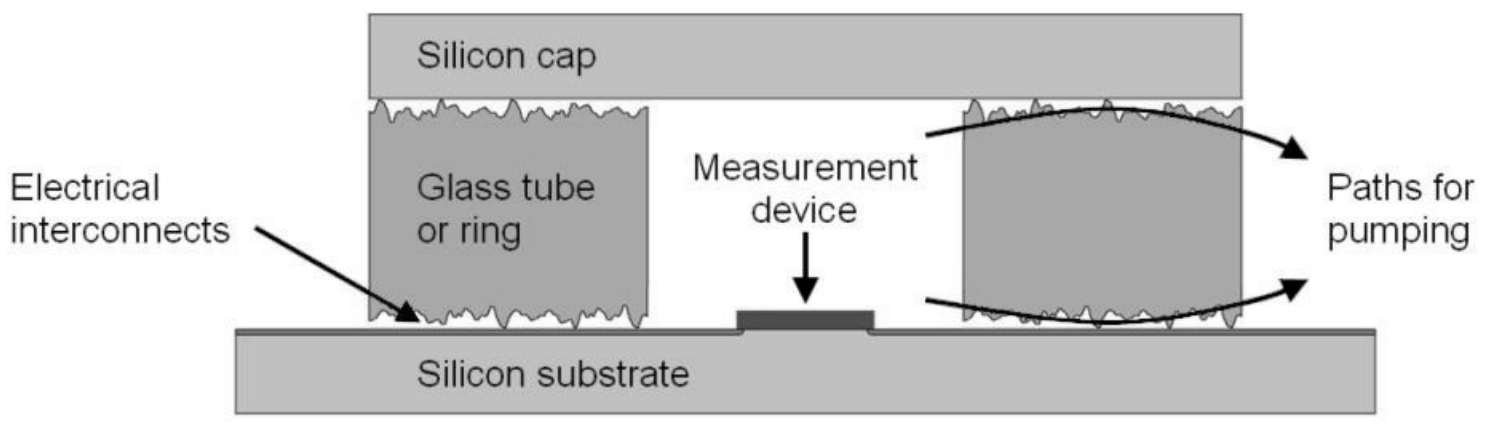

Figure 7.4 Cross-section of a specimen before the bonding is performed in vacuum.

The cross-section of a rough glass tube sandwiched by two silicon layers is shown in Figure 7.4. After the initial pump down, the specimen can be annealed below the transition temperature of the glass for a couple of hours to allow outgassing of the materials. Then the temperature can be raised and the bonding can be performed. After this step, the oven should not be vented until the specimen cools below $100{ }^{\circ} \mathrm{C}$ in order to prevent any disturbance. In the end, a vacuum will be trapped in the volume encapsulated by the silicon layers and the tube or ring.

For monitoring the vacuum level over time, a measurement device can be designed and built in the silicon substrate layer before the bonding as displayed in Figure 7.4. In-plane electrical leads will be of prime importance for the communication between 
the device inside the tube volume and the outside air atmosphere. One possibility is to build an on-chip Pirani gauge for the measurement of the vacuum. Another possibility is to use a mechanical resonator and measure its Q-factor over time to assess the pressure development of the cavity. The final product is depicted in Figure 7.5. The most important requirement for this device to be designed is that it should be able to survive the bonding step. The technique can also allow encapsulation of MEMS structures/devices under selected gas environments.

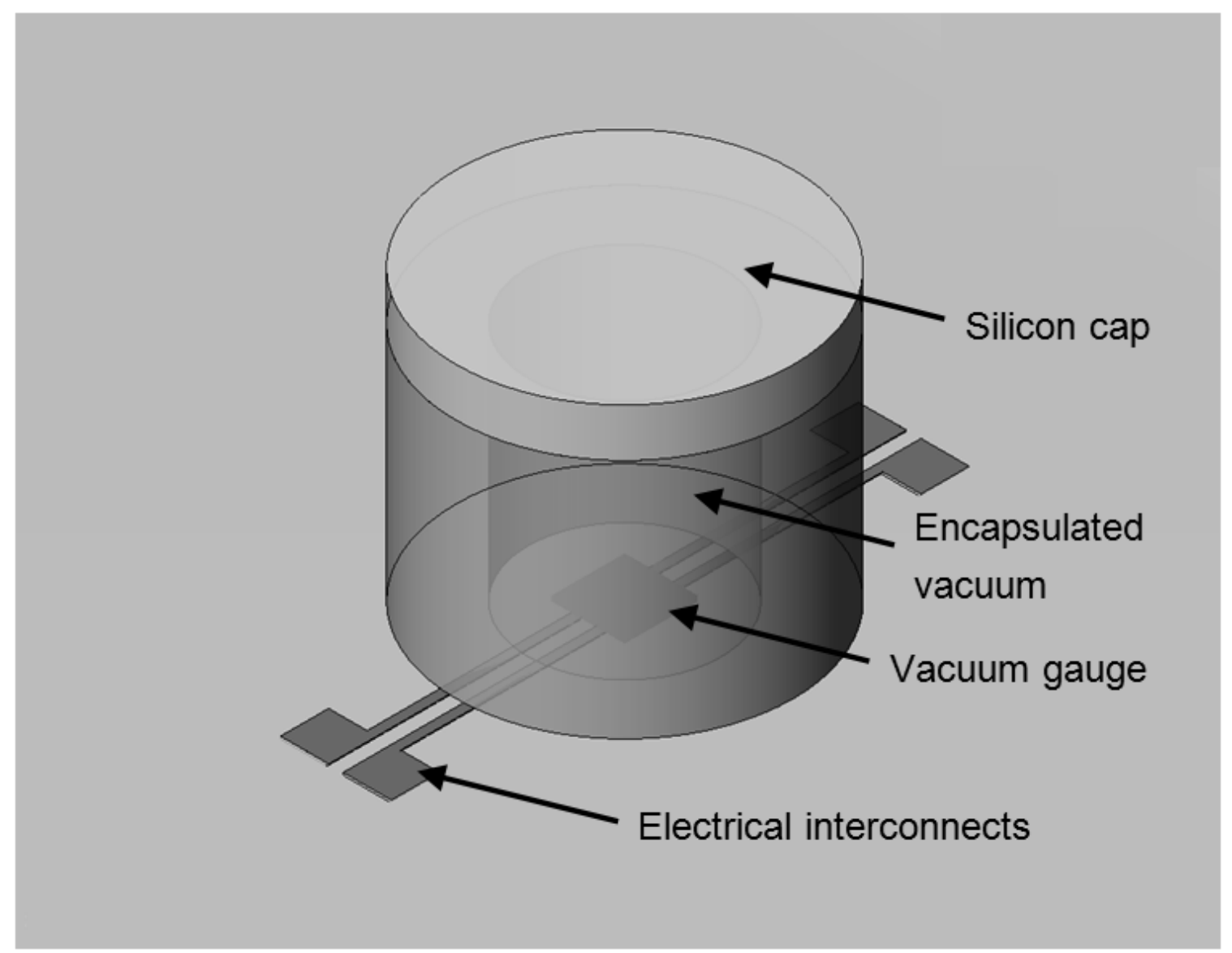

Figure 7.5 Final product after the vacuum bonding to seal the volume enclosed by the glass tube or ring. 


\subsection{Summary}

Microsieves, gas separation membranes, check valves and micro-propulsion units were demonstrated to be among the microfluidic devices which can be interfaced by or built in the borosilicate glass tubes. The long term encapsulation of MEMS structures under vacuum or selected gas environments is another potential use of the reflow bonding. The applications of MEMS-on-tube assembly are not limited to what is presented in this chapter and the reflow bonding of glass tubes presents a versatile technology for packaging and interfacing microstructures.

\section{References}

[7.1] S. Unnikrishnan, H. V. Jansen, J. W. Berenschot, B. Mogulkoc, and M. C. Elwenspoek, Lab chip 9, 1966 (2009).

[7.2] S. Unnikrishnan, H. V. Jansen, J. W. Berenschot, I. Fazal, M. C. Louwerse, B. Mogulkoc, R. Sanders, M. J. de Boer, and M. C. Elwenspoek, A method for making a glass supported system, such glass supported system, and the use of a glass support therefor, European Patent 08007746.4-2111 (2008).

[7.3] M. C. Louwerse, H. V. Jansen, and M. C. Elwenspoek, J. Micromech. Microeng., accepted. 


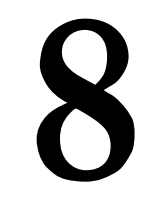

\section{Conclusions and outlook}

A detailed summary of the thesis and an outlook for the reflow bonding are provided in this chapter. The conclusions of the investigations on the joining of borosilicate glass $\left(\right.$ Duran $\left.^{\circledR}\right)$ tubes to silicon substrates for MEMS-on-tube assembly are presented and the future prospects of this joining technology are discussed to better define its application range. 


\subsection{Conclusions}

Reflow bonding was presented as the joining technology of borosilicate glass tubes to silicon substrates, where the tubes are designed as fluidic interconnects to wafer-level microfluidic devices. The silicon substrates and the glass tubes were selected and prepared as detailed in Chapter 2. Then the glass tubes are placed on silicon wafers and the whole assembly is heated up above the glass transition temperature of the glass. By the help of its reduced viscosity, the glass at the interface with silicon flows due to capillarity thereby producing a bond between the glass tube and the silicon substrate.

The joining process is mask-less and adhesive free. The tubes can be treated as a very reliable interface for microdevices as well as a robust package. The technology is capable of mass production and the tubes can be used as a package for the so-called MEMS-on-a-tube assembly. Furthermore, the technique can allow encapsulation of MEMS structures $\backslash$ devices under vacuum conditions or selected gas environments.

The reflow bonding takes place at around $700{ }^{\circ} \mathrm{C}$ in at least 10 hours. However, surface crystallisation of the borosilicate glass occurs at these temperatures in addition to its flow at the interface to create the bond. The devitrification of the glass arises from heterogeneous nucleation and growth of cristobalite crystals. The kinetics and morphology of this crystal growth have been studied for temperatures at and above $660{ }^{\circ} \mathrm{C}$ in Chapter 3. Analysis of the devitrification kinetics suggested the diffusion of boron-containing species in silica as the rate-limiting step. Qualitatively, the boron connected to the glass network needed to be rejected out of the amorphous silica framework for further growth of cristobalite. In addition, the nucleation and growth of crystals on the surface of the glass was inhibited if contact with air was prevented, either by deposition of a thin film or simply by covering the surface. Lastly, the implications of the devitrification of glass on the reflow bonding were discussed. 
The connections formed by the reflow bonding of Duran tubes to silicon wafers have been characterised as fluidic interconnect and packaging technology for MEMS-ontube assembly in Chapter 4 to test the practical limitations of the bond. Thermal stresses, which develop within the bonded system as it is cooled down to room temperature, were addressed because they could affect the performance of the bond and the packaged MEMS device. For sufficiently large cristobalite crystals microcracking occurred on the tube surface due to thermal expansion difference between the precipitated cristobalite crystals and the surrounding glass matrix. While the bulk of the borosilicate glass remained unaffected by crystallisation and the magnitude of the thermal stress between borosilicate glass matrix and silicon was well below that likely to cause spontaneous fracture in the glass adjacent to the bond. The strength of the resulting package has been tested by pressurising it to failure. The strength of the join was limited by the strength of the borosilicate glass and silicon and the silicon-glass bond never failed. Failure occurred in the glass and the silicon adjacent to the bond, rather than along the bond itself. In addition, the bond formed was hermetic and the only leakage was due to gas diffusion through the glass. In summary, the bonds were tested to be hermetic and can be safely operated up to 7 MPa. Pressure and hermeticity test results indicated that the microcracking on the surface was not detrimental to the viability of this joining technology for microfluidic interconnections.

The borosilicate glass-silicon interface formed by the reflow bonding has been inspected by SEM and TEM in Chapter 5. Two types of samples are prepared suitable for TEM and the micrographs of the interface revealed that glass was in intimate contact with silicon. The joins did not have any voids, openings or intermediary porous layers. Cristobalite crystals, which precipitated before the bond was formed, were trapped at the interface and were occasionally encountered during microscopy of the interface. Higher resolution microscopy of the interface confirmed 
that the glass was intact with silicon even at the atomic scale. EELS scans, which were taken from the interfacial region, revealed formation of thin amorphous silica layer between the borosilicate glass and the silicon. Overall, the microscopy of the bonds ensured the robustness of the joining technology.

The incorporation of in-plane electrical interconnects to reflow bonding has been studied in Chapter 6 in order to be able to probe the region inside the glass tube. Two types of electrical interconnects, which should survive the bonding and not alter the quality of the bond interface, were presented. The first design was to fabricate boron doped lines in an n-type substrate. The sheet resistances between 5-20 $\Omega / \square$ were obtained after doping and the conductivity of the lines did not change after the reflow bonding. The doped lines did not cause any leakage or reduction in the strength of the tube-silicon assembly. The second design was to deposit metal lines. Platinum or rhodium metallic lines were deposited on oxidised silicon using titanium adhesion layer. The sheet resistance of both types of metal were about $0.5 \Omega / \square$ after deposition. After the reflow bonding, the resistivity of platinum lines slightly reduced while the rhodium lines lost their conductivity. Both types of metallic interconnects caused direct leak paths through the bond interface because both types of metals lost adhesion to the underlying silicon substrate after the post-deposition annealing for the reflow bonding. The results show that the doping process is easily integrable to the reflow bonding, as they survive the bonding process and preserve the bond quality. However, the platinum and rhodium lines suffered from loss of adhesion after the reflow bonding. Although the platinum lines stayed conducting, the rhodium lines were oxidized during the annealing in air environment.

Lastly, a number of microfluidic device applications using MEMS-on-tube assembly were presented in Chapter 7, where the glass tube could be perceived both as an interface and a package. Numerous micro-nano devices built on MEMS-on-tube assembly, such as microsieves, gas separation membranes, check valves and 
micro-propulsion units, were presented. The concept of long term encapsulation of MEMS structures under vacuum or selected gas environments was explained as another potential use of the joining technology.

\subsection{Outlook}

In this section, the future prospects of the joining of glass tubes to silicon substrates as fluidic interconnect are highlighted. In addition to the study of reflow bonding presented in this thesis, the chemical and thermal shock resistance of the package can be tested. The strength and hermeticity of the bonds can be controlled after shock treatment of the specimens. The weight loss of the specimens after treating them in chemical solvents for various time intervals can be measured and compared to chemical resistivity standards [8.1]. Moreover, the burst pressure measurements can be carried out for tubes of different inner and outer diameter and silicon substrates of different thickness. These tests will help to define the application range of the connection technology.

The specimens can be heat treated on a hot-plate instead of an oven in order to apply local heat at the glass-silicon interface to produce the required bond. If the viscosity of glass adjacent to the silicon can be rapidly lowered to a sufficient level, the bonding can be done in short periods of time and parts of the glass tube away from the interface can remain relatively solid. Then the tube deformation along their length because of gravitational effects introduced by the non-levelled dicing and thermal gradients in the oven can be prevented. Use of hot-plates can also allow selected gas environments during bonding without the need of more dedicated equipment such as vacuum ovens and as part of the bonding, the surface devitrification of the borosilicate glass in vacuum or various gas environments will be relevant to study.

Another option is opting for a better polishing process for the preparation of the tube ends. If defect-free and clean surfaces can be obtained after the polishing and 
cleaning of the tube ends, the bonding can be done at lower temperatures. It might be relevant to recall that above their glass transition temperature and below $650^{\circ} \mathrm{C}$, the Duran tubes would go through phase separation, which affects the bulk properties of the material [8.2] unlike the surface devitrification.

\section{References}

[8.1] http://www.duran-group.com/en/about-duran/duran-properties/chemicalproperties.html, accessed 1 July 2010.

[8.2] J. H. Simmons, S. A. Mills, and A. Napolitano, J. Am. Ceram. Soc. 57, 109 (1974). 


\section{Summary}

The subject of the thesis was the use of borosilicate glass $\left(\operatorname{Duran}^{\circledR}\right)$ tubes as an interface to wafer-level microfluidic devices. The tubes are compatible with the standard fluidic connectors and can be used as a package for the so-called MEMS-ona-tube assembly. The connection technology is based on the brief reflow of the glass tubes after they are placed on single crystal silicon wafers. Because of the decreased viscosity of the glass at the bonding temperature, the glass at the interface with the silicon flows slowly over time enabling the voids at the interface to be filled, producing a permanent bond between the glass and the silicon substrate.

The selection and cleaning of the silicon substrates, the selection and surface preparation of glass tubes, positioning of the samples in an oven and the formation of the bond at high temperature were explained and the selection of bonding parameters was discussed. The heterogeneous nucleation and growth of crystals in borosilicate glass during its heat treatment for the reflow bonding above its glass transition temperature were investigated, although the bulk of the borosilicate glass remained unaffected by crystallisation. The activation energy for crystal growth was estimated and attributed to the diffusion of boron being the rate-limiting step within the borosilicate framework. Interfacial effects on nucleation were shown and the implications of the devitrification of glass on the reflow bonding were discussed.

The strength of the connections between borosilicate glass tubes and silicon substrates has been tested by pressurising it to failure. Failure occurred in the bonded materials rather than along the bond itself. The bond formed was hermetic. The only leakage was due to gas diffusion through the glass. The interface of borosilicate glass tube-silicon joins formed after the reflow bonding was studied by scanning electron microscopy (SEM) and transmission electron microscopy (TEM). Amorphous 
borosilicate glass has been found to be fully intact with silicon even at the atomic scale. Cristobalite crystals trapped at the interface have been occasionally observed with cracks around them. The compositional analysis of glass-silicon interface has revealed the formation of a thin amorphous silica layer adjacent to the silicon.

The incorporation of in-plane electrical interconnects to reflow bonding has been studied. After joining the tubes to silicon substrates, the electrically conductive lines will allow probing into the volume confined by the tube. Therefore methods of fabrication of electrical interconnects, which would survive the bonding and not alter the quality of the bond interface, were investigated. Lastly, the examples of applications of borosilicate glass tubes as package or fluidic interconnects were given and the concept of long term encapsulation of MEMS structures under vacuum or selected gas environments was explained.

The thesis was concluded with a detailed summary of the results and an outlook for the reflow bonding process. 


\section{Samenvatting}

Het onderwerp van dit proefschrift is het gebruik van boriumsilicaat glas $\left(\operatorname{Duran}^{\circledR}\right)$ als een koppeling voor microscopische vloeistof systemen in een silicium substraat. De glas buisjes zijn compatibel met standaard koppelingen voor vloeistof systemen en kunnen gebruikt worden voor de zogenaamde MEMS-on-a-tube assemblage. De koppelingstechniek is gebaseerd op het kort laten vloeien van de glazen buisjes nadat ze zijn geplaatst op een silicium substraat. Door de verlaagde viscositeit van het glas tijdens een verhoogde temperatuur, wordt de leegte tussen het glazen buisje en het silicium substraat opgevuld, waardoor een permanente verbinding wordt gemaakt.

De selectie en het schoonmaken van de silicium substraten en de selectie en oppervlakte voorbereiding van de glazen buisjes zijn besproken. Ook het positioneren van de buisjes in een oven en de formatie van de verbinding op hoge temperatuur wordt belicht als wel de keuze van de proces parameters. De hitte behandeling die zorgt voor het vloeien van het glas wordt gedaan boven de glas transitie temperatuur. De heterogene nucleatie en groei van kristallen op de oppervlakte van boriumsilicaat glas gedurende de hitte behandeling zijn onderzocht. De activeringsenergie voor de groei van de kristallen is afgeschat en wordt toegeschreven aan de diffusie van borium, welke de snelheidsbeperkende factor is in het boriumsilicaat raamwerk. Grensvlak effecten op de nucleatie zijn aangetoond en de implicaties van de devitrificatie van glas op het vloei proces zijn besproken.

De sterkte van de verbinding tussen het boriumsilicaat glazen buisjes en het silicium substraat is getest door de druk op te voeren tot de verbinding breekt. De breuk bevindt zich in het verbonden materiaal, niet langs het verbindingsoppervlak zelf. De verbinding vormt een hermetische afsluiting. De enige gemeten lek is toe te schrijven aan de diffusie van gas door het glas. De verbinding tussen het boriumsilicaat glazen buisje en het silicium na het vloeien is onderzocht met scanning elektron microscopie 
(SEM) en transmissie elektron microscopie (TEM). Het amorfe boriumsilicaat glas is volledig in contact met het silicium tot op atomaire schaal. Cristobaliet kristallen die gevangen zitten tussen de verbindingsoppervlakken zijn enkele keren waargenomen met eromheen kleine barstjes. De compositie van de glas-silicium verbinding is geanalyseerd en laat de formatie van een dunne amorfe laag silica zien sluitend aan het silicium.

De intergratie van elektrische verbindingen langs het verbindingsoppervlak van de glas-silicium verbinding is bestudeerd. Hiermee kan een elektrische verbindingen worden gerealiseerd naar de ruimte omvat door het glazen buisje, nadat deze met het silicium substraat verbonden is. Verschillende elektrische verbindingen zijn onderzocht, welke de hitte behandeling kunnen weerstaan en de kwaliteit van de mechanische verbinding niet beïnvloeden. Als laatste worden er voorbeelden gegeven van toepassingen voor de boriumsilicaat buisjes als verpakking of voor vloeistof verbindingen. Ook wordt het concept van lange termijn inkapseling van MEMS structuren onder vacuüm of een bepaalde gas omgeving belicht.

Het proefschrift wordt afgesloten met een gedetailleerde samenvatting van de resultaten en een blik op de toekomst van deze verbindingsmethode. 


\section{Acknowledgements}

In this section, I will express my gratitude to the people who have been around me for the last years to show their support and encouragement. I would like to start by thanking our group leader, Miko Elwenspoek, for giving me the opportunity to do research and earn the Ph. D. title. You are one of the most analytical and observant people I have ever met and definitely know how to handle people. Although our contact was limited, you could always relieve my stress and boost my confidence. I can't help remembering your comment after the end of my master's assignment about my lack of patience. It was very true to say the least. I want to continue with my daily supervisor Henri Jansen, who is nothing if not patient and understanding with me. In the beginning, I was easily overwhelmed by the way you think and express yourself but every time we had pen and paper in our hands, you had been meticulous and critical - both of which are very important for scientific research. Moreover, you allowed me to freely define research problems within the framework of my project. Thank you for being who you are and making my Ph. D. more pleasant then it would have been otherwise.

I consider myself lucky to be associated with the next addressee, Kevin Knowles. I would never expect my questions in a couple of e-mails would lead to the connection we have right now. You have been very responsive and interested from the very beginning and I am always amazed by the extents of your knowledge and your editorial skills. I have to mention that without you, I would not have been that far in the research I have carried out. Thanks for your openness and being an excellent mentor. I would also like to thank Marcel ter Brake, who is one of my project leaders. Your professional and positive approach has considerably helped me and I particularly enjoyed having you as an objective referee of my work. Thanks for all the time and efforts you have invested in me. 
I continue acknowledgements with our group technicians, Remco Sanders, Meint de Boer, Erwin Berenschot, Henk van Wolferen and Martin Siekman; the cleanroom technicians, Peter Linders, Hans Mertens, Marion Nijhuis-Groen, Samantha Ooijman-Geerdink, Eddy Ruiter, Huib van Vossen and Rene Wolf; the members of the central material analysis laboratory, Mark Smithers, Gerard Kip and Rico Keim; the technician of the Inorganic Material Science group, Gerrit van Hummel; and the technicians of the Material Science and Metallurgy department of the University of Cambridge, David Nicol and Simon Griggs. Thanks for all your help and patience.

My special thanks go to all our group members, who make Transducer Science and Technology group one of the most pleasant research groups of the university and my time as enjoyable as possible. You have been very good colleagues and friends. I would also like to thank all the Turkish friends for their company. Unfortunately, it is impossible to share all the memories and name the people who have touched my life in the last years. Therefore, I would like to thank everyone, who considers himself / herself a friend of mine.

Last but not the least; I thank all members of my family for their continuous support.

I wish everyone the best.

Sevgili eşim ve ailem, hepinizin desteği ve bana inancı olmadan bu günlere gelmem imkansızdı. Tüm fedakarlıklarınız, sabrınız ve anlayışınız için çok teşekkürler. Hepinizi çok seviyorum.

Gelecek nice güzel günlere...

Berker 


\section{About the author}

Berker Moğulkoç was born on May 13, 1982 in Eskişehir, Turkey. He attended Eskissehir Anatolian High School with the focus in Mathematics and Natural Sciences. Due to his excellent credentials, he was admitted to the Electrical and Electronics Engineering department of the Middle East Technical University, Ankara for his Bachelor of Science studies. In addition to the engineering curriculum, he completed Double Minor studies on Solid State Physics at the Physics department. After the graduation, he moved to the Netherlands and started Master of Science studies at the University of Twente, Enschede with the specialisation in Microsystems and Microelectronics. His studies concentrated on the physical understanding and modelling of microsystems and microfabrication technologies. Since September 2006, he is employed by the University of Twente as Ph. D. candidate at the Transducer Science and Technology group. During that period, he participated in courses in France and Switzerland as Marie Curie Fellow and visited the University of Cambridge, Cambridge to undertake part of his research work. The results of his $\mathrm{Ph}$. D. research are presented in this thesis. 